TOWARDS UNDERSTANDING THE DETERMINANTS OF HOUSEHOLD ENERGY USE: EXPLORING THE ROLE OF INDIVIDUAL, HOUSEHOLD, SOCIAL, AND PHYSICAL CHARACTERISTICS ON HOUSEHOLD ELECTRICITY AND GAS USE

by

\author{
RUNA DAS \\ Bachelor of Science, Mount Allison University, 2002 \\ Bachelor of Arts, Carleton University, 2006 \\ Master of Arts, York University, 2009 \\ A dissertation \\ presented to Ryerson University \\ in partial fulfillment of the \\ requirements for the degree of \\ DOCTOR OF PHILOSOPHY \\ in \\ the Program of \\ Environmental Applied Science and Management
}

Toronto, Ontario, Canada, 2016

CC RUNA DAS 2016 


\section{Author's Declaration}

\section{AUTHOR'S DECLARATION FOR ELECTRONIC SUBMISSION OF A DISSERTATION}

I hereby declare that I am the sole author of this dissertation. This is a true copy of the dissertation, including any required final revisions, as accepted by my examiners.

I authorize Ryerson University to lend this dissertation to other institutions or individuals for the purpose of scholarly research.

I further authorize Ryerson University to reproduce this dissertation by photocopying or by other means, in total or in part, at the request of other institutions or individuals for the purpose of scholarly research.

I understand that my dissertation may be made electronically available to the public. 
Runa Das

Towards understanding the determinants of household energy use: Exploring the role of individual, household, social, and physical characteristics on household electricity and gas use

PhD, Environmental Applied Science and Management (Convocation 2016)

Ryerson University

\section{Abstract}

This research is an investigation of people and their relationship with energy. This dissertation first presents an analysis of national surveys: Statistics Canada's 2013 Households and the Environment Survey and the 2013 Energy Use Supplement. These surveys were used to investigate the relationships between dwelling characteristics, household characteristics, electricity use, and natural gas use. Approximately $20 \%$ of the variance in overall energy use was explained by dwelling and household characteristics, leaving a large portion of the variance unaccounted for. It was also found that household characteristics have more impact on electricity use than natural gas use. In contrast, dwelling characteristics have more impact on natural gas use than on electricity use.

In order to better gauge the unexplained variation in household energy use, an instrument was developed to measure public energy literacy, which was conceptualized using previous surveys as well as frameworks and models from academic and grey literature, as well as literacy and educational initiatives and programs. Such conceptualization created the parameters within which survey items could be developed, created, and therefore generated. Instrument development included pretesting, cognitive interviews, and quantitative and qualitative analysis of instrument items. The resulting survey is a 15item, 5-item, and 9-item measure of energy-related knowledge, attitudes, and behaviours, respectively.

Energy literacy, along with environmental concern, was assessed among a sample of Toronto homeowners. In general, participants demonstrated environmental concern, positive attitudes, performed energy-saving behaviours and demonstrated satisfactory understanding of energy-related knowledge (i.e., average score of 66 percent). Interesting relationships were found between the measures of energy literacy as well as some additional measures of knowledge and behaviour, suggesting that examination of energy use should be broken down into smaller examinable components, such as curtailment and efficiency behaviours. The attitudinal and behavioural subscales belonging to the measure of energy literacy added to the explanation of household energy use in the Toronto sample: for electricity $11 \%$ of the variation was explained and $4 \%$ for natural gas. Surveys and examination of household energy use need to therefore consider examining energy literacy variables in addition to socio-demographics and dwelling characteristics. 


\section{Acknowledgements}

Sincere thanks to Russell, your continued support, positivity, and insights are greatly appreciated. Thank you also to Andie for your support, for your dedication to the process of learning, and for being a fountain of knowledge. I would also like to thank the members of the validity panel and all other committee members who took the time to review and assess materials for this study. Thanks to all the research assistants who helped with data collection, in particular, Nadia Corsetti. Thanks to Craig for always reminding me about the importance of humour. Finally, thank you to all my teachers who encourage me to ask questions and to keep asking more. 
Dedication

For Ma and Baba 


\section{Table of Contents}

\section{Contents}

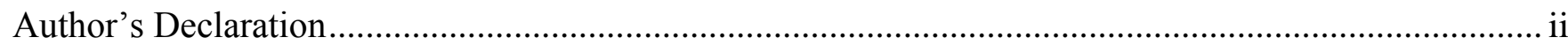

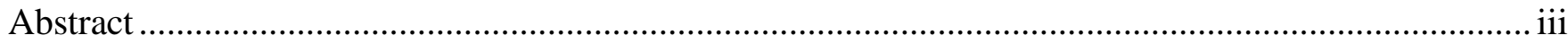

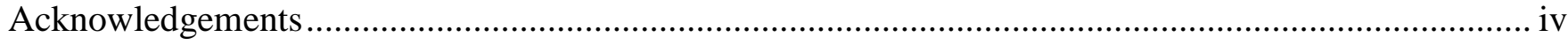

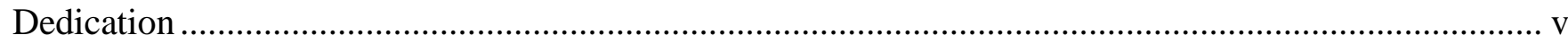

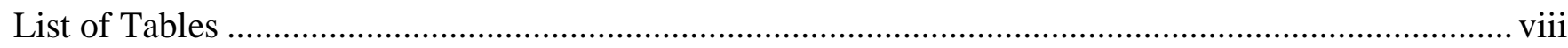

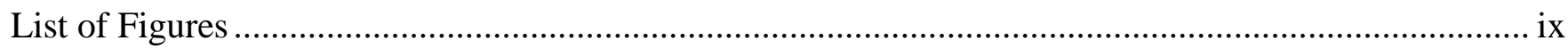

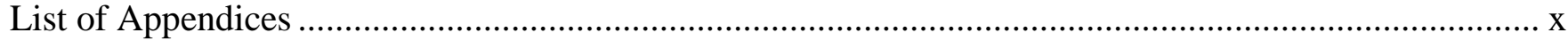

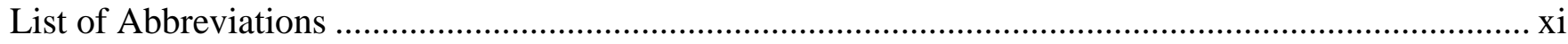

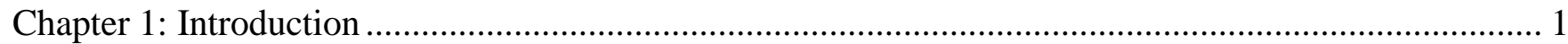

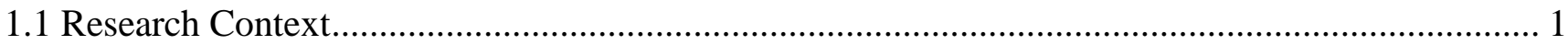

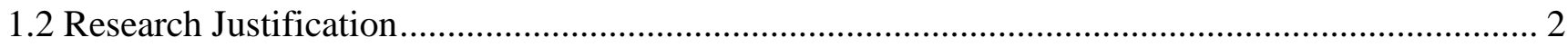

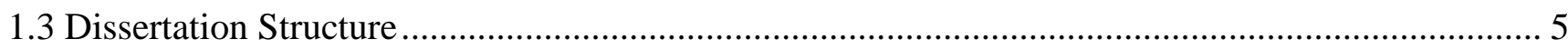

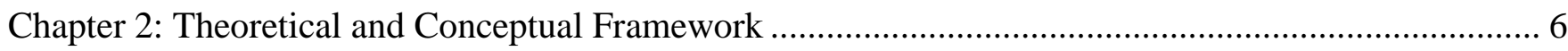

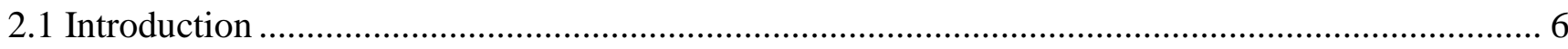

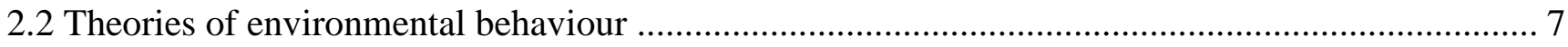

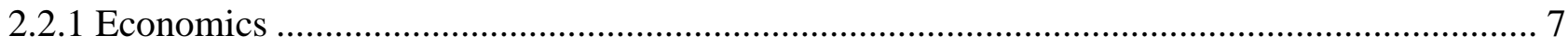

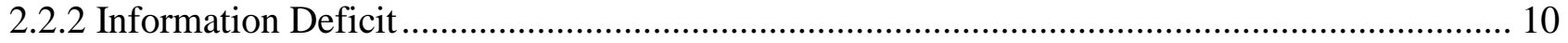

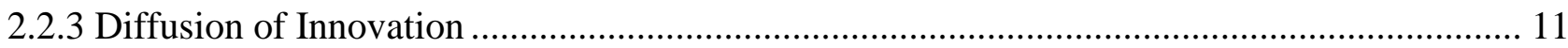

2.2.4 Theory of Reasoned Action and Theory of Planned Behaviour........................................ 13

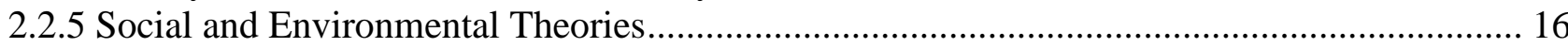

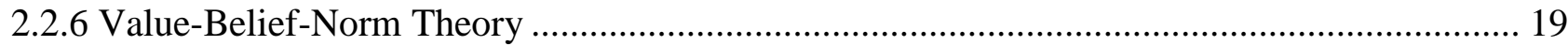

2.2.7 Attitudes-Behaviour-Context and a Coherent Theory of Behaviour.................................. 21

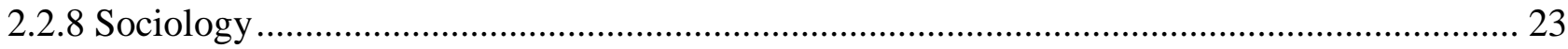

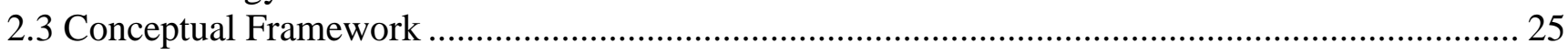

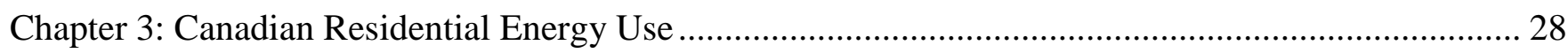

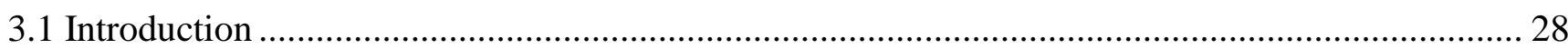

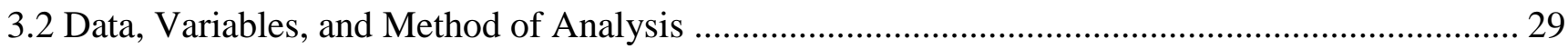

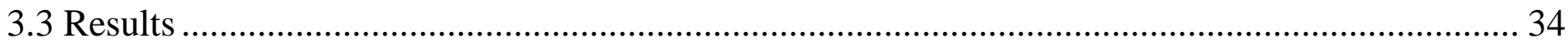

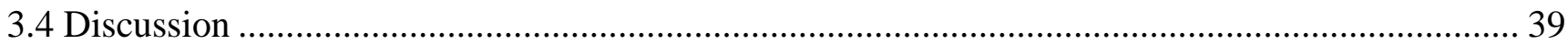

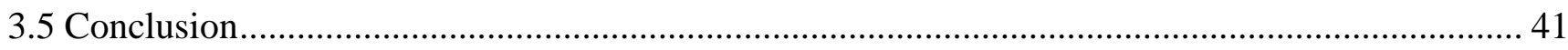

Chapter 4: Development of a Public Energy Literacy Instrument.................................................. 42

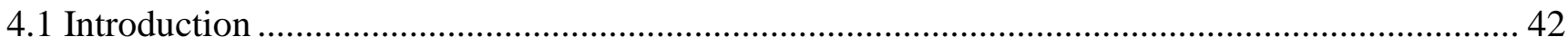

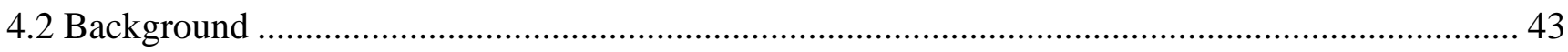

4.3 Conceptualizing Energy Literacy_-Parallels to Scientific, Technological, and Environmental

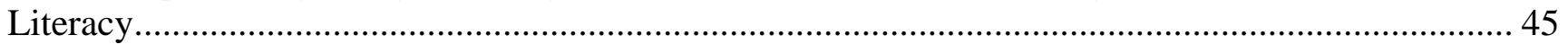

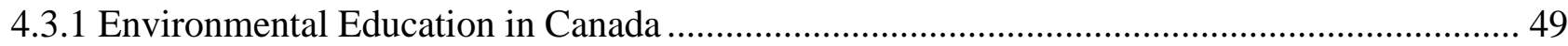

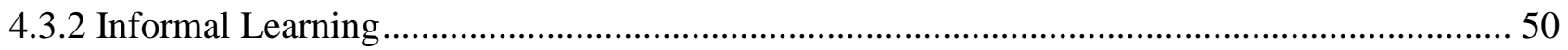

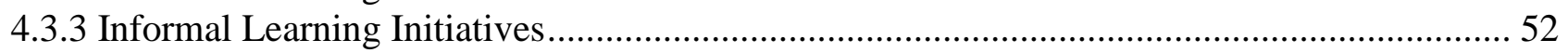

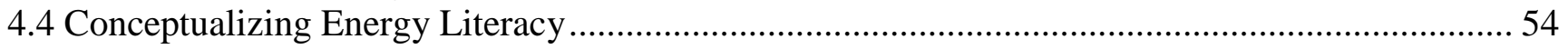

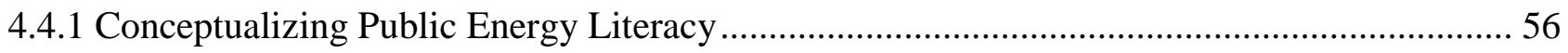

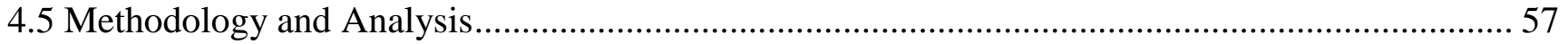




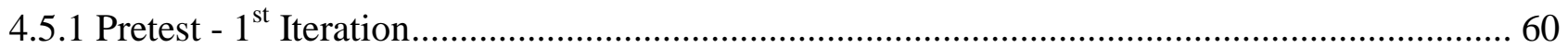

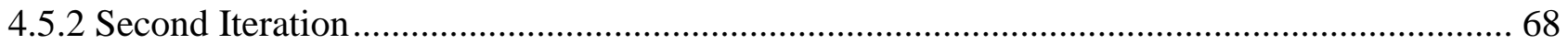

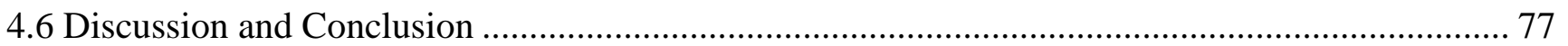

Chapter 5: Energy Literacy and Household Energy Usage ......................................................... 79

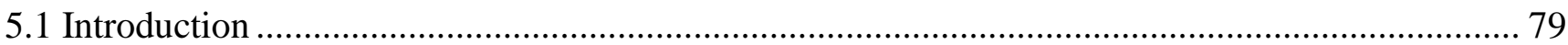

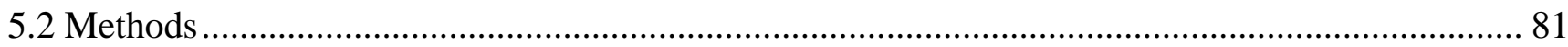

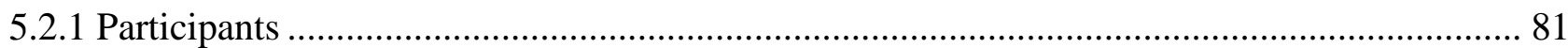

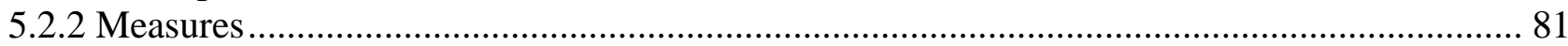

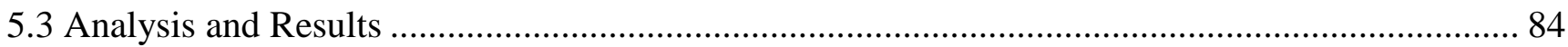

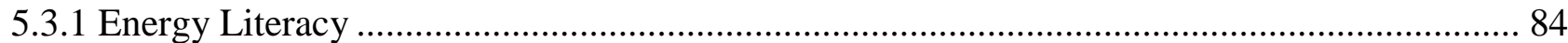

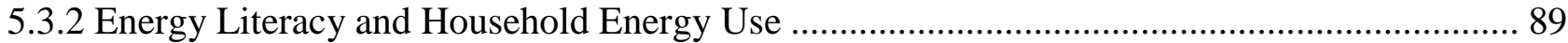

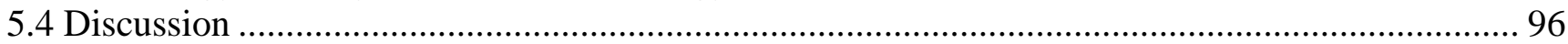

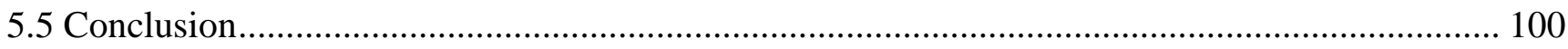

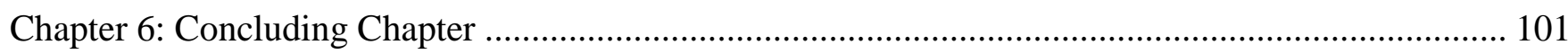

6.1 Summary of Dissertation Objectives.......................................................................... 101

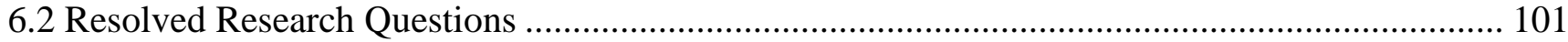

6.2.1 Chapter 3 - Canadian Residential Energy Consumption ................................................ 101

6.2.2 Chapter 4 - Development of Public Energy Literacy Instrument .................................. 102

6.2.3 Chapter 5 - Energy Literacy and Household Energy Use .................................................. 103

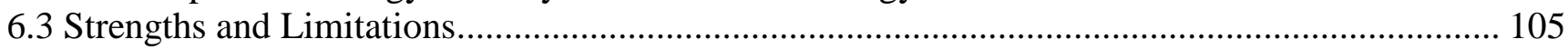

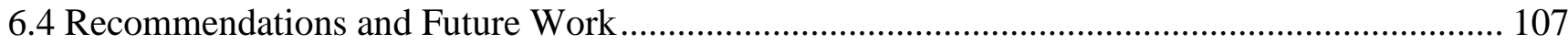

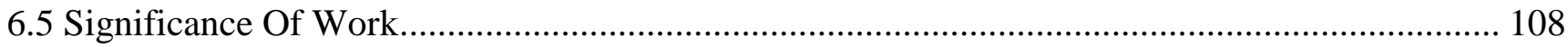

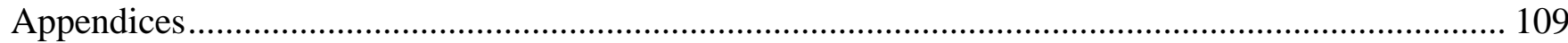

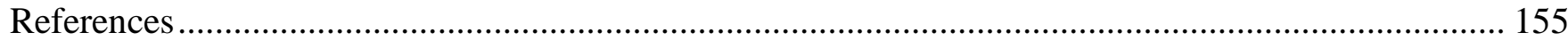




\section{List of Tables}

Table 3.1: $\quad$ List of Variables and Measurement, p. 31

Table 3.2: $\quad$ Descriptive Statistics of Electricity Model Variables (weighted), p. 32

Table 3.3: Descriptive Statistics of Natural Gas Model Variables (weighted), p. 33

Table 3.4: $\quad$ Linear Regression Predicting Household Electricity Use in 2013, p. 36

Table 3.5: $\quad$ Linear Regression Predicting Household Natural Gas Use in 2013, p. 38

Table 4.1: $\quad$ Components of Environmental Education and Literacy by Literacy Dimension, p. 48

Table 4.2: $\quad$ Descriptive and Item Analysis Statistics for Iteration 1, p. 62

Table 4.3: Descriptive and Item Analysis Statistics for Iteration 2, p. 71

Table 4.4: A Comparison of Reliability for Iteration 2 Subscales, p. 72

Table 4.5: $\quad$ Rotated Factor Loadings for the Knowledge Subscale, p. 74

Table 4.6: $\quad$ Rotated Factor Loadings for the Behaviour Subscale, p. 75

Table 5.1: $\quad$ Performance on Individual Knowledge items $(N=204)$, p. 85

Table 5.2: $\quad$ Frequency Distributions (in percentages) for Energy Attitudinal Items $(N=204)$, p. 86

Table 5.3: Frequency Distributions (in percentages) for NEP Items $(N=204)$, p. 86

Table 5.4: $\quad$ Frequency Distributions (in percentages) of Behavioural Items $(N=204)$, p. 87

Table 5.5: $\quad$ Pearson Correlations Between Energy Literacy, Conservation Knowledge, and Renovation Behaviour $(N=202)$, p. 88

Table 5.6: $\quad$ Pearson Correlations Between Natural Gas Use, p. 89

Table 5.7: $\quad$ Pearson Correlations Between Electricity Use, p. 89

Table 5.8: $\quad$ List of Variables and Measurement, p. 91

Table 5.9: Descriptive Statistics of all Electricity Model Variables, p. 92

Table 5.10: Descriptive Statistics of all Natural Gas Model Variables, p. 92

Table 5.11: $\quad$ Linear Regression Predicting Household Electricity Use $(n=102)$, p. 93

Table 5.12: $\quad$ Linear Regression Predicting Household Natural Gas Use $(n=95)$, p. 94 


\section{List of Figures}

Figure 1.1: Residential Energy Use in 2013, p. 4

Figure 4.1: Methodology for Developing a Public Energy Literacy Instrument, p. 58 


\section{List of Appendices}

Appendix 1: Instrument Development Framework, p. 108

Appendix 2: Pretest Form A, p. 110

Appendix 3: Pretest Form B, p. 116

Appendix 4: Iteration 2 Items, p. 122

Appendix 5: Recruitment Notice, p. 130

Appendix 6: Modified Framework, p. 131

Appendix 7: Online Survey in Text Form, p. 135

Appendix 8: Research Ethics Board Approval, p. 154 


\section{List of Abbreviations}

\begin{tabular}{|c|c|}
\hline $\mathrm{ABC}$ & Attitudes-Behaviour-Context \\
\hline CCE & Climate Change Education \\
\hline CCHS & Canadian Community Health Survey \\
\hline CFL & Compact Fluorescent Light \\
\hline CMEC & Council of Ministers for Education Canada \\
\hline CTT & Classical Test Theory \\
\hline DESD & Decade of Education for Sustainable Development \\
\hline DoI & Diffusion of Innovations \\
\hline DSF & David Suzuki Foundation \\
\hline $\mathrm{EE}$ & Environmental Education \\
\hline EIA & Energy Information Administration \\
\hline ESAC & Environmental Studies Association of Canada \\
\hline ESD & Education for Sustainable Development \\
\hline EUS & Energy Use Supplement \\
\hline GDP & Gross Domestic Product \\
\hline GHG & Greenhouse Gas Emissions \\
\hline HES & Households and Environment Survey \\
\hline IEA & International Energy Agency \\
\hline IPCC & Intergovernmental Panel on Climate Change \\
\hline ISTE & International Society for Technology Education \\
\hline ISO & International Organization for Standardization \\
\hline ITEA & International Technology Education Association \\
\hline LED & Light Emitting Diode \\
\hline
\end{tabular}


LSF Learning for a Sustainable Future

NAAEE North American Association of Environmental Education

NAEP National Assessment of Educational Progress

NALL New Approaches to Lifelong Learning

NAM Norm Activation Model

NEB National Energy Board

NEETF National Environmental Education and Training Foundation

NHS National Household Survey

NRCan Natural Resources Canada

OECD Organization for Economic Co-operation and Development

OLS Ordinary Least Squares regression

SCD Sustainable Canada Dialogues

SHEU Survey of Household Energy Use

STEM Science Technology Engineering and Mathematics

TEA Toronto Environmental Association

TPB Theory of Planned Behaviour

TOU Time of Use

TRA Theory of Reasoned Action

TRCA Toronto and Region Conservation Authority

UNEP United Nations Environmental Program

UNFCC United Nations Framework Convention on Climate Chang

UNESCO United Nations Educational, Scientific and Cultural Organization

VBN Value Belief Norm Theory

VIF Variance Inflation Factor 


\section{Chapter 1: Introduction}

\subsection{Research Context}

Energy is a synonym for power, strength, and vitality. It cannot be created nor destroyed. It surrounds us in everything we do, and is embodied in everything we are in contact with. Without question we have progressed as humans and societies due to our ability to develop, produce, and use energy. Major developments such as agriculture, transportation, and industry have depended on and continue to depend on energy. But it also affects us in our day-to-day lives. We cannot cook without energy. We cannot watch TV or listen to music without energy. We cannot travel to work on the subway without energy. For many countries, energy contributes to economic growth. For developing countries, access to energy can improve lives and move people out of poverty.

Both domestically and globally, humans are at a pivotal point and making significant decisions regarding our energy future. As a country, how much should we decrease our energy use? In which sector is this most important? Should we invest more in renewables? How important is energy production for the economy? Are certain groups of people more severely impacted by energy development than others? Yet the intangible nature of energy use makes it difficult to understand, which may affect how individuals or groups of people answer the questions above.

Attempting to better understand our relationship with energy is the impetus for the present study. Overall, this study focuses on learning more about the characteristics that influence household energy use as well as learning more about what people know and feel about energy and energy-related issues, as well as their energy-related behaviours. At minimum, Canadian households rely on energy to heat, cool, light their homes, to heat domestic water, and to operate appliances. These are fundamental services that provide the public with want they truly want-everyday accessibility, comfort, enjoyment, and convenience. But are people aware of relevant energy-related issues and does this factor into the choices (conscious or not) they make with respect to their energy use? In order to explore this, household characteristics (inclusive of energy literacy), dwelling characteristics, household energy use ${ }^{1}$, and the relationship (s) between them will be examined. Hence there are two main research themes in this dissertation. The first theme comprises understanding patterns of household energy use. Specifically, what are some important determinants of household energy use? The second theme relates to energy

\footnotetext{
${ }^{1}$ Throughout this study the terms household and residential will be used interchangeably. It should be noted that the term household will be used when discussion surrounds a micro area of focus whereas the term residential will be used for broader contexts, i.e., the residential sector.
} 
literacy. Specifically, what is it? How can it be measured? And how does it relate to household energy use? Overall, the goal is to better understand the users of energy (i.e., the occupants of households) as well as the variables that contribute to their energy use.

\subsection{Research Justification}

The Canadian energy landscape benefits from an abundance and diverse range of energy resources. In fact, Canada is one of the world's major producers of oil, natural gas, hydroelectricity, and uranium. In 2013, total primary energy supply was 253.20 million tonnes of oil equivalent (Mtoe) (International Energy Agency [IEA], 2016). Canada's natural resource boon also translates to national wealth. That is, Canada is one of the largest Organization for Economic Co-operation and Development (OECD) economies, with the energy sector contributing significantly to the Canadian economy. In 2014, Canada's energy sector accounted for the direct and indirect employment of approximately 950,690 people (Natural Resources Canada [NRCan], 2015). Further, in 2014, the energy sector accounted for approximately fourteen percent of gross domestic product (GDP) (NRCan, 2015).

Generally, energy use can be simplified into two categories. Primary energy use (not to be confused with primary energy) refers to the total energy requirements of all energy users and includes secondary energy use (NRCan, 2015). Specifically, primary energy use includes 1) the energy required to transform one form of energy into another form of energy (e.g., coal to electricity); 2) the energy used to move energy supplies to consumers (e.g., pipelines); and 3) the energy used for industrial processes (e.g., natural gas liquids used as feedstock by chemical industries) (NRCan, 2015). Secondary energy use, also known as end use, refers to the energy used by consumers (NRCan, 2015). Specifically, it includes 1) the energy used to run vehicles in the transportation sector; 2) the energy used to heat and cool buildings in the residential, commercial, and institutional sectors, and 3) the energy used to run machinery in the industrial and agricultural sectors (NRCan, 2015). In 2012, the total amount of primary and secondary energy use was $12,394 \mathrm{PJ}$ and 8,735 PJ, respectively ${ }^{2}$ (NRCan, 2015). This research is concerned with secondary energy use as it includes activities like heating and cooling homes, lighting, plug loads, etc. According to the IEA, energy demand in Canada increased by 35 percent between 1990 and 2007 and is predicted to increase by another 25 percent between 2007 and 2020 (2009).

Canada's per person energy use is among the highest in the world (EIA, 2016) and there are several reasons for this. The first is geography. With people living in various parts of the country, it takes a lot of energy to move energy commodities to all parts of the country. The Canadian climate can

\footnotetext{
${ }^{2}$ One petajoule (PJ) is equivalent to the energy used by 9,000 households in one year (excluding transportation) (NRCan, 2016).
} 
also be very cold and this requires using a lot of energy for heating. In Canada, the abundant supply of domestic resources is largely inexpensive - the majority of Canadians pay less for electricity, natural gas, and gasoline than people living in other parts of the world. Further, Canada is a developed country and, on average, Canadians experience a high standard of living with many owning homes, driving cars, and using lots of energy consuming devices. Last, Canada has a heavy industrial sector — natural resources, mining, forestry, petroleum refining, pulp and paper, metal foundries — which require a lot of energy for extraction and processing.

The intense use of energy in Canada highlights its importance but, problematically, many energy sources that Canadians rely on are finite. Fossil fuels like coal, oil, and natural gas are limited but are relied upon for both personal use and commercial activities. In fact, 77 percent of Canada's energy demand is supplied by fossil fuels and is used to heat homes and businesses, transport goods and people, and power industrial equipment (ecoENERGY Carbon Capture Storage Task Force, 2008; National Energy Board [NEB], 2016). In addition to being limited, the use of these resources is not without consequences. Burning fossil fuels for transportation, heating services, and electricity generation is responsible for approximately 80 percent of worldwide anthropocentric greenhouse gases (Pollution Probe, 2011) and increased amounts of greenhouse gases can have dire effects. Average global temperatures are expected to rise between $2^{\circ} \mathrm{C}$ and $4.5^{\circ} \mathrm{C}$ this century (Intergovernmental Panel on Climate Change [IPCC], 2007). Further, climate change is predicted to threaten up to 30 percent of mammal, bird, and amphibian species with extinction this century (Rockstrom et al., 2009). With temperature increases between $2^{\circ} \mathrm{C}$ and $3{ }^{\circ} \mathrm{C}$, coastal regions will experience flooding, which will displace hundreds of millions of people and increase their risk of hunger and disease (Ewing \& Rong, 2008). Further, we do not have to look to the future to see the effects of climate change: arctic sea ice is currently shrinking, there are more extreme droughts, hurricanes, wildfires, and extreme storms, and these are expected to continue (e.g., Herring, Hoerling, Kossin, Peterson, \& Stott, 2015).

Originally, under the Kyoto Protocol, Canada committed to a six percent emissions reduction by 2012 compared to 1990 levels but was unable to meet these targets (Sustainable Canada Dialogues [SCD], 2015). In 2010, as a part of the Copenhagen Accord, Canada announced its commitment to reduce emissions 17 percent from 2005 levels by 2020 (SCD, 2015). On April 22, 2016, at the recent 2015 Paris-Climate Conference Canada made another commitment: to limit temperature increase to less than two degrees Celsius (NRCan, 2016). Currently, the Government of Canada's priority lies in reaching a global agreement for a low carbon and climate resilient economy as well as supporting those most vulnerable to the effects of climate change (i.e., developing countries) (Government of Canada, 2016). The government plans to realize this priority through setting a national achievable target, working 
with provinces and territories, investing in projects to support transitioning to a low carbon future, and working on a Canadian Energy Strategy (Government of Canada, 2016).

Strategies for decreasing carbon emissions include non-binding approaches. Thus if some strategies depend on voluntary participation by people and organizations, then an understanding of people and their energy use is invaluable. Within this context, the Canadian residential sector is central and households provide an important opportunity for examining individual and collective energy behaviour. In 2013, Canadian households accounted for 17 percent of energy end-use, contributing to 14 percent of Canada's greenhouse gas emissions (NRCan, 2016). This end use can be further broken down as shown in Figure 1.1. Herein lies an opportunity to better understand Canadian households and their energy use patterns. An understanding of household characteristics (i.e., socio-demographics and energy literacy) and dwelling characteristics related to energy use will provide the necessary context for understanding household energy use. The decision to investigate energy literacy is based on the idea that an energy literate population will be more likely to make and engage in decisions and behaviours that will conserve energy. Energy is inextricably connected to who we are and has the potential to be connected to what we can be.

Figure 1.1 Residential Energy Use in 2013

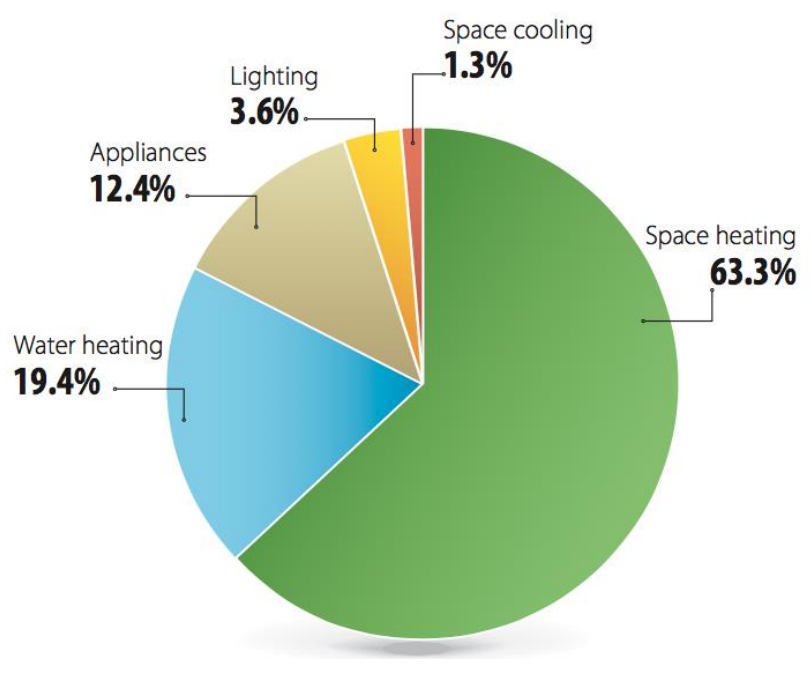

Published in "Improving Energy Performance in Canada," Natural Resources Canada, p. 14 (2016). 


\subsection{Dissertation Structure}

Chapter 2 provides an overview of theories and models relevant to this dissertation. These stem from various disciplines and provide the rationale for examining energy use through these various lens. It should be noted that chapter two does not discuss building science perspectives, though it is assumed that building characteristics (e.g., insulation R-values) are important determinants of household energy use. This level of specificity is beyond the scope of this dissertation; i.e., this study does not study household energy use from an engineering perspective. Instead the theories and models discussed in Chapter 2 provide the basis for variable selection and guide this study.

Chapter 3 is a study of Canadian residential energy use. This chapter reports on patterns of household energy use and identifies household characteristics as well as dwelling characteristics that contribute to Canadian electricity and natural gas use. Using a nationally representative dataset and statistical methods the objective of this chapter was to examine the relationship between household characteristics, dwelling characteristics, electricity use, and natural gas use.

Chapter 4 is divided into two subsections. The first presents a conceptualization of energy literacy. The second presents the methodology that was used to develop a public energy literacy instrument. The objectives of this chapter were to: 1) establish criteria for measuring public energy literacy and 2) develop a valid and reliable instrument to measure energy literacy.

Chapter 5 is divided into two subsections. The first section presents performance on the energy literacy instrument developed in Chapter 4. The second section focuses on the relationship between energy literacy and the electricity and natural gas use of a sample comprised of single-family households in Toronto. The main objectives of this chapter were to: 1) address performance on a measure of energy literacy and 2) examine the relationship between energy literacy and household energy use.

Chapter 6 revisits the major findings in this dissertation. Objectives and research questions are revisited first. Attention is then paid to discussing the strengths and limitations of the present study, and making recommendations for future work. 


\section{Chapter 2: Theoretical and Conceptual Framework}

\subsection{Introduction}

For several decades, researchers have been actively pursuing the determinants of household energy use and conservation. This work stems from the desire to better understand household energy use, but much of the work has grown out of research concerning the broader area of environmental behaviour. Energy use is therefore often grouped with other environmental behaviours, which, consequently, has resulted in the application of overarching theories of environmental behaviour to explain the phenomena of household energy use. However, it should be noted that some work has attempted to be more specific, resulting in particular theories of household energy use typically framed within discipline specific contexts. For example, a sociologist may perceive energy use to be socially and technologically influenced whereas a psychologist may perceive energy use to be based at the individual level. An engineer may perceive energy use to depend primarily on building characteristics whereas an economist may perceive energy use to be influenced by utility and budget. In reality, energy use transcends disciplinary boundaries and therefore its examination is best served by utilizing several perspectives.

Regardless of discipline, a central issue is the lack of agreement regarding the determinants of energy use. That is, current understandings of environmental behaviour may be due to the lack of collaboration on the parts of researchers and not because of a lack of research (Hines, Hungerford, \& Tomera, 1987). Why is it important to find out what contributes to energy related behaviour? According to Frederiks, Stenner, and Hobman (2015a), it has to do with knowing how to intervene, with whom, where, and when. These authors also support a better understanding of household energy use so that undesirable behaviours can be altered through initiatives, technology, public policy, or other strategies; an ideal likely shared by others.

In what follows, the goal is to be more descriptive than prescriptive. That is, in an effort to better understand the framework that guides the current work, this chapter will provide an overview of the most relevant and popular theories concerning environmental behaviour including those specific to household energy use. These theoretical perspectives span several disciplines and domains including those rooted in individual and social level theory. The main objective is to compare and contrast several theories in order to enumerate the possible frameworks for understanding the results of the current inquiry. At this point, the goal is not to be overly prescriptive, or to claim knowing which approach is the 'best' for understanding energy use. Here, the goal is only to justify the approach that will be taken in the proceeding chapters. Plausibly, 'correctness' of this decision can be decided once the framework has been applied and after empirical examination (see Chapter 6). 


\subsection{Theories of environmental behaviour}

\subsubsection{Economics}

Econometric models are routinely used to model the energy use of households. Of these, top-down modeling is used to study the broad implications of energy use, in aggregate form. Using this approach, common macro indicators such as GDP and employment, in conjunction with residential energy use, inform phenomena like national energy supply requirements (Swan \& Ugursal, 2009).

Under the umbrella of economics, a more micro approach to examining energy use is also common. In general, classical microeconomics assumes that choices and decision-making lie within the individual and that these are both "rational" and guided by "utility" (Frederiks, Stenner, \& Hobman, 2015b; Gillingham, Newell, \& Palmer, 2009). In relation to household energy use, this assumption could be used to argue that households are consumers that make rational choices driven by utility (Wilson \& Dowlatabadi, 2007). That is, households make choices based on how optimal the outcomes are and whether or not they fit within budget constraints. Using this outlook, choices regarding household equipment and equipment use are largely driven by the price of equipment, price of fuels, price of alternative methods for obtaining energy services, household income, payback periods, and consumer preferences (Stern, 2014). Within the broader context of environmental behaviour, economic theory extends to individuals who first examine their needs (e.g., purchase of a new showerhead versus purchase of insulation) and, second, behave in agreement with their "economic self-interest" (McKenzie-Mohr, 2011, p. 6). In this example consumer choice may not be based solely on utility but also on maximizing utility—getting the most in the most cost effective way. Therefore, both a new showerhead or new insulation may be useful and within budget but the insulation may prove to be the better energy saver with more financial gains.

Behavioural economists often study decision making by examining the discrete choices of individuals. This type of examination combines economic assumptions of rational choice with the "role" of actors, who could conceivably be influenced by "non-rational” social elements (Simon, 1959); more weight, however, appears to be placed on the economic variables. Further, attempts to understand these choices can be made by looking at discount rates (Wilson \& Dowlatabadi, 2007). This is most easily understood with a popular thought experiment: if you are given the choice between receiving $\$ 100$ today or $\$ 100$ tomorrow what option will you pick? Next, you are given the choice between receiving $\$ 75$ today or $\$ 100$ in five years. The decision becomes trickier. A high discount rate places value on immediate gains over future gains whereas a low discount rate places value on future gains rather than immediate gains (Wilson \& Dowlatabadi, 2007). Therefore, a discount rate is the percentage that a 
benefit declines in value for the increase in time period the benefit is available. From these types of studies insight can be gained into the valuation of a good or service and, at least in part, human patience.

A related phenomenon is time discounting, which accounts for individuals demonstrating a preference for goods and services now rather than in the future (Frederick, Loewenstein, \& O’Donoghue, 2002) and hence the use of high discount rates. For example, Brounen, Kok, and Quigley (2013) presented participants with a hypothetical situation in which the participants were homeowners with broken heating systems. They were presented with two replacement options. Option one had a higher initial price but a shorter payback period whereas option two had a lower initial price but a longer payback period. In line with time discounting, Brounen et al. (2013) found that some participants chose the heating system with the lower initial cost but with the longer payback period. The traditional economic assumption that rational individuals have preferences that are "ordered, known, invariant and consistent" (Wilson \& Dowlatabadi, 2007, p. 172) appears to be violated.

According to McFadden (1999), behavioural economists have become more relaxed in regard to the assumptions of classical microeconomics. McFadden states that rationality is a "complex behavioral theory that can be parsed into statements about preferences, perceptions, and process" (p. 73). That is, irregularities in choices or decisions can be attributed to errors in perception due to the manner in which information is stored, retrieved, and processed, as well as the errors in the processing of information (McFadden, 1999). That is, irrational decision making appears to stem from issues in cognitive processing. As such, there appear to be other non-economic influences on decision making and these corroborate the problem with using a solely economic, at least in the traditional sense, approach to predicting energy-related behaviour; it appears that contemporary behavioral economists are aligned with this approach. Potentially these other influences have to do with bounded rationality, wherein cognitive constraints have an effect on information processing (Simon, 1959), as well as the use of decision heuristics (e.g., ignoring expensive alternatives using elimination heuristic) to guide energyrelated decisions (Todd \& Gigerenzer, 2003; Wilson \& Dowlatabadi, 2007). It is also quite possible that decisions that appear to be irrational (e.g., high discount rates for appliances) are based on capital costs, i.e., not having enough money at the time of purchase for an essential good or service.

Similarly, Gifford (2011) discusses the influence of cognitive constraints on climate change mitigation. Gifford notes that the human brain is not evolved enough to take into account future events. That is, the human brain stopped evolving (significantly) prior to the development of agriculture and at a time when concern and planning surrounded day-to-day issues. Further, Gifford (2011) notes that for many people, ignorance is still present — with knowing that climate change is an issue and with knowing the cause and extent of it. Other cognitive constraints include judgmental discounting, similar to 
temporal discounting, and optimism bias (i.e., having an optimistic view regardless of reality) (Gifford, 2011). It is reasonable to think that these cognitive constraints may factor into decision making surrounding household energy use, consequently impeding behaviour change.

Another central idea in economics is the idea of incentives to motivate individuals to action. However, the effectiveness of incentives (e.g., interest-free loans, low-interest loans) appears to be mixed. For example, in a study focusing on master-metered apartments (i.e., households not having their own gas meters), contests were held for and rewards were given to the apartment block able to conserve the most energy (McClelland \& Cook, 1980). The researchers found that groups participating in the contest used almost seven percent less electricity than the control group. However, savings decreased over the course of the study and as a consequence these results support a short-term effect.

In another study, Pitts and Wittenbach (1981) evaluated the effects of tax credits, in the form of deductions from total income tax, on decisions to insulate homes. Two years later a telephone survey revealed that the tax credit had no effect on decisions to insulate homes. Even more, a study reviewing the American Federal Conservation Service found that even when homeowners had access to audits and interest-free or low-cost loans, homeowners did not take advantage of these incentives (Hirst, 1984). Approximately six percent of eligible homeowners requested the audit and, of these, 50 percent acted to increase energy efficiency in their homes. Interestingly, most of the actions taken by the households were inexpensive in nature.

Some studies have found energy savings related to the use of incentives but these savings are questionable. For example, Hayes and Cone (1977) looked at the effects of rewards, feedback, and information on electricity use. The researchers found positive effects but their sample size $(n=4)$ limits generalizability. Likewise, Slavin, Wodanski, and Blackburn (1981) examined the effects of information, reminders, feedback, and rewards among individuals living in master-metered apartments and found significant electricity savings. However, due to the design of their study, it is difficult to differentiate between the effects of the individual interventions so the unique potential of rewards, here, remains unknown.

Another problem can been found in studies of home weatherization programs. Specifically, research has found large variation in responses to home weatherization programs offering similar financial incentives when administered by different electric and gas utilities. Generally, adoption rates have been found to increase with incentives, however, these have varied according to the utility program through which they were offered (Stern et al., 1986). Uptake could therefore have been due to variables such as company reputation and marketing, namely other non-financial variables (Stern, 1994). 


\subsubsection{Information Deficit}

Early work in environmental behaviour used a straightforward linear approach to conceptualizing behaviour. Probably the simplest of these is the belief that environmental knowledge leads to environmental attitudes which leads to environmental behaviour (Kollmuss \& Agyeman, 2002). This model is commonly known as the information deficit model (Burgess, Harrison, Filius, 1998, p. 1447) because it is hypothesized that the 'deficit' of information is what contributes to inaction in environmental situations. According to several researchers, this model was quickly dismissed with research showing, in most cases, that increases in knowledge and environmental awareness do not lead to behaviour change (e.g., Kollmuss \& Agyeman, 2002). In any case, the relationship is not simple.

Previous research has found the effectiveness of information to be largely mixed. For example, Geller (1981) found workshops to increase participant concern and intentions to conserve energy, but failed to see the adoption of energy saving measures among workshop attendees. In another study, which made use of personalized information (i.e., information which takes into account a household's current energy use), McMakin, Malone, and Lundgren (2002) found that Washington households saved 10 percent on their gas and electricity use, whereas, interestingly, Arizona households increased electricity use by two percent, relative to baseline levels. The personalized information targeted heatingrelated energy use among the Washington sample and cooling-related energy use among the Arizona sample.

In a few cases information provision seems to have a positive effect, however, upon closer examination, the effects are uncertain. For example, in an evaluation of the US Department of Energy's Low Cost/No Cost energy conservation program, through which 4.5 million households received an information booklet on energy-saving tips and a complimentary low flow shower head, Hutton and McNeill (1981) found that households who had received materials reported implementing tips more often than households who had not received materials. Problematically, success was measured using self-reports and, therefore, from a measurement standpoint, failed to acknowledge actual energy conservation. In another example, Hirst and Grady (1982-1983) compared gas use among households who had received home audits and households who had not received home audits. The researchers found the treatment group to save on gas use in comparison to the control group (i.e., four percent savings for the treatment group) but expressed uncertainty regarding their data quality.

There are several reasons why information may not be effective for changing behaviour. According to Racjecki (1982), direct experiences have a stronger effect on behaviour than indirect experiences. For example, learning about environmental problems in class (e.g., pollution) may have 
less impact on behaviour than experiencing environmental problems firsthand (e.g., seeing dead fish in a polluted river). He also believes cultural traditions and family to be important, especially in their roles for enforcing social norms. The idea that social norms play a key role in determining behaviour is prevalent and, as will be discussed, is included in other theories and models of environmental behaviour. Last, Racjecki (1982) makes a good point regarding the measurement of attitudes and behaviour. Specifically, the author notes that attitudes are often measured very broadly (e.g., general caring for the environment) in comparison to the actions that are supposed to be determined by them (e.g., recycling behaviour). This is plausibly one source of the inconsistencies between knowledge, attitudes, and behaviours. The role of information (and for some knowledge: e.g., Azjen, 2011) is not limited to this linear model and is an important aspect of several other theories and models.

\subsubsection{Diffusion of Innovation}

Energy efficiency through innovation can have a major impact on energy use. Consequently, it is useful to understand what guides the adoption of innovations and the rate at which this occurs. Here, innovations include new technologies but can extend to also include new ideas and practices (Wilson \& Dowlatabadi, 2007). The diffusion of innovations (DoI) theory was developed by sociologist E. M. Rogers in 1962 and is one of the oldest to examine how ideas spread over time.

A particular feature of the DoI theory is adopter classification. That is, according to this theory, innovation adopters vary in terms of their adoption times and can therefore be grouped accordingly (Mahajan, Muller, \& Srivastava, 1990). Generally, adopters belong to one of five categories: innovators, early adopters, early majority, late majority, or laggards (Rogers, 2003). Innovators are considered to be individuals who try new things, show interest in new ideas, and take risks; this group does not need encouraging (Rogers, 2003). Early adopters are seen as leaders who believe in the importance of change (Rogers, 2003). Hence, appeals to this group to adopt innovation are more procedural (e.g., supplying information guides and manuals) than persuasive (Rogers, 2003). Very similar are those belonging to the early majority group. These individuals are not at the forefront of adoption however they generally adopt new ideas before the average person; usually following evidence of a particular innovation's success (Rogers, 2003). The following two groups are quite different from the previous three groups. The late majority group are known to be skeptical of change and will only adopt an innovation after its acceptance by a large number of individuals (Rogers, 2003). Last, the laggards are unaccepting of change; they are very difficult to convince (Rogers, 2002).

In addition to knowing the characteristics of adopters, adopter groups are expected to be normally distributed (Rogers, 2002). That is, the probability of individuals belonging to a particular 
adopter group follows a probability distribution resembling a bell curve. Innovators comprise the first two and a half percent of adopters, followed by 13.5 percent of individuals categorized as early adopters. Next, the middle 68 percent is comprised of early and late majority adopters followed by the laggards who comprise the last 16 percent of adopters (Rogers, 2002). According to Rogers (2002), most distributions of individuals, with regard to innovation adoption, demonstrate this pattern.

The diffusion of innovations originated as an area of study for sociologists interested in communication studies (Katz, Levin, \& Hamilton, 1963). Rogers furthered this idea by stating that diffusion is "the process through which (1) an innovation (2) is communicated through certain channels (3) over time (4) among the members of a social system" (2002, p. 990). This thought reverberates in several editions of Diffusion of Innovations. Katz et al.'s (1963) discussion of diffusion is similar to Rogers (1962) but the former stresses the importance of values and culture embedded within these social systems. This is important because adoption may differ based on the variability of these values and cultures. Further, Wilson and Dowlatabadi (2007) assert that the diffusion of innovations is a process of social communication occurring through media as well as person-to-person interactions. They classify the DoI as a behavioural model, thereby inferring that adoption occurs at the individual level. As such, it appears Wilson and Dowlatabadi consider the diffusion of innovations to be influenced by social mechanisms and that these, potentially, influence adoption at the individual level.

There are several assumptions associated with the diffusion of innovations and their influence on decision-making. Individuals (1) are exposed to and gain knowledge about an innovation; (2) form either favorable or unfavorable attitudes toward the innovation; (3) make a choice to accept or reject an innovation; (4) use the innovation; (5) seek validation through feedback (at this time adopters may reverse their decision) (Rogers, 2003). Further, the successes or failures of an innovation can vary according to its specific attributes. Therefore the degree to which an innovation demonstrates an advantage in terms of expense and convenience can influence adoption (Wilson \& Dowlatabadi, 2007); this appears to compliment economic theory. Also important is compatibility. That is, innovations need to be compatible with the needs and values of its users (Rogers, 2003). For example, energy efficiency will not be attractive if it deviates from current norms (Dennis, Soderstrom, Koncinski, \& Cavanaugh, 1990). Innovation uptake can also be influenced by whether or not it is difficult to use or implement (Rogers, 2003). For example, the installation of solar panels may be perceived as challenging with respect to installation as well as cost. Likely, as solar technology decreases in costs it will have more appeal. Also, a newer innovation like solar paint may influence adoptability given the potential for usability (i.e., easier to 'install'). Last, and most obvious, an innovation needs to be testable (Rogers, 
2003). For example, prior to being available on the market, a new type of spray foam insulation needs to be tested, given that once it is installed it is almost impossible to remove.

The DoI theory has been criticized for assuming that individuals adopt technologies in a consistent manner (Mahajan et al., 1990). Adopter types may deviate from those specified in Rogers (2003), particularly with respect to the number and characteristics of groups traditional to DoI. Further, these adopter groups may demonstrate unique distribution patterns according to type of innovation. Other weaknesses include the DoI's linearity (i.e., moving from knowledge, attitudes, intention, to behaviour) as well as its limited explanatory power in contexts wherein individuals suffer from a lack of resources or limited access to technologies (Wilson \& Dowlatabadi, 2007).

\subsubsection{Theory of Reasoned Action and Theory of Planned Behaviour}

Perhaps one of the most notable theories of behaviour is Icek Ajzen's theory of planned behaviour (abbreviated TPB) (Azjen, 1985). According to Ajzen (2011), since its introduction, this theory has become one of the most influential models for predicting human behaviour; a 2010 Google Scholar search for the keyword 'theory of planned behaviour' revealed 4550 citations. Even more, when using other metrics for assessing influence, such as in Nosek et al. (2010), Azjen's research program gets noteworthy mention for having the highest scientific impact among Canadian and American social psychologists.

The theory of planned behaviour was developed from Fishbein and Azjen's theory of reasoned action (Ajzen \& Fishbein, 1980; Fishbein \& Ajzen, 1975). Thus it makes sense to begin with a discussion of the original theory. The theory of reasoned action (abbreviated TRA) is chiefly concerned with human behaviours under volitional control (Madden, Ellen, \& Azjen, 1992). Here, volitional behaviours are everyday behaviours that people can easily perform, such as watching television or going to the movie theatre (Ajzen, 1985). According to the TRA, human behaviour under volitional control is predictable, goal-directed, and planned - though Azjen acknowledges that some behaviour can be rote and performed almost unconsciously (e.g., typing a letter) (1985). He posits that the TRA is still applicable in such situations, explaining that writing a letter requires a plan, which can be either "explicit or implicit", and that the components of said plan ultimately do not affect volition (Azjen, 1985). Therefore he appears to be implying that if the majority of actions associated with a behaviour are explicit, then the overall behaviour is explicit.

Subsequently, an individual's plan or goal is translated into an intention. As such, the most important predictor of behaviour becomes the intention (Azjen, 1985). In the theory of reasoned action, the relationship between intentions and actions can be parsimoniously described using the equation: 
$\mathrm{B} \sim \mathrm{I} \infty\left[\mathrm{w}_{1} \mathrm{~A}_{\mathrm{B}}+\mathrm{w}_{2} \mathrm{SN}\right]$ (Azjen, 1985). In this equation, behaviour is approximately predicted by intentions, which are determined by attitudes and subjective norms. Therefore, a person's intention to carry out (or not carry out) a behaviour is the primary determinant of behaviour. Further, Azjen notes it is assumed that individuals will behave in accordance with their intentions unless there is some unforeseen event or reason to change the intention. And further, intentions are strongest when latency (i.e., time elapsed between intention and behaviour) is kept to a minimum (Azjen, 1985).

The question then becomes, what determines an individual's attitudes and norms? First, attitudes are a person's positive or negative evaluations of performing specific behaviours, which are guided by beliefs about those behaviours (Azjen, 1985). Second, subjective norms are beliefs guided by how people view the pressures put on him or her to perform or not perform certain behaviours (Azjen, 1991). According to Azjen (1985), the importance of attitudes and norms may be different from person to person, hence the weighting of these variables in the equation. For some, attitudes may be more important than subjective norms while, for others, it could be the reverse. The best case scenario for progressing from an intention to a behaviour is to have positive attitudes and to have the belief that others want you to perform the behaviour (Azjen, 1985).

With respect to the TRA, attitude formation is influenced by the outcomes individuals associate with specific behaviours as well as the evaluation of these outcomes (Ajzen, 1985). For example, going on a diet (behaviour of interest) may result in the following outcomes: blood pressure drop, lifestyle changes, and food option restrictions (Ajzen, 1985). Each of these are evaluated in terms of their desirability (i.e., outcome evaluation) and how likely these are to be true (i.e., belief strength) (Ajzen, 1985). For example, desirability of blood pressure drop could be measured on a scale from bad (1) to good (5) whereas beliefs associated with blood pressure drop could be measured on a scale from unlikely (1) to likely (5). Attitude formation then becomes the result of multiplying belief strength by outcome evaluation and summing these across all possible outcomes (Azjen, 1985).

Subjective norms (i.e., normative beliefs) are based on the beliefs one has of their expected role (Azjen, 1991). Generally speaking, if an individual believes that most referents with whom he or she is motivated to comply think he or she should perform a behaviour, then that individual will perceive social pressure to comply. This idea also works in reverse. If an individual believes that most referents with whom he or she is motivated to comply think he or she should not perform the behaviour, then that individual will perceive social pressure to not perform the behaviour. Subjective norms are calculated by multiplying an individual's normative beliefs with their motivation to comply (Fishbein \& Ajzen, 1975). As in Connor and Sparks (2005, p. 198) examining norms can begin with asking "Most persons who are important to me think I should/should not ." Here the behaviour in question can be inputted into 14 
the blank and this can be evaluated on a scale ranging from should (1) to should not (7) (Connor \& Sparks, 2005). Similarly, motivation to comply can be evaluated with the statement and scale, "In general, I want to do what my thinks I should do", with responses ranging from want to (3) to want not to (-3) (adapted from Jaccard and Davidson as cited in Fishbein \& Ajzen, 1975, p. 309). The scores to both normative beliefs and motivation to comply are multiplied and then summed across referents, if there are several (Azjen, 1985).

Attitudes and subjective norms have been studied across various behavioural phenomena. In these, questions and their respective scales, as noted above, have served as examples for assessing attitudes and norms with several researchers developing their own assessment according to their specific research questions. For example, Primack, Switzer, and Dalton (2007, p. 435) measured cigarette smoking beliefs using multiple statements and thereby a scale $(\alpha=.82)$ :

According to my parents, it is very important for me to not smoke cigarettes.

According to my friends, it is very important for me to not smoke cigarettes.

According to most people my age, it is very important for me to not smoke cigarettes.

During the 1970s, several researchers, including Fishbein and Azjen, realized that the TRA was insufficient for explaining behaviour (Godin \& Kok, 1996). Admittedly Ajzen (1985) states that the theory of reasoned action is not without limitation, specifically with respect to volitional control. For example, if an individual wants to see a movie, the individual may arrive at the movie theatre only to find out that tickets are sold out (Ajzen, 1985). Another simple example: an individual may want to watch television, only to find out that his or her television set will not turn on (Azjen, 1985). Consequently, what appears to be volitional is not. According to Azjen (1985), variables affecting volitional control include: individual differences, information, skills, abilities, will power (e.g., students with an exam and a party conflict), emotions, external factors, time and opportunity, and behaviours requiring cooperation.

To improve upon the original theory and to take into account these limitations, Ajzen (1985) added a third element to the TRA — perceived behavioural control. Accordingly, this concept examines the degree to which individuals believe they have control over their behaviour by examining potential factors which may facilitate or inhibit a behaviour as well as their power (Ajzen, 1985). For example, an individual may be asked to rate their agreement with the statement, "I expect that my work will place high demands on my time in the next 30 days", with responses scored from strongly disagree (1) to strongly agree (7) (Knabe, 2012, p. 34). The power of work's demands on behaviour can be ascertained 
with the statement, "My work placing high demands on my time in the next 30 days would it make it much more difficult (score of 1) or easy (score of 7) to perform a given behaviour", (Knabe, 2012, p. 34). Scores on potential factors affecting control are multiplied by their power and these are summed (Ajzen, 1985).

With the inclusion of perceived behavioural control, the theory of reasoned action now becomes the theory of planned behaviour and can be defined with the equation: $\mathrm{B} \sim \mathrm{I} \infty\left[\mathrm{w}_{1} \mathrm{AB}+\mathrm{w}_{2} \mathrm{SN}+\right.$ $\mathrm{w}_{3}$ PBC] (Conner \& Sparks, 2005). Further, this theory has been used by several researchers examining alcohol use, public transportation use, online course adoption, technology acceptance, and green consumerism, among others (e.g., Collins \& Carey, 2007; Heath \& Gifford, 2002; Knabe, 2002, Mathieson, 1991; Sparks \& Shepherd, 1992).

The model is appealing given its simplicity and clarity. However, these characteristics do not take away from its oversimplification of behaviour as well as the assumption of individuals acting rationally. Further, it should be noted that the originators of TPB do not believe factors such as demographics or personality traits to directly affect behaviour (Azjen, 1985). However, de Leeuw, Valois, Azjen, and Schmidt (2015) recently acknowledged the influence of socio-demographic factors such as age, sex, education, socio-economic status, and others on beliefs.

The information deficit model, diffusion of innovations theory, the theory of reasoned action, and the theory of planned behaviour all make assertions about the influence of attitudes on decisionmaking and behaviour. In any case, the formation of attitudes seems to play a dominant role in these theories of individual level behaviour.

\subsubsection{Social and Environmental Theories}

Western industrialized nations have seen substantial changes in their environmental policies owing to environmentalists and their "effective mobilization" of public support (Stern, Dietz, \& Black, 1985). Interestingly, Olsen (1965, as cited in Stern et al., 1985) suggests that this type of mobilization is problematic for social scientists given that "simple" behavioural models, rooted in self-interest behaviour, cannot account for the collective notions found in and promoted by social movements. If individuals behaved merely in accordance with rational actor models we would expect to see fewer people participating in social movements whereas, in actuality, support for environmental movements is prevalent (e.g., Dunlap, 1985; Morrison \& Dunlap, 1986). Accordingly, there are several theories and models that examine behaviour, outcomes, and decision making outside of rational actor models. These will be examined in the following sections. 


\subsubsection{Altruism}

Altruism falls under the umbrella of prosocial behaviour, which can be defined as voluntary actions intended to benefit others (Eisenberg \& Miller, 1987). Being agreeable — one of the "Big Five" personality traits - has been linked to greater environmental concern, with those lower in Agreeableness tending to be more selfish and less concerned with the welfare of others (Hirsh \& Dolderman, 2007; Hirsh, 2010). Borden and Francis (1978) also previously suggested that individuals having selfish and competitive orientations towards the world are less likely to be environmentally concerned.

Furthermore, Borden and Francis (1978) argue that basic human needs have to be satisfied before one can act ecologically; ecological behaviour is often categorized as environmental behaviour (Bamberg \& Moser, 2007). For example, if an individual has food, shelter, clothing, and feels safe then he or she has the capacity to devote, in some manner (e.g., time, money), to pro-environmental issues. This suggestion is in line with Maslow's hierarchy of needs (1943) with pro-environmental behaviour, in this context, considered a higher order need.

Related is Geller's theory of pro-environmental behaviour. In particular, Geller attempts to combine behaviour based psychology with person based psychology (i.e., humanism) and attributes proenvironmental behaviour to a form of altruism he terms "actively caring" (1995). According to Geller, pro-environmental behaviour requires individuals to care "considerably" about others and their community before acting on behalf of the environment. Individuals therefore need to focus beyond themselves and makes others a top priority in order to be truly altruistic; this occurs when individual self-esteem, sense of belonging, personal control, self-efficacy, and optimism needs have been met (Geller, 1995). Again, the influence of Maslow's hierarchy of needs (1943) is demonstrated.

Geller's model of pro-environmental behaviour has been tested-though, not directly. Specifically, Geller, Roberts, and Gilmore (1996) and Roberts and Geller (1995) found self-esteem, sense of belonging, personal control, and optimism to be related to coworker protection behaviour (i.e., their measure of actively caring). Though their study did not directly examine pro-environmental behaviour, according to Geller and his colleagues, their study supports a model for examining proenvironmental behaviour given that their indicators of actively caring and altruistic behaviour were found to be related. Inspired by the actively caring model, Allen and Ferrand (1999) found a significant relationship between personal control and sympathy (i.e., their measure of actively caring) but did not find significant relationships between self-esteem, sense of belonging, and pro-environmental behaviour (e.g., recycling, conservation). 


\subsubsection{Norm activation}

Norms play an important role in guiding expectations of how people should think, act, and feel (Popenoe, 1983). Interest in norms is widespread with various disciplines, such as sociology and psychology, taking interest in their study. As in the theory of planned behaviour, norms are often used in the 'social norm' sense. However, norms can also be activated at the individual level with these being referred to as personal norms. Particularly, the concept of personal norms pertains to the expectations individuals have of themselves; the development of this concept can be credited to Schwartz (1973). According to Schwartz, norms can be distinguished as personal given that their violation affects feelings of guilt, self-deprecation, and loss of self esteem while their conformity results in feelings of pride and boosted self-esteem (1973). Moreover, personal norms concern internal standards whereas social norms concern external standards thus making personal norms self-sanctioned and social norms socially sanctioned (Ellickson, 2001; Kallgren, Reno, \& Cialdini, 2000).

Schwartz (1977) used the concept of personal norms to form the norm activation model (abbreviated NAM), with personal norms specifically being defined as "feelings of moral obligation not as intentions" (p. 227). The model states that personal norms are determined by two factors: 1) the awareness that performing (or not performing) a given behaviour has consequences and 2) the feeling of responsibility associated with performing a given behaviour (Schwartz, 1977). Consequently, this model is said to predict altruistic behaviour when a moral norm is activated, occurring when an individual becomes aware that his or her behaviour can have negative consequences for others (i.e., awareness of consequences) and when an individual takes responsibility for the well being of others (i.e., ascription of responsibility to self) (Stern et al., 1985). Heberlein (1972) first suggested that the norm activation model could be adapted to predict pro-environmental behaviours. Particularly, Heberlein (1972) hypothesized that individuals should act to protect the environment when an individual understands that his or her actions can have a negative impact on the environment and feels personally responsible for the associated consequences.

Several researchers have successfully used the norm activation model to predict proenvironmental behaviours (e.g., Doran \& Larsen, 2016; Guagnano, 1995; Hopper \& Nielsen, 1991; Van Liere \& Dunlap, 1978). For example, Van Liere and Dunlap (1978) found that those individuals who were most aware of the negative environmental consequences associated with burning yard waste and who also accepted responsibility for the consequences associated with burning yard waste, were least likely to burn yard waste. Similarly, Guagnano (1995) found that awareness of environmental consequences and willingness to take responsibility could be combined to predict willingness to take 
action on a range of environmental issues (e.g., signing a petition in support of environmental laws). Recently, Doran and Larsen (2016) found personal norms to be related to eco-friendly travelling.

Findings from such studies are consistent with Geller's model in that environmentally friendly behaviors were explained by altruism, albeit 'different' types of altruism. NAM findings are also consistent with actively caring in that personal responsibility, conceptually related to personal control, was shown to be a precursor to feelings of altruism. A major difference between the norm activation and actively caring models is in the inclusion (or omission) of different predictor variables. That is, the norm activation model does not specifically include examination of self-esteem or belonging as model predictors. Further, and more noteworthy, an important difference lies in how both models define altruism. The NAM's concept of altruism is the "adherence" to a norm and feelings of obligation whereas Geller's notion of altruism appears to be having concern without the implication of guilt (i.e., a no strings attached form of intention). Therefore actively caring can be seen as genuine intention without the moral obligations associated with personal norms.

\subsubsection{Value-Belief-Norm Theory}

Although the value-belief-norm (abbreviated VBN) theory can be grouped with other social and environmental theories, it is being presented on its own due to its prominence in the literature. This theory originates in the study of social movements, which, as previously noted, includes environmentalism. According to Stern, Dietz, Abel, Guagnano and Kalof (1999), environmental movements are based in similar beliefs and values: human actions have the potential for negatively affecting the environment, changes in the environment can negatively affect things people care about, and harmful actions affecting the environment should therefore be diminished.

With respect to social movements, Stern et al. (1999) differentiate between activism and social movement support, though they acknowledge that the boundaries can be fuzzy. In particular, there are three main types of support demonstrated by movement supporters. The first is low commitment active citizenship and it is associated with political activities that are low in risk and less public than those associated with activism (Stern et al., 1999). Low commitment active citizenship activities include writing letters to political officials and donating funds to movements (Stern et al., 1999). The second type of support is the acceptance of public policies requiring - potentially-some public sacrifice (Stern et al., 1999). Examples include higher taxes in support of public policy or adhering to regulations (e.g., mandatory recycling) (Stern et al., 1999). The last type of support is behaviour change (i.e., when individuals change their behaviour to support a movement) (Stern et al., 1999). For example, when 
individuals conscientiously turn off lights they are demonstrating support to conserve energy even though there might not be any regulation requiring them to do so.

Stern et al. (1999) proposed that the various forms of movement support, as described above, arise from an individual's values, beliefs, and personal norms, with the concept of personal norms stemming from Schwartz (1977). The authors claim that altruism behaviour, and therefore the activation of personal norms, is relevant in explaining social movements given that movements are often based on the premise that individuals are not acting out of self-interest but for the 'larger good'. Hence the distinction between social and personal norms is important because if a social norm surrounding a given social movement was to not pursue the movement then there would be no drive in movement support (Stern, et al., 1999).

Although the original NAM is based on altruistic sentiments for other humans, Stern et al. posit that norm activation may occur for other 'things'. For example, with respect to environmentalism, threats to animals and biodiversity can also be important and similarly we can feel responsible for these (Stern et al., 1993; Stern \& Dietz, 1994). Accordingly, the value-belief-norm theory proposes that environmental behaviour stems from individual values regarding other humans, other species, and the biosphere (Stern, 2000). These values, in turn, shape and inform an individual's worldview regarding human-environment relationships and take into account an individual's beliefs regarding threats to the environment and the individual's sense of responsibility for those threats imposed on the environment (Stern, 2000). Taken together, an individual's values and beliefs activate individual personal norms and moral obligations which result in either action or inaction (i.e., behaviour) (Stern, 2000). Theirs is a causal chain starting with the elements of personality and belief structure, continuing with the focused beliefs on human-environment relationships, and ending with moral obligation that creates a reason to act in support of movement goals (Stern et al., 1999).

Using survey data, Stern et al. (1999) tested their theory for predicting social movement support against the theory of post-materialist values (Inglehart, 1997), the idea of spiritual or religious world view (i.e., the view that those who hold nature sacred due to it being God's creation or not are more active supporters of environmental protection) and cultural theories (Douglas \& Wildavsky 1982). The authors found their theory to be better at explaining movement support that the two competing theories. The value-belief-norm theory has been applied in several studies examining corporate sustainability, energy policies, organic and local food behaviour, among others (e.g., Andersson, Shivarajan, \& Blau, 2005; Steg, Dreijerink, \& Abrahamse, 2005; Zepeda \& Deal, 2009). 


\subsubsection{Attitudes-Behaviour-Context and a Coherent Theory of Behaviour}

In the preceding theories and models, behaviour has been put forward as an outcome stemming from the individual. While this makes sense - energy use is ultimately related to human behaviour (Abrahamse,

Steg, Vlek, \& Rothengatter, 2005) - the question of context has been given less priority. Appropriately, the importance of context has been highlighted in the attitudes-behaviour-context (abbreviated ABC) model (Guagnano, Stern, Dietz, \& 1995).

In their study, Guagnano et al. (1995), examined curbside recycling and found behaviour to be co-determined by attitudinal and contextual variables. Context can include structural facilitation or barriers and general support or lack of support (Guagnano et al., 1995). In their study, the authors used a survey to assess demographic characteristics, environmental attitudes, community behaviour, selfreported recycling behaviour, and concepts related to norm activation (Guagnano et al., 1995). They found an interaction whereby norm activation occurred for households without recycling bins but did not occur for households with recycling bins (Guagnano et al., 1995).

These findings provide general support for attitudes and behaviour being most strongly correlated when behaviour is facilitated by the context, however, in the instance of a contextual barrier, behaviour is less likely to be determined by attitudes. Further demonstration of these relationships can be found in Black, Stern, and Elworth (1985). In their study of household energy conservation, the relative explanatory power of social-psychological variables declined as effort or cost increased, from $59 \%$ of the explainable variance in self-reported home thermostat settings to $50 \%$ for minor curtailments such as shutting off heat in unused rooms, $44 \%$ for low-cost energy efficiency improvements such as caulking and weather-stripping, and $25 \%$ for major investments such as adding insulation or storm windows (Black et al., 1985).

In an effort to marry internal and external influences, Stern (2000) proposes a coherent theory of environmentally significant behaviour. Environmental behaviour, here, can be defined according to its impact with some of these being direct (e.g., clearing a forest) while others are indirect (e.g., behaviours affecting policies) (Stern, 2000). Further, Stern highlights that previous notions of environmental impact had to do with the behaviours associated with human desires for comfort, mobility, and technologies, however, more recently, environmental behaviours can also be those that are performed with the purpose of environmental protection. Stern calls these pro-environmental intent, however, they could be called pro-environmental behaviours.

Accordingly, Stern (2000) identifies several types of environmental behaviour, with many being similar to the types of support demonstrated by social movement supporters (Stern et al., 1999). First is 
environmental activism, which is active participation in environmental organizations (Stern, 2000). Second is non-activist behaviours in the public sphere such as support for public policies and willingness to pay higher taxes (Stern, 2000). These behaviours appear to indirectly affect the environment but their indirect effect can be larger than the effect of some direct behaviours like recycling (Stern, 2000). Third is private-sphere environmentalism-consumerism, which is the consumer behaviour of purchasing, using, and disposing of personal and household products (Stern, 2000). Private sphere behaviours are different than public sphere behaviours in that they have direct environmental impact, however, this may be small. So much so, that indirect behaviours may have more impact that direct behaviours. Private sphere behaviours, however, can be impactful in aggregate form. Last is the other environmental significant behaviour category (Stern, 2000). Behaviours belonging to this category have to with the behaviours individuals can perform within organizations and hence affect organizational behaviour (Stern, 2000).

In order to explain these environmental behaviours, Stern (2000) considers several determinants. He considers attitudinal variables that have been previously discussed (i.e., norms, beliefs, and values). Stern also considers context by accounting for the widespread effects of: interpersonal influences (e.g., persuasion, modeling); community expectations; advertising; government regulations; other legal and institutional factors (e.g., contract restrictions on occupants of rental housing); monetary incentives and costs; the physical difficulty of specific actions; capabilities and constraints provided by technology and the built environment (e.g., building design, availability of bicycle paths, solar energy technology); the availability of public policies to support behavior (e.g., curbside recycling programs); and various features of the broad social, economic, and political context (e.g., the price of oil, the sensitivity of government to public and interest group pressures, interest rates in financial markets) (Stern, 2000). It is worth noting that a contextual factor may have different meanings to people with different attitudes or beliefs. For example, the higher price of 'organic' produce may be a price barrier for some people, whereas for others, it may be a marker of a superior product (Stern, 2000).

Stern also considers personal capability to be a determining factor. These include knowledge and skills required for particular behaviours (e.g., the skills of a movement organizer for activism, mechanical knowledge for energy-conserving home repairs), time availability, and general capabilities and resources such as literacy, money, social status, and power (Stern, 2000). Further, Stern notes that socio-demographic variables such as age, educational attainment, race, and income may be indicators or proxies for personal capabilities. These variables can be important when behaviours depend on particular capabilities. For instance, socio-demographic variables were found to be unrelated to consumer behavior and policy support when social-psychological variables were held constant, but 
environmental citizenship was found to be positively associated with income and with race (Stern et al., 1999). The findings reflect the fact that the efficacy of environmental citizenship depends on an individual's social and economic resources (Stern et al., 1999). Also, environmental activism, for which attitudinal variables had very little explanatory power, was significantly associated (negatively) with age and income (Stern et al., 1999).

Another determinant of environmental behaviour, in this theory, is that of habit or routine (Stern, 2000). Although these are acknowledged, their discussion is limited. Mostly Stern notes that some behaviours/habits need to be broken in order for progress to be made. Wilson \& Dowlatabadi (2007) also acknowledge habits around the home that involve energy use and this is similar to the conceptualization of social practices in the home and will be discussed in a further section.

This framework or coherent theory is an attempt to be comprehensive with Stern suggesting that this theory is based on hypotheses that seem "fairly obvious" (Stern, 2000, p. 418). Further, Stern offers that different causal factors appear to influence behaviour in different situations, such as in the ABC model. Therefore, he suggests that the next step is to examine interactions. In particular he notes:

The insight of the $\mathrm{ABC}$ formulation, that the different types of causal factors may interact, implies that interpretations based only on main effects can be seriously misleading. Studies that examine only attitudinal factors are likely to find effects only inconsistently, because the effects are contingent on capabilities and context. Similarly, studies that examine only contextual variables, such as material incentives, social norms, or the introduction of new technology, may find effects but fail to reveal their dependence on individuals' attitudes or beliefs. Single-variable studies may demonstrate that a particular theoretical framework has explanatory power but may not contribute much to the comprehensive understanding of particular environmentally significant behaviors that is needed to change them. (Stern, 2000, p. 418).

\subsubsection{Sociology}

Thus far, the emphasis has been on individuals performing or not performing certain behaviours. That is, previous theories and models view behaviours to flow from the self-directed individual. These, in turn, may be influenced by various factors such as those in the personal domain (e.g., attitudes, values, beliefs) or those in the contextual domain (e.g., ease of behaviour). However, sociologists argue that behaviours and decisions are influenced by social and technological systems. This perspective has also been used to explain social influence on attitudes (Summerton, 1992). 
Within sociology and studies of consumption, the concept of lifestyle may be explored by looking at socio-economics. According to Bourdieu (1984), everything can be understood as structured by economic and cultural capital, that is, by amount of money, assets, knowledge, skills, education. Gram-Hanssen (2014) notes that Bourdieu uses economic and cultural capital for explaining "everything from food, music and leisure time to housing consumption" (p. 94). Bourdieu also introduced the concept of "habitus" which deals with how cultures and social surroundings can influence unconscious individual performance of behaviours as well as unconscious preference for certain things. Therefore, according to this concept, individuals grow up unconsciously taking in their surroundings and are subsequently influenced to behave in different ways. Therefore a working class family and a middle class family behave in different ways, not only due to economics, but also due to cultural upbringing (Gram-Hanssen, 2014). Lifestyle has been defined by Lutzenhiser and Gossard (2000) as modes of existence "distinctive modes of existence that are accomplished by persons and groups through socially sanctioned and culturally intelligible patterns of action" (p. 215).

The concept of lifestyle has been widely used in consumer research and advertising but has also been examined with respect to energy use (Sanquist, Orr, Shui, \& Bittner, 2012). In fact, significant relationships have been found between energy use and income, lifecycle stage, and ethnicity (e.g., Hackett \& Lutzenhiser, 1991; Lutzenhiser, 1993; O’Neill \& Chen, 2002). Bourdieu also claims that differences in culture are also used by social groups to demonstrate their differences as a form of their identity. Some have taken the concept of lifestyle and have placed less emphasis on social class and have placed more emphasis on showing identity through their consumption or choice of products (e.g., Beck, 1992; Giddens, 1990; Sobel, 1981). According to Sanquist et al. (2012), lifestyle can be conceptualized as patterns that are influenced at specific points across the lifespan, such as where to live, to have or not have children, what energy appliances to purchase, etc.

The extent to which lifestyle, especially demonstrating identity through lifestyle, can explain or account for ordinary and routine consumption such as energy consumption has been questioned (Gronow \& Warde, 2001). In particular, Shove (2003) argued that the routine and technological aspects of consumption need their own examination. These can be defined as practices: "routinized type of behavior" (Reckwitz , 2002, p. 249) which are the elements of day-to-day life (Foulds, Powell, \& Seyfang, 2016). Examples of practices include cooking, hosting dinner parties, playing hockey, and showering. Subsequently, the application of social practice theory is becoming more widespread (e.g., Hargreaves, 2011; Røpke, 2009; Shove \& Walker, 2010).

According to social practice theory, energy use is not a whole but a sum of parts and these are uniquely guided. That is, energy use is not a practice in itself but is composed of various activities and 
these are influenced by different elements (Gram-Hanssen, 2014). These elements include unconscious habits, knowledge, engagement (i.e., the practice of doing something for the sake doing it and not for the sake of using energy; e.g., cooking), and technologies (e.g., we use energy differently now than we did before the existence of freezers) (Gram-Hanssen, 2014). Therefore, individuals do not make specific decisions to use energy or to use resources but rather energy provides useful services that allow individuals to carry out everyday behaviour, i.e., practices (Wilhite, Shove, Lutzenhiser, \& Kempton, 2000). Further, many practices associated with energy use are inherently intertwined in home life (e.g., cooking, cleaning, child care, entertaining) (Wilson \& Dowlatabadi, 2007).

Another important sociological contribution is the idea that needs and wants are socially constructed. Wilson and Dowlatabadi (2007) use air conditioning to demonstrate this point. In particular the authors state that the social construction of household needs and expectations with respect to thermal comfort has caused them to changed over time. In particular, house design (e.g., room sizes), energy technologies (e.g., thermostats), supporting infrastructure and institutions (e.g., energy services), and social norms (e.g., indoor temperature set points) have changed (Whilhite et al., 2000). During the period from 1962 to 1992, use of household air conditioning in the US increased from 12 percent to 64 percent (Kempton \& Lutzenhiser, 1992) and by 2001 air conditioning use increased to 75 percent (US EIA, 2001). Further, the availability and adoption of air conditioning led to changes in the house design (i.e., verandas, eaves, thermal mass, and other forms of passive cooling were not considered integral) (Wilson \& Dowlatabadi, 2007). This example shows the interconnectedness between what households want, their change in thermal comfort expectations, how these effect housing design (which also affects thermal comfort), and the diffusion of air conditioning technology.

\subsection{Conceptual Framework}

Each of the preceding paradigms provide valuable insights and many are accompanied by complimentary frameworks for guiding behaviour studies. Problematically, many disciplinary outlooks do not transcend their disciplinary boundaries, even though many acknowledge the importance of doing so (Moezzi \& Lutzenhiser, 2010). Given the complex nature of household energy use, it is prudent to move away from siloed investigations. In doing so, researchers have the opportunity to engage in work that explores the objective reality (so to speak) of household energy use as being a multi-faceted phenomenon. Not doing so can result in superficial, incomplete, or misleading examinations. The promise and importance of an interdisciplinary approach are highlighted by Moezzi \& Lutzenhiser (2010): 
Household energy use is not a physics problem, e.g., with stable principles across time and place, conditions that can be clearly articulated, and laboratory experiments that readily apply to the real world. Of course not; but since analysis in the energy efficiency field is so steeped in physics, classical economics, and quantification, it is easy to mistake the 'variables' of theories and statistical analyses as levers that can be manipulated, rather than as clues to more dynamic processes. (p. 209).

A key assumption guiding this work is that household energy use is broad, complex, and dynamic and cannot be explained through a single disciplinary lens. Therefore an interdisciplinary approach can be used to examine variables in both a traditional manner (i.e., unique to their discipline) as well as dynamically (i.e., blurring of disciplinary boundaries). Here is a hypothetical situation that can be used to demonstrate both: a family has recently installed high-performance windows in their house of ten years. How can this variable be operationalized (i.e., the high-performance windows)? In line with a traditional building science perspective the windows may be perceived as simply a measure of energy efficiency. From a sociological perspective, the high-performance windows may be operationalized as an indicator of social class (i.e., social and economic status). From a psychological perspective, the highperformance windows may be an indicator of one's environmental 'position'. This type of operationalization might typically be fine but becomes problematic when used to explain dynamic phenomena such as household energy use. Therefore, using the above example, can household energy use be attributed to efficiency, social class, or being environmental? If we begin by looking at household energy use narrowly we might restrict our viewpoint of what really affects household energy use. However, with respect to a dynamic view and the above example, we might start to think that only those with high social class can use the best possible windows, therefore maybe only individuals from higher social classes can be energy efficient? Taken together, an interdisciplinary view can be used to look at all the possible interactions of these variables so that examination is not exclusive to one discipline.

Research on household energy use typically consists of two approaches: theoretical, i.e., focused on identifying household or individual level characteristics related to energy use, such as sociodemographic or attitudinal variables (e.g., Steg, Dreijerink, \& Abrahamse, 2005); and applied, i.e., focused on testing the effectiveness of interventions aimed at reducing energy use (e.g., Katzev \& Johnson, 1984). The approach taken here aligns with the first and therefore, in this study, the overall aim is to determine influential variables related to household energy use. As well, this study will be used to assess key gaps in the literature. In particular, examination of energy literacy will address key gaps in the information deficit model with respect to variable measurement. That is, many studies examining the 
relationship between information and behaviour have operationalized information as knowledge or knowledge as information. For example, Racjecki (1982) categorizes learning about environmental problems in a classroom as information. It is being argued that this is, rather, knowledge. Further, the examination of energy literacy will extend Stern's coherent theory (2000), in part, to household energy use by examining energy literacy as a general capability variable, along with several others as suggested by Stern (2000). That is, private sphere environmentalism (here household energy use) is hypothesized to be related to several variables. Although discrete choices (e.g., upgrading appliances) will not be examined per se, behavioural economics and econometric models will be influential for providing examples of household energy use modeling due to several covariates being examined together, including household income. As well, psychological variables such as environmental concern and attitudes will be examined given their inclusion in several theories and models such as the theory of planned behaviour, value-belief-norm theory, the DoI, and the ABC model.

In this respect, attention will be paid primarily to dwelling characteristics (i.e., building characteristics, e.g., dwelling type, heated area) and household characteristics (i.e., socio-demographic variables such as household income and psychological variables such as attitudes). For this study, the term household characteristics will be used to refer to both psychological and socio-demographic variables given that these attributes belong to individual people who possibly live together as a household. This classification is in line with other studies such as Abrahamse and Steg (2009) who distinguished between socio-demographic variables (e.g., income, number of residents) versus psychological variables (e.g., attitudes); Brounen, Kok, and Quigley (2012) who distinguished between dwelling characteristics (e.g., size, type, thermal qualities) and socio-demographics (e.g., number of household residents); Santin, Itard, and Visscher, (2009) who distinguished between building characteristics (e.g., vintage, insulation, heating system), household characteristics (e.g., respondent age, number of household residents, household income), and behaviour (e.g., ventilation practices).

The above chapter has presented the various perspectives through which household energy consumption can, and has been, understood, and advocates for an interdisciplinary approach which combines contemporary insights where applicable. The following chapters thus present research that examines energy use and, specifically, people's interactions with energy use from different perspectives. 


\section{Chapter 3: Canadian Residential Energy Use}

\subsection{Introduction}

The residential sector provides opportunities for energy efficiency and energy conservation. Several governments have and continue to support initiatives directed at improving dwelling efficiencies. For example, by June 2015, more than 70,000 new homes had been built all across Canada since the beginning of the ENERGY STAR for New Homes and R-2000 initiatives, which means that they use 20 to 50 percent less energy use than typical homes (NRCan, 2016). Similarly, during the 2013-2015 reporting period, Canadians saved 8.3 petajoules (PJ) of energy from using ENERGY STAR products, which is equivalent to the energy used by 1.8 million cars in one year (NRCan, 2016). As a result of these and other energy efficiency measures, Canada's overall energy efficiency has greatly improved and has led to Canadians saving money on their energy bills as well as avoiding greenhouse gas (GHG) emissions (NRCan, 2016). The popularity of energy efficiency measures is not limited to Canada. In fact, energy efficient buildings are a worldwide trend (Guerra Santin, Itard, \& Visscher, 2009).

While increases in building energy efficiency are important, the behaviour of building occupants is still part of the equation. For example, imagine several households all living in extremely energy efficient homes. All of these homes are built the same (i.e., all are energy efficient in design) and all have the exact same (i.e., type and number of) energy efficient appliances. The energy efficient building design and the energy efficient appliances have the potential for reducing the amount of energy used by these households but the occupants, the individuals and groups of people in these homes, may differ in their characteristics or their behaviours. Potentially, differences in household characteristics and behaviours will contribute to differences in household energy use. Therefore, building improvements have the potential for reducing energy use up to a certain point, after which occupants will continue to influence and drive end use. In order to keep improving on the state of energy efficiency, and just as importantly energy conservation, more needs to be known about the occupants of these buildings (i.e., households). In what way are household characteristics related to household energy use?

There is a substantial amount of work that has focused on building characteristics and their impact on household energy use (e.g., Tokarik \& Richman, 2016). Particularly, engineering methods have been used to model residential energy use by developing housing databases representative of the national housing stock and subsequently using simulation programs to estimate the energy use of the houses in the databases (Aydinalp, Ugursal, \& Fung, 2003). These types of studies have informed guidelines for calculating space heating and cooling (e.g. International Organization for Standardization [ISO], 2008). Aydinalp et al. (2003) acknowledge that some of the problems associated with the 
engineering method involve the difficulty of incorporating consumer behaviour and socio-demographic variables into simulations. Particularly, socio-demographic predictors are important because they can, "shape the amount, frequency and duration of a household's energy use" (Frederiks, Stenner, \& Hobman, 2015, p. 579).

Overall, there is limited research on electricity and natural gas use, emphasizing both dwelling characteristics (i.e., building) as well as household characteristics. Further, there are limited studies on Canadian electricity and natural gas use, emphasizing household characteristics. Though dwelling characteristics have been used in engineering models, less work exists on examining them from a statistical perspective; though it appears this area is becoming more common (e.g., Brounen, Kok, \& Quigley, 2013; Brown, Gorgolewski, \& Goodwill, 2015; Guerra Santin et al., 2009; Steemers \& Yun, 2009). These statistical studies use methods such as quantile regressions, ordinary least squares regressions, neural networks, and decision trees to examine energy use (e.g., Kaza, 2010; Liao \& Chang, 2002; Sanquist, Orr, Shui, \& Bittner, 2012; Valenzuela et al., 2014), thus providing the direction for the present methodology (i.e., regression modeling). In this chapter, the most recent 2013 Statistics Canada dataset on Canadian household energy use was analyzed, with a focus on dwelling characteristics and household characteristics. Overall, this chapter addresses three major research questions:

1. In what way do household and dwelling characteristics contribute to electricity use?

2. In what way do household and dwelling characteristics contribute to natural gas use?

3. How much variation in energy use can be explained by household and dwelling characteristics?

\subsection{Data, Variables, and Method of Analysis}

Data for this analysis came from the 2013 Households and Environment Survey (HES) ${ }^{3}$, previously administered in 1991, 1994, 2006, 2007, 2009, and 2011. The survey was conducted in two parts. First a computer-assisted telephone interview was conducted as a supplement to the Canadian Community Health Survey (CCHS) between October 2013 and November 2013. Second, households that participated in the telephone interviews were contacted with a follow up mail survey (i.e., the Energy Use Supplement [EUS]) between January 2014 and April 2014. The telephone interview focused on a

\footnotetext{
${ }^{3}$ The analysis in this chapter uses Statistics Canada's 2013 Households and Environment Survey as well as the Energy Use Supplement microdata. The interpretation and views expressed in this document do not represent in any manner the position or views of Statistics Canada. Data were provided by Statistics Canada and accessed at the Research Data Center at the University of Toronto. The analysis and results are the author's alone.
} 
wide range of behaviours and practices having to do with the environment (e.g., use of air conditioning to the safe disposal of batteries) whereas the mail survey included questions on the energy used by households during the 2013 calendar year; the second part is formerly known as the Survey of Household Energy Use (SHEU).

The HES is a sample survey with a cross-sectional design consisting of households selected from respondents to the $2013 \mathrm{CCHS}$, which generated its sample using an area frame, a list frame of telephone numbers, and random digit dialing. The CCHS data is collected from people aged 12 years and over living in private dwellings within the 10 provinces and three territories. Excluded from the CCHS' coverage are residents of Indian Reserves and Crown land, full-time members of the Canadian Armed Forces, inmates, residents of institutions, and residents living in isolated areas. The CCHS thus represents approximately $98 \%$ of the Canadian population aged 12 years and over. Sample weights were applied to account for the sampling design.

In total, 11,290 households completed both the 2013 HES and EUS. However, for the purposes of this analysis, only those who owned their homes and paid energy bills were considered. In particular the exact questions posed to respondents were: "Are you the owner of this dwelling/Is this dwelling owned by a member of this household?" and "Is anyone in your dwelling responsible for paying the bills for any of the following: electricity/natural gas/heating oil?" These exclusions are based on the assumption that owners, compared to renters, are more likely and able to invest in energy efficiency (Frederiks et al., 2015a). Additionally, owners and renters may differ in their motivations to use and save energy. For electricity use, only households who did not use an electric furnace were considered and, as a result, most households using electric baseboards, electric radiant heating, and heat pumps were excluded; a handful of these households remained in the sample for unknown reasons. Possibly these households used a natural gas furnace and another one of these sources. This exclusion was used in order to focus on non-heating, electricity use (i.e., lighting, appliances, and plug-loads). For natural gas use, only households that used a natural gas furnace were considered in order to study natural gas use as a primary heating source.

As shown in Table 3.1, two dependent variables were examined in this analysis (Table 3.1 also provides the measurement of all model variables). The first, electricity use, was measured by asking respondents for their households' electricity use in 2013 and was converted from gigajoules (GJ) to kilowatt-hours $(\mathrm{kWh})^{4}$. The second dependent variable, natural gas use, was measured by asking respondents for their households' natural gas use in 2013 and was measured in gigajoules (GJ). Four

\footnotetext{
${ }^{4} 1$ gigajoule (GJ) is equal to $277.8(\mathrm{kWh})$.
} 
variables that measure household characteristics were used as the independent variables. The first independent variable is the highest level of education ever completed by a member of the household. This variable was included as a set of dummy variables, which distinguishes between: people with a high school education or less; people with some post-secondary or postsecondary certificate or diploma; and people with university level education. The second independent variable is household income and was included as a set of dummy variables which distinguishes between household incomes of less than $\$ 40,000, \$ 40,000$ to less than $\$ 60,000, \$ 60,000$ to less than $\$ 80,000, \$ 80,000$ to less than $\$ 100,000$, $\$ 100,000$ to less than $\$ 150,000$, and $\$ 150,000$ or more. The third dependent variable is household type and was based on categories created by Statistics Canada. This variable was included as a set of dummy variables which distinguishes between households composed of members 18-64 years old only, adults with young children, adults with young children and teenagers, households composed of members 65 years and older only, and an "other" group which consisted of other household type variations. The fourth independent variable is number of household residents.

Table 3.1 List of Variables and Measurement

\begin{tabular}{ll}
\hline Variables & Measurement \\
\hline Electricity $(\ln )$ & Scale variable \\
Natural gas & Scale variable \\
Heated area in $\mathrm{m}^{2}$ & Scale variable \\
Air conditioning & Dichotomous variable: $1=$ yes/ $0=$ no \\
Dwelling type & Dichotomous variable: $1=$ Detached/0=semi-detached, row house, town \\
hintage & house, low-rise apartment \\
& Scale variable \\
Education & Dummy variables: 0 to 8 years or some secondary; grade 11 to $13 ;$ \\
& graduate /some post secondary or postsecondary certificate or \\
diploma/university (reference) & Dummy variables: Less than $\$ 40,000$ (reference)/ $\$ 40,000$ to less than \\
Income & $\$ 60,000 / \$ 60,000$ to less than $\$ 80,000 / \$ 80,000$ to less than $\$ 100,000 /$ \\
& $\$ 100,000$ to less than $\$ 150,000 / \$ 150,000$ or more \\
Household type & Dummy variables: Members $18-64$ years old only (reference)/ adults with \\
Number of residents & young children/ adults with young children and teenagers/ households \\
\end{tabular}

Control variables were also included based on research suggesting their impact on electricity and natural gas use (e.g., Brounen et al., 2013; Ritchie, McDougall, \& Claxton, 1981). The following control variables were included in the electricity and natural gas models: heated floor area, dwelling type (i.e., detached versus semi-detached, row houses, town houses, and low-rise apartments), whether or not households use air-conditioning, and vintage (i.e., year dwelling was built). Low-rise apartments were included in the analysis given that some households who owned their homes lived in these types of 
dwellings and, further, these dwellings are similar to semi-detached, row houses, and town houses in that they share common walls with other households (i.e., a dwelling characteristic that leads to saving energy). Therefore, exclusion of low-rise apartment, owner occupied dwellings seemed unnecessary. Additionally, some condominium dwellers live in row houses, town houses, and low-rise apartments. Given that one objective of this study was to examine the effect of dwelling type - and therefore detached versus non-detached dwellings - condominium, owner occupied dwellings, were included in the analyses. Their removal would have 1) reduced the overall percentage of households belonging to the semi-detached, row house, town house, or low-rise apartment dwelling type group (i.e., a variable that had been already recoded (i.e., collapsed) to account for low group memberships in different dwelling types) and 2) made comparisons between dwelling types unavailable. Though it is noted that most condominiums use a shared cost system for energy use, it was hypothesized that their inclusion would not impact the analyses ${ }^{5}$. Tables 3.2 and 3.3 provide the descriptive statistics for all variables that were included in the models predicting electricity and natural gas use, respectively.

Table 3.2 Descriptive Statistics of Electricity Model Variables (weighted)

\begin{tabular}{|c|c|c|c|}
\hline Variable & Categories & $\begin{array}{l}\text { Percentage/M } \\
\quad(\mathrm{SD})\end{array}$ & $\begin{array}{c}\text { Valid } \\
\text { Responses }\end{array}$ \\
\hline Electricity $(\ln )$ & Scale & $9.04(0.57)$ & $5,738,731$ \\
\hline Heated floor area in $\mathrm{m}^{2}$ & Scale & $158.76(69.18)$ & $5,738,731$ \\
\hline \multirow[t]{2}{*}{ Air conditioning } & Yes & $60.50 \%$ & $5,738,731$ \\
\hline & No & $39.50 \%$ & \\
\hline \multirow[t]{2}{*}{ Dwelling type } & Detached & $87.10 \%$ & $5,451,794$ \\
\hline & $\begin{array}{l}\text { Semi-detached, row house, town house, low- } \\
\text { rise apartment }\end{array}$ & $12.90 \%$ & \\
\hline \multirow[t]{3}{*}{ Education } & $\begin{array}{l}0 \text { to } 8 \text { years or some secondary, grade } 11 \text { to } \\
13 \text {, graduate }\end{array}$ & $17.10 \%$ & $5,647,453$ \\
\hline & $\begin{array}{l}\text { Some post secondary or postsecondary } \\
\text { certificate or diploma }\end{array}$ & $27.50 \%$ & \\
\hline & University & $55.40 \%$ & \\
\hline \multirow[t]{6}{*}{ Income } & Less than $\$ 40,000$ & $14.50 \%$ & $4,709,540$ \\
\hline & $\$ 40,000$ to less than $\$ 60,000$ & $15.90 \%$ & \\
\hline & $\$ 60,000$ to less than $\$ 80,000$ & $13.90 \%$ & \\
\hline & $\$ 80,000$ to less than $\$ 100,000$ & $11.60 \%$ & \\
\hline & $\$ 100,000$ to less than $\$ 150,000$ & $22.40 \%$ & \\
\hline & $\$ 150,000$ or more & $21.70 \%$ & \\
\hline \multirow[t]{5}{*}{ Household type } & Members $18-64$ years old only & $25.30 \%$ & $5,738,731$ \\
\hline & Members 65 and older only & $20.80 \%$ & \\
\hline & Adults with young children & $13.60 \%$ & \\
\hline & Adults with young children and teenagers & $18.80 \%$ & \\
\hline & Other & $21.40 \%$ & \\
\hline Number of residents & & $2.64(1.27)$ & $5,738,731$ \\
\hline
\end{tabular}

\footnotetext{
${ }^{5}$ The regression model used for predicting household electricity and natural gas use was run on single-detached dwellings only with no substantive changes compared to the models that are discussed here (i.e., R square change $=.01$ ).
} 
Table 3.3 Descriptive Statistics of Natural Gas Model Variables (weighted)

\begin{tabular}{|c|c|c|c|}
\hline Variable & Categories & $\begin{array}{l}\text { Percentage } / \mathrm{M} \\
\text { (SD) }\end{array}$ & $\begin{array}{c}\text { Valid } \\
\text { Responses }\end{array}$ \\
\hline Natural gas (GJ) & Scale & $102.03(50.99)$ & $4,924,840$ \\
\hline Heated floor area in $\mathrm{m}^{2}$ & Scale & $159.02(68.06)$ & $4,924,840$ \\
\hline Vintage & Scale & $1975.81(27.68)$ & $4,925,265$ \\
\hline \multirow[t]{2}{*}{ Dwelling type } & Detached & $85.50 \%$ & $4,925,265$ \\
\hline & $\begin{array}{l}\text { Semi-detached, row house, town house, } \\
\text { low-rise apartment }\end{array}$ & $14.50 \%$ & \\
\hline \multirow[t]{3}{*}{ Education } & $\begin{array}{l}0 \text { to } 8 \text { years or some secondary, grade } \\
11 \text { to } 13 \text {, graduate }\end{array}$ & $15.00 \%$ & $4,925,265$ \\
\hline & $\begin{array}{l}\text { Some post secondary or postsecondary } \\
\text { certificate or diploma }\end{array}$ & $26.20 \%$ & \\
\hline & University & $58.80 \%$ & \\
\hline \multirow[t]{6}{*}{ Income } & Less than $\$ 40,000$ & $12.50 \%$ & $4,043,032$ \\
\hline & $\$ 40,000$ to less than $\$ 60,000$ & $15.20 \%$ & \\
\hline & $\$ 60,000$ to less than $\$ 80,000$ & $13.30 \%$ & \\
\hline & $\$ 80,000$ to less than $\$ 100,000$ & $11.20 \%$ & \\
\hline & $\$ 100,000$ to less than $\$ 150,000$ & $24.60 \%$ & \\
\hline & $\$ 150,000$ or more & $23.30 \%$ & \\
\hline \multirow[t]{5}{*}{ Household type } & Members $18-64$ years old only & $24.70 \%$ & $4,925,265$ \\
\hline & Members 65 and older only & $19.70 \%$ & \\
\hline & Adults with young children & $15.80 \%$ & \\
\hline & $\begin{array}{l}\text { Adults with young children and } \\
\text { teenagers }\end{array}$ & $18.20 \%$ & \\
\hline & Other & $21.60 \%$ & \\
\hline Number of residents & & $2.66(1.26)$ & $4,925,265$ \\
\hline
\end{tabular}

All analyses were carried out using SPSS version 23. To examine the effect of the independent variables on the continuous measures of energy use (i.e., electricity and natural gas use), ordinary least squares regressions (OLS) were used. Further, block loading was used to examine the unique effects of the independent variables on the dependent variables. Regression diagnostics were performed prior to performing analyses. Since the distribution of electricity use was highly skewed, it was transformed by taking the natural log of electricity use. For electricity, tolerance and variance inflation factors (VIFs) were checked with none of these exceeding 0.1 or 10 , respectively. Outliers and leverage were examined using Cook's and Mahalanobis distances. None of the Cook's distances exceeded 1, further only a few Mahalanobis distances exceeded critical values. The regression was run without the cases having high Mahalanobis distances and resulted in no change; these were not omitted from the analysis. Finally, the unstandardized residuals for the overall model were examined and were plotted against all model variables, with no obvious problems. Similarly, for natural gas, VIFs and tolerance levels did not exceed critical values. Further no cases exceeded Cook's distances of 1 and only a few cases exceeded critical 
Mahalanobis values; these were left in the regression model. The histogram of the unstandardized residuals as well as a normal probability plot demonstrated some skew, however a log transformation of the natural gas variable tended to over transform the data and cause negative skew; thus natural gas was left untransformed.

Missing data were also examined carefully. With the exception of income, the variables in the model had less than $5 \%$ of cases missing for an unknown reason, and were therefore not a significant concern. With respect to income, approximately $18 \%$ of respondents did not report their household income. An analysis of these missing cases indicated that there were no substantively significant relationships between not reporting one's income and using either electricity or natural gas. Further, there were no statistically significant relationships between not reporting one's income and the type of dwelling in which one lives, the size of one's home (i.e., heated area), and the year one's home was built (i.e., vintage). However, those with university level education reported their income less than respondents with lower levels of education. Furthermore, households composed of members 65 years and older only, reported their income less than other household types. Interestingly, those reporting using air-conditioning also reported their income less than households not using air-conditioning. As such, caution should be exercised when interpreting the effects of income, given the ways in which the missing cases may be biasing these estimates.

\subsection{Results}

In 2013, for households owning their homes, paying energy bills, and not using an electric furnace, average electricity use was $9979.96 \mathrm{kWh}$ (i.e., approximately 36 gigajoules). This finding is approximately 10 percent lower than what Statistics Canada has reported for average Canadian electricity use in 2011 (i.e., 40 gigajoules) (HES; Statistics Canada, 2013). It was expected that average electricity use in this study would be less compared to the average overall electricity use in 2011 because this sample excluded households that used electricity for heating. That is, this study was concerned with electricity used for lighting, appliances, and plug loads.

Table 3.4 presents the results of the linear regression predicting Canadian household electricity use in 2013. The first model shows the control variables. Dwelling characteristics, which included heated area, dwelling type, and the use of air conditioning, together, explain $6.8 \%$ of household electricity use and all have a statistically significant effect. In particular, for every square meter increase, electricity use increases by $0.2 \%$, controlling for all other variables. A detached house compared to a semi-detached, row house, town house, or low-rise apartment dwelling uses $17.7 \%$ more electricity, controlling for the other dwelling characteristics. As expected, households using air conditioning use 
$14 \%$ more electricity compared to households not using air conditioning, controlling for heated area and dwelling type.

The second model specifically examines the effect of income on household electricity use and increases explanation of the variance in electricity use by $3 \%$. In particular, all income groups use significantly more electricity than households making less than $\$ 40,000$ in 2013 , controlling for dwelling characteristics. The third model includes the survey respondents' highest level of education. It was found that education minimally increased the amount of variance explained in electricity use; in part, this is because this measure only captures the characteristics of a single household member. Nonetheless, level of education, in combination with income, is a rough proxy for social class or socioeconomic status. Interestingly, households with members having university level education use less electricity than households with members having less than university level education, controlling for income and dwelling characteristics.

In the final model, household type and number of household residents were added. These variables substantially increase the amount of variance in electricity use that is explained by the model. In particular, all dwelling characteristics, income, education, household type, and number of household residents explain $17.5 \%$ of the variance in Canadian household electricity use. In this model, households living in detached homes use $10.3 \%$ more electricity than households living in semi-detached, row house, town house, or low-rise apartment dwellings. Households that use air conditioning also use more electricity (11.1\% more) than households not using air conditioning. In general, households falling into higher income brackets (with the exception of households making between $\$ 80,000$ to less than $\$ 100,000)$ use more electricity than households making less than $\$ 40,000$, controlling for all other model variables. Last, households composed strictly of adults and young children and households composed only of members aged 65 years and older only use less electricity than households composed of individuals 18 to 64 years only, controlling for all other model variables. Controlling for dwelling characteristics, income, education, and household type, each additional person in a household increases electricity use by $13.4 \%$. Analyses demonstrate that the number of residents, income level of more than $\$ 150,000$, and heated floor area are the strongest predictors of household electricity use; standardized beta coefficients for these predictors are 0.30, 0.15, and 0.11, respectively. Further, a comparison of all the models demonstrates that among the measured variables, household characteristics have more influence on household electricity use than dwelling characteristics. 
Table 3.4 Linear Regression Predicting Household Electricity Use in 2013

\begin{tabular}{|c|c|c|c|c|c|c|c|c|c|c|c|c|}
\hline \multirow[t]{2}{*}{ Variable } & \multicolumn{3}{|c|}{ Model 1} & \multicolumn{3}{|c|}{ Model 2} & \multicolumn{3}{|c|}{ Model 3} & \multicolumn{3}{|c|}{ Model 4} \\
\hline & $\beta$ & $\mathrm{SE}$ & beta & $\beta$ & SE & beta & $\beta$ & $\mathrm{SE}$ & beta & $\beta$ & SE & beta \\
\hline Heated floor area & 0.002 & 0.00 & 0.19 & 0.001 & 0.00 & 0.13 & 0.001 & 0.00 & 0.14 & 0.001 & 0.00 & 0.11 \\
\hline Detached & 0.177 & 0.03 & 0.10 & 0.166 & 0.03 & 0.10 & 0.161 & 0.03 & 0.09 & 0.103 & 0.03 & 0.06 \\
\hline Air conditioning & 0.138 & 0.02 & 0.12 & 0.127 & 0.02 & 0.11 & 0.122 & 0.02 & 0.10 & 0.111 & 0.02 & 0.09 \\
\hline Income (in thousands) ${ }^{\mathrm{a}}$ & & & & & & & & & & & & \\
\hline 40 to less than 60 & & & & 0.143 & 0.03 & 0.09 & 0.151 & 0.03 & 0.09 & 0.105 & 0.03 & 0.07 \\
\hline 60 to less than 80 & & & & 0.188 & 0.04 & 0.11 & 0.200 & 0.04 & 0.12 & 0.104 & 0.04 & 0.06 \\
\hline 80 to less than 100 & & & & 0.147 & 0.04 & 0.08 & 0.162 & 0.04 & 0.09 & 0.043 & 0.04 & \\
\hline 100 to less than 150 & & & & 0.275 & 0.03 & 0.20 & 0.300 & 0.03 & 0.22 & 0.147 & 0.03 & 0.11 \\
\hline More than 150 & & & & 0.350 & 0.03 & 0.25 & 0.379 & 0.03 & 0.27 & 0.212 & 0.04 & 0.15 \\
\hline Education $^{\mathrm{b}}$ & & & & & & & & & & & & \\
\hline $\begin{array}{l}0 \text { to } 8 \text { years or some } \\
\text { secondary, grade } 11 \text { to } 13 \text {, } \\
\text { graduate }\end{array}$ & & & & & & & 0.068 & 0.04 & 0.04 & 0.119 & 0.03 & 0.08 \\
\hline Some post secondary or & & & & & & & 0.109 & 0.02 & 0.08 & 0.120 & 0.02 & 0.09 \\
\hline $\begin{array}{l}\text { postsecondary certificate or } \\
\text { diploma }\end{array}$ & & & & & & & & & & & & \\
\hline Household Type $^{c}$ & & & & & & & & & & & & \\
\hline Members 65 and over & & & & & & & & & & -0.070 & 0.03 & -0.05 \\
\hline only & & & & & & & & & & & & \\
\hline Adults and young children & & & & & & & & & & -0.091 & 0.04 & -0.06 \\
\hline Adults, young children, & & & & & & & & & & -0.017 & 0.04 & \\
\hline teens & & & & & & & & & & & & \\
\hline Other combinations & & & & & & & & & & -0.025 & 0.03 & \\
\hline Number of residents & & & & & & & & & & 0.134 & 0.01 & 0.30 \\
\hline Constant & 8.55 & & & 8.45 & & & 8.38 & & & 8.24 & & \\
\hline Adj. $R^{2}$ & 0.068 & & & 0.100 & & & 0.106 & & & 0.175 & & \\
\hline
\end{tabular}

Source. 2013 Households and Environment Survey and Energy Use Supplement.

Note. Beta coefficients are presented only for independent and control variables that have a statistically significant effect on the dependent variable. $\mathrm{p}<.05$. Standardized weighted $N=3588$.

${ }^{a}$ Reference group: Income less than $\$ 40,000$.

${ }^{\mathrm{b}}$ Reference group: University.

${ }^{\mathrm{c}}$ Reference group: Members 18-64 years old only. 
In 2013, for households owning their homes, paying energy bills, and using a natural gas furnace, average natural gas use was $102.03 \mathrm{GJ}$ and is comparable to the natural gas used by all Canadian households in 2013 (97.5 GJ, CANSIM table 153-0161, Statistics Canada, 2016). The higher average amount of natural gas used by households in the current study likely reflects the exclusion of renters living in high-rise apartment buildings, who are likely lower-use households.

Table 3.5 presents the results of the linear regression predicting Canadian household natural gas use in 2013. The first model shows the control variables and it is immediately evident that dwelling characteristics account for a large portion of household natural gas use: heated floor area, dwelling type, and vintage, together, explain $19.7 \%$ of the variance in natural gas use. In particular, increasing the size of a home is associated with using more natural gas. Detached dwellings use more natural gas than semidetached, row house, town house, or low-rise apartment buildings. Further, new buildings use less natural gas for heating than older buildings.

The second model specifically examines the effect of household income on natural gas use and most household income groups, with the exception of households making between $\$ 60,000$ to less than $\$ 100,000$, use more natural gas than households who make less than $\$ 40,000$, controlling for dwelling characteristics. According to the third model, education is not a significant predictor of household natural gas use. In the final model, household type and number of residents were added. Households with members 65 years and over only, use significantly more natural gas (10.44 more gigajoules of natural gas per year) than households composed only of members aged 18 to 64 only, controlling for all other model variables. Additionally, households composed of adults, young children and teenagers use 7.71 more gigajoules of natural gas per year than households composed only of members aged 18 to 64 only, controlling for all other model variables. The full model explains $20.9 \%$ of natural gas use. Analyses demonstrate that heated floor area, vintage, and an income level of more than $\$ 150,000$, are the strongest predictors of household natural gas use; beta coefficients for these predictors are 0.39, -0.12 , and 0.13 , respectively. Further, a comparison of all the models demonstrates that among the measured variables, dwelling characteristics account for more of the variance in natural gas use than household characteristics. 
Table 3.5 Linear Regression Predicting Household Natural Gas Use in 2013

\begin{tabular}{|c|c|c|c|c|c|c|c|c|c|c|c|c|}
\hline \multirow[t]{2}{*}{ Variable } & \multicolumn{3}{|c|}{ Model 1} & \multicolumn{3}{|c|}{ Model 2} & \multicolumn{3}{|c|}{ Model 3} & \multicolumn{3}{|c|}{ Model 4} \\
\hline & $\beta$ & $\mathrm{SE}$ & beta & $\beta$ & $\mathrm{SE}$ & beta & $\beta$ & $\mathrm{SE}$ & beta & $\beta$ & $\mathrm{SE}$ & beta \\
\hline Heated floor area & 0.31 & 0.01 & 0.42 & 0.29 & 0.01 & 0.39 & 0.28 & 0.013 & 0.39 & 0.28 & 0.01 & 0.39 \\
\hline Detached & 13.47 & 2.36 & 0.10 & 13.11 & 2.37 & 0.09 & 13.14 & 2.372 & 0.09 & 12.99 & 2.39 & 0.09 \\
\hline Vintage & -0.23 & 0.03 & -0.13 & -0.24 & 0.03 & -0.13 & -0.24 & 0.03 & -0.13 & -0.22 & 0.03 & -0.12 \\
\hline Income (in thousands) & & & & & & & & & & & & \\
\hline 40 to less than 60 & & & & 6.33 & 3.21 & 0.04 & 6.28 & 3.217 & 0.04 & 6.27 & 3.22 & 0.04 \\
\hline 60 to less than 80 & & & & 2.37 & 3.23 & & 2.28 & 3.262 & & 4.24 & 3.31 & \\
\hline 80 to less than 100 & & & & -1.84 & 3.41 & & -1.93 & 3.436 & & 0.16 & 3.51 & \\
\hline 100 to less than 150 & & & & 7.71 & 2.92 & 0.07 & 7.53 & 2.993 & 0.07 & 10.4 & 3.13 & 0.09 \\
\hline More than 150 & & & & 11.88 & 3.02 & 0.10 & 11.67 & 3.09 & 0.10 & 14.75 & 3.26 & 0.13 \\
\hline Education & & & & & & & & & & & & \\
\hline $\begin{array}{l}0 \text { to } 8 \text { years or some } \\
\text { secondary, grade } 11 \text { to } 13 \text {, } \\
\text { graduate }\end{array}$ & & & & & & & -0.59 & 2.57 & -0.00 & -2.26 & 2.60 & \\
\hline Some post secondary or & & & & & & & -0.53 & 1.989 & -0.00 & -0.66 & 1.99 & \\
\hline $\begin{array}{l}\text { postsecondary certificate or } \\
\text { diploma }\end{array}$ & & & & & & & & & & & & \\
\hline Household Type & & & & & & & & & & & & \\
\hline $\begin{array}{l}\text { Members } 65 \text { and over } \\
\text { only }\end{array}$ & & & & & & & & & & 10.45 & 2.68 & 0.08 \\
\hline Adults and young children & & & & & & & & & & -1.38 & 3.45 & \\
\hline Adults, young children, & & & & & & & & & & 7.71 & 3.55 & 0.06 \\
\hline teens & & & & & & & & & & & & \\
\hline Other combinations & & & & & & & & & & 4.04 & 2.69 & \\
\hline Number of residents & & & & & & & & & & -0.48 & 1.11 & \\
\hline Constant & 501.31 & & & 512.55 & & & 513.03 & & & 477.47 & & \\
\hline Adj. $\mathrm{R}^{2}$ & 0.197 & & & 0.204 & & & 0.203 & & & 0.209 & & \\
\hline
\end{tabular}

Source. 2013 Households and Environment Survey and Energy Use Supplement.

Note. Beta coefficients are presented only for independent and control variables that have a statistically significant effect on the dependent variable. $p<.05$.

Standardized weighted $N=3071$.

${ }^{\mathrm{a}}$ Reference group: Income less than $\$ 40,000$.

${ }^{\mathrm{b}}$ Reference group: University.

${ }^{\mathrm{c}}$ Reference group: Members 18-64 years old only. 


\subsection{Discussion}

Many of the results found here align with past studies as well as common-sense expectations. In particular, heated floor area is both important for predicting electricity and natural gas use in that increasing area leads to increased energy use. For natural gas, this is logical: the more space that is required to be heated, the more natural gas is used to heat that area (i.e., floor area). Though the effect is very small, it is not directly apparent why increasing heated floor area leads to more electricity use and requires further study. However, it is possible that larger homes are indicative of lifestyle characteristics. That is, households living in larger homes may be households that use more electronic appliances and devices, and therefore more electricity. Further, it is not surprising that detached homes use more natural gas than semi-detached, row house, town house, or low-rise apartment dwellings given that detached homes have no shared walls and therefore have physical characteristics that precipitate consuming more energy. In particular, dwelling type appears to directly influence energy use due to varying on important characteristics such as sun and wind exposure and number of exposed walls (Frederiks et al., 2015). Though the effect is small for electricity, it is again plausible that households living in detached homes have different lifestyle preferences than households living in semi-detached, row house, town house, or low-rise apartment dwellings. For electricity, it was expected that households that used air conditioning would use more electricity compared to households not using air conditioning, given that space cooling accounts for a significant portion of household electricity use. Though not discussed in detail in the results, vintage was shown to have an effect on natural gas use and is not surprising given that older homes tend to be less thermally efficient. This finding substantiates the continued existence of energy efficiency programs and building codes that support energy efficiency retrofit programs for older homes as well as programs such as the ENERGY STAR for New Homes and R-2000 initiatives.

With respect to income, a substantial body of research confirms that higher income households generally use more energy than lower income households (Abrahamse \& Steg, 2009, 2011; Biesiot \& Noorman, 1999; Gatersleben et al., 2002; Lewis \& Gwendolyn, 1999; O’Neill \& Chen, 2002; Poortinga, Steg, Vlek, \& Poortinga, 2004; Ritchie et al., 1981). While most studies find a positive relationship, there are studies that show weak or no statistically significant effects (e.g., Nair, Gustavsson, \& Mahapatra, 2010). Interestingly, some researchers have posited that middle-income households may be the most likely to save energy given that low-income energy users are unable to further reduce their energy use and high-income users might not want to reduce their energy use. Similar results were found here. In particular, for electricity, all income groups used more electricity than households making less than $\$ 40,000$ with the exception of households making between $\$ 80,000$ to less than $\$ 100,000$ (i.e., the 
middle-income group). For natural gas, households earning between $\$ 40,000$ to less than $\$ 60,000$ and those earning more than $\$ 100,000$ used more natural gas than lower income households (i.e., households making less than \$40,000). This implies that middle-income households are not using substantially more natural gas compared to the lower income group, because they are the only group who is looking to substantially save on natural gas use and therefore reduce costs. These results suggest that there might be middle-income Canadians who are energy-conscious with respect to electricity and natural gas use.

With respect to education, past research demonstrates mixed results. Particularly, some studies have failed to find a connection between levels of education and energy use (e.g., Gatersleben, Steg, \& Vlek, 2002; Ritchie et al., 1981). However, some studies have demonstrated that individuals with higher levels of education are slightly more inclined to be pro-environmental; but these effects are usually weak or not statistically significant (Hines, Hungerford, Tomera, 1987; Tonn \& Berry, 1986). Similarly, in the current study, households with survey respondents with university level education live in households that use less electricity than households with survey respondents with less education and points to potential pro-environmental behaviour. Additionally, this finding may be connected to employment and time at home (i.e., occupancy rates) and these may be also be related to the respondent's age. This study was unable to control for these variables, but it is possible that there may be a relationship between education, employment status, time spent at home, and age and that these may be influencing electricity use.

Several studies demonstrate connections between the number of residents and energy use. In particular, studies have found that household energy use is positively related to the number of residents, so that an increase in the number of residents corresponds to more energy being used (Abrahamse \& Steg, 2009, 2011; Gatersleben et al., 2002). Possibly, having more individuals in a home could be indicative of possessing more electronic devices and appliances or having greater energy demand requirements (cooking, cleaning, washing, cooling) (Van Raaij \& Verhallen, 1983). However, it is not expected that the number of residents affects natural gas use in the same way, especially since temperature set points are unlikely to be highly variable as more members are added to households. For example, if a household has a preference for maintaining their home temperature at 21 degrees Celsius, this set point is unlikely to vary considerably if the number of residents living in the household increases, and therefore an economy of scale is achieved whereby the costs (i.e., energy consumed) per unit (e.g., person) decrease as the system's (i.e., household) size increases (Brounen et al., 2012; Ironmonger, Aitken, and Erbas 1995; Vringer and Blok 1995).

One important finding of this study is that there are differences in consumption between income groups. In showing that households making less than $\$ 40,000$ use less electricity and natural gas than 
some other households, more work needs to be done to make sure these groups are getting their energy needs meet, especially in the context of natural gas use. That is, if lower income households are using less natural gas, controlling for heating area, than other income groups, it is possible that these households are not heating their homes to comfortable and healthy levels. The results for household income also demonstrate that more needs to be done to increase the social (non-economic) incentives for high-income households to reduce their energy use.

There were some limitations with this study. Particularly, the 2013 HES and EUS datasets were limited in terms of the variables that could be used to model electricity and natural gas use. That is, the data set was limited on the possible number of independent and dependent variables. For example, age of respondent, amount of time spent at home, employment status, type of renovations, performance of energy conservation behaviours are all important variables that should be included in a comprehensive model of energy use, as well as indicators of energy knowledge and literacy.

\subsection{Conclusion}

In the present study, electricity and natural gas use were explained using dwelling characteristics as well as household characteristics. The results show that both household and dwelling characteristics impact energy use. However, there is a noticeable difference in the way that these characteristics impact energy use. Specifically, for electricity, household characteristics, more than dwelling characteristics, predicted household use. In contrast, for natural gas, dwelling characteristics, more than household characteristics, predicted use. This difference suggests that electricity and natural gas use have different determinants. Moreover, according to this study, about $20 \%$ of the variation in household electricity and natural gas use is explained by household and dwelling characteristics, suggesting that there is still substantial variation that relates to other variables and that could be accounted for. It is very possible that these missing variables include control variables that were lacking in the examined data (e.g., age of respondent, time spent at home, employment status, etc.). Further, it is possible that these missing variables include psychological variables (e.g., attitudes) and behavioural measures related to energy conservation and efficiency behaviours (e.g., performance of renovations). The amount of unexplained variation speaks to the importance of learning more about what Canadians know and feel about energy and energy-related matters and how they behave with respect to using energy in their homes. 


\section{Chapter 4: Development of a Public Energy Literacy Instrument}

\subsection{Introduction}

Although residential consumers use large amounts of energy, their understanding of energyrelated issues appears to be low. For example, the National Environmental Education and Training Foundation (NEETF) found that only one-in-eight Americans could pass a basic energy quiz (NEETF, 2002). Domestically, a survey commissioned by the non-profit organization Canadian Centre for Energy Information, indicated that two-in-three Canadians feel well informed about energy-related issues, however, only two-in-five Canadians were able to correctly identify that space heating uses the most energy in their homes (Angus Reid Public Opinion, 2010).

Low levels of energy-related knowledge have the potential to negatively affect future energy progress. According to Sovacool (2009a, 2009b), the slow uptake of alternative energy technologies, such as solar and wind power, is due in part to a lack of public support stemming not only from technical barriers but also from social and educational barriers such as lack of information, disinterested attitudes, incorrect understanding of costs associated with fossil fuels, and resistance to change. For instance, a 2006 Massachusetts Institute of Technology study on public attitudes towards climate change and mitigation technologies discovered that almost half

of the approximately more than 1200 American respondents did not know about wind or nuclear energy (Curry, Ansolabehere, \& Herzog, 2007). Findings from a similar survey conducted in Great Britain revealed that less than half of the approximately 1000 respondents had not recently heard or read about technologies such as efficient appliances, nuclear energy, hydrogen cars, bioenergy/biomass, carbon capture and storage, or carbon sequestration (Curry, Reiner, de Figueiredo, \& Herzog, 2005). Even more, Britons who ranked global warming as a primary environmental concern were not more likely to know about these technologies (Curry et al., 2005).

In an applied sense, research indicates that household members misperceive how and where to reduce their energy use (Gardner \& Stern, 2008). In particular, household members overestimate the potential savings of highly visible actions (e.g., turning lights off) and underestimate the potential savings of poorly visible actions (e.g., investment in energy efficient appliances) (Attari, DeKay, Davidson, \& Bruine de Bruin, 2010). Even more, perception-based 
household estimates of energy use and pricing have been shown to diverge with expert knowledge by a factor of four (Kempton, Harris, Keith \& Weihl, 1985). That is, individuals misjudge the amount of energy they use for household activities.

With respect to climate change the problem of ignorance is twofold (Gifford, 2011). In particular, not knowing that a problem exists and not knowing what to do once you know there is a problem can both act as barriers to action (Gifford, 2011). These points are relevant to household energy use. How can individuals be expected to decrease energy use without knowing that using too much energy is a problem? Consistent with Gifford (2011), even when individuals know about the importance of decreasing energy use they still demonstrate misperceived efforts.

Issues such as climate change, fossil fuel constraints, environmental pollution, biodiversity, economics, and energy equity are likely to affect the future decisions that Canadians make with respect to energy use. Consequently, this research assumes that thoughtful, well informed, and committed decision-making by all actors will contribute to future success in transitioning to a low carbon society. Further, the stance taken in this research is similar to that of DeWaters and Powers (2013) in making the assumption that success will rely not only on those with technical, scientific, and professional energy expertise but also on everyday individuals. Thus, one group of key actors in Canada's energy future is the general public. Their thoughtful, well informed, and committed decision-making will be applicable in various contexts and will be demonstrated through their purchasing behaviours, voting behaviours, and support for energy policies, among others. With respect to energy and energy-related issues, the questions therefore become: what do everyday Canadians know about these issues? How do they think and feel about them? And what are their energy practices? These questions broadly relate to energy literacy - the focus of this chapter.

\subsection{Background}

To date, relatively few studies have assessed Canadians' energy literacy. There are two known studies but these are limited in scope, in that energy literacy was assessed using a limited number of survey questions and literacy dimensions (i.e., RBC's 2010 Energy Literacy Quiz, Pollution Probe, personal communication, October 11, 2011; Energy Literacy Survey, Angus Reid Public Opinion, 2010). In 2012, a University of Calgary study found that Canadians "have a good general knowledge of energy use and relative cost but lack detailed knowledge about sources of 
energy fuels, as well as sources and linkages with environmental impacts" (Turcotte, Moore, \& Winter, 2012, p. summary). The authors measured general knowledge using three questions; two focused on energy imports and exports. Recently, Comeau, Stedman, Beckley, and Parkins (2015) conducted a national survey, primarily emphasizing citizen perspectives (i.e., attitudes and values related to energy issues). However, the researchers also asked some factual questions and found that actual knowledge of how energy is used in Canada to be low (Comeau et al., 2015). Other non-Canadian studies have investigated energy literacy but most are outdated (e.g., Kuhn, 1979), directed at middle and high school students (e.g., Barrow \& Morrisey, 1989; DeWaters, Qaqish, Graham \& Powers, 2013; Gambro \& Switzky, 1996), or not applicable because they do not address domestic energy-related issues (e.g., NAEP, 1978; NEETF, 2002; Southwell, Murphy, DeWaters, \& LeBaron, 2012).

In addition to the small number of studies, this area is limited by the approaches taken by different researchers. The area (s) of focus (e.g., trade versus energy generation), choice of questions, and survey objectives (e.g., curricular versus consumer research) vary considerably. For example, for Southwell et al. (2012) public energy literacy consisted of knowing how to interpret an energy bill whereas Turcotte et al. (2012) examined public energy literacy by asking respondents to provide their opinions on a wide range of energy-related issues, e.g., "Using a scale of zero to ten where zero is 'not at all important' and ten is 'very important,' how important are each of the following issues in Canada right now?"; "What do you think that the average Canadian does not understand about energy issues in Canada?” (p. 30, 31). Turcotte et al. (2012) define energy literacy as:

[a] fundamental understanding of energy - from the basic units of measurement (watts, British thermal units, etc.), to energy production and distribution, to the economic and environmental factors that affect decisions about energy use. (p. 4).

As such, there seems to be some discrepancy between their measure of energy literacy and their assessment of energy literacy. This is problematic because it 1) implies that the phenomenon is too wide-ranging and therefore unable to be assessed via a measure or that 2) the existing measures of energy literacy are measuring different phenomena. Both surveys addressed and answered important questions on public understanding and opinions of energy-related issues, 
however, their differences make comparisons difficult. These differences also make it difficult to pinpoint what energy literacy is, exactly, and how it can be measured.

Given the lack of standardized instruments for examining public energy literacy, the objectives of this chapter are to 1) establish criteria for measuring public energy literacy and 2) develop a valid and reliable instrument to measure energy literacy. This work was chiefly influenced by the work of DeWaters and Powers (2013) and their Instrument Development Framework (IDF), which they relied on to guide the development of an energy literacy questionnaire for middle and high school youth. The IDF along with DeWaters and Powers' (2013) conceptualization of energy literacy were used as starting points.

\subsection{Conceptualizing Energy Literacy—Parallels to Scientific, Technological, and Environmental Literacy}

DeWaters and Powers (2013) started their analysis of energy literacy by first examining the notion of 'literacy'-i.e., what does it mean to be literate, generally. Hirsch (as cited in DeWaters and Powers, 2013, p. 41) defines literacy "as a shared body of knowledge that enables people to communicate with each other and make sense of the world around them." Aptly, DeWaters and Powers (2013) recognized literacy to be more than the possession of a particular body of knowledge. They continued by examining conceptualizations of scientific, technological, and environmental literacy (DeWaters and Powers, 2013).

The term, scientific literacy, grew out of the American educational goals of the 1950s (DeWaters \& Powers, 2013). Emphasis at that time was placed on understanding basic scientific constructs and the information and skills used by scientists who were discovering the natural world (and space) (Yager, 2004). This narrow emphasis soon expanded to include processes such as problem solving as well as the higher cognitive functions of Bloom's taxonomy (i.e., analysis, synthesis, and evaluation) (Bloom, Engelhart, Furst, Hill, \& Krathwohl, 1956; DeWaters \& Powers, 2013; Yager, 2004). Eventually, conceptualization of scientific literacy began to incorporate the relationship between science and society and the application of scientific inquiry to real world problems (Yager, 2004). This is shown in the National Science Teachers Association's (NSTA) (1971) definition of a scientifically literate individual as one who: 
uses concepts, process skills, and values in making everyday decisions as he interacts with other people and his environment [and] understands the interrelationships between science, technology and other facets of society including social and economic development. (p. 47).

DeWaters and Powers (2013) also found many similarities between conceptualizations of scientific literacy and technological literacy. For example, they note that the Standards for Technology Education, developed by the International Technology Education Association (ITEA) and the International Society for Technology Education (ISTE), stipulates that technological literacy is "the ability to use, manage, analyze, assess, and understand technological systems for solving problems, communicating, and participating in society" (as in DeWaters \& Powers, 2013, p. 42). In the same vein, the National Academy of Engineering and the National Research Council have broadly defined technological literacy as involving the three dimensions of 1) knowledge, 2) capabilities, and 3) ways of thinking and acting (Pearson \& Young, 2002). Even more, Pearson and Young (2002) comment that it is impossible to uniquely separate these:

It is hard to imagine a person with technological capability who does not also know something about the workings of technology, or a person who can think critically about a technological issue who does not also have some conceptual or factual knowledge of technology and science. So, although such a framework can be helpful in thinking and talking about technological literacy, it is important to remember the dimensions are arbitrary divisions. (p. 15).

More work has gone into the area of environmental literacy. DeWaters and Powers (2013) note that as early as the 1970s environmental educators and education professionals were emphasizing the application of knowledge as well as environmental literacy and social relationships as important. In 1975, the Belgrade Charter described the goals of environmental education as increasing awareness of and concern for the environment as well as increasing the knowledge, skills, attitudes, motivations, and commitments of citizens to solve current problems and prevent future problems (United Nations Educational, Scientific and Cultural Organization [UNESCO]/United Nations Environmental Program [UNEP]). Since then, several frameworks 
have been developed for environmental literacy and environmental education (e.g., Disinger \& Roth, 1992; Harvey, 1977; Hollweg et al., 2012; Hungerford \& Peyton, 1976; Hungerford, Peyton, \& Wilke, 1980; Iozzi, Laveault, \& Marcinkowski, 1990; North American Association of Environmental Education [NAAEE], 2004; Roth, 1992, 1996; Simmons, 1995; Stapp et al., 1969; UNESCO, 1978; Vandevisse \& Stapp, 1975; Volk \& McBeth, 1997; Wilke 1995).

Though minor differences exist between some of the frameworks listed above, DeWaters and Powers (2013) demonstrate that their components fit into the three major dimensions of learning — cognition, affect, and behaviour — as per Bloom et al. (1956), Krathwohl, Bloom, and Masia (1973), and Simpson (1972). In particular, DeWaters and Powers (2013) note that some frameworks specify certain components as separate or not belonging to the cognitive, affective, or behavioural dimensions but, upon closer inspection, should be included. For example, skills have often been categorized as a separate dimension but, according to DeWaters and Powers (2013), these can be operationalized to include critical thinking, decision making, and problem solving (e.g., Hungerford et al., 1980; Iozzi et al., 1990; Roth 1992, 1996; Disinger \& Roth, 1992). This is further supported by Hollweg et al. (2012) whose definition of environmental literacy includes cognitive (i.e., knowledge and skills), affective, and behavioural components. As shown in Table 4.1, DeWaters and Powers (2013) have taken the literacy components belonging to these various frameworks and have organized them by dimension membership. These include cognitive (knowledge, understanding, cognitive and problem solving skills), affective (awareness, attitudes, values, locus of control, sense of personal responsibility), and behavioural (participation, action skills) components (DeWaters \& Powers, 2013). This table is useful in that it provides a comprehensive overview of the literacy dimensions that have been discussed in this chapter as well as the studies that have paid attention to these literacy dimensions. Further, in general, it provides a foundation for examining literacy. 
Table 4.1 Components of Environmental Education and Literacy by Literacy Dimension

\begin{tabular}{|c|c|c|c|}
\hline Study & Cognitive & Affective & Behavioural \\
\hline Stapp (1969) & Understanding & Attitudes of concern & \\
\hline $\begin{array}{l}\text { Vandevisse and Stapp } \\
(1975)\end{array}$ & $\begin{array}{l}\text { Cognitive-knowledge, } \\
\text { understanding, skill } \\
\text { (critical thinking, } \\
\text { problem solving) }\end{array}$ & $\begin{array}{l}\text { Affective (concern, motivation, } \\
\text { interest, sensitive/total } \\
\text { awareness, valuing) }\end{array}$ & $\begin{array}{l}\text { Skill - behavior } \\
\quad \text { (change strategy) }\end{array}$ \\
\hline $\begin{array}{l}\text { Hungerford and Peyton } \\
\text { (1976) }\end{array}$ & $\begin{array}{l}\text { Cognitive knowledge, } \\
\text { cognitive process } \\
\text { (ability, skill) }\end{array}$ & Affect (desires, willingness) & $\begin{array}{l}\text { Environmental action } \\
\text { skills }\end{array}$ \\
\hline Harvey (1977) & $\begin{array}{l}\text { Cognitive (understanding, } \\
\text { cognitive skills) }\end{array}$ & $\begin{array}{l}\text { Affect (awareness, dedication, } \\
\text { values) }\end{array}$ & $\begin{array}{l}\text { Psychomotor } \\
\text { (behaviours, action } \\
\text { skills) }\end{array}$ \\
\hline $\begin{array}{l}\text { Tbilisi (UNESCO, 1977); } \\
\text { Hungerford et al. (1980) }\end{array}$ & $\begin{array}{l}\text { Knowledge, cognitive } \\
\text { skills }\end{array}$ & $\begin{array}{l}\text { Awareness, attitudes, affective } \\
\text { skills }\end{array}$ & $\begin{array}{l}\text { Participation, action } \\
\text { skills }\end{array}$ \\
\hline Iozzi et al. (1990) & $\begin{array}{l}\text { Cognitive - knowledge, } \\
\text { cognitive skills }\end{array}$ & $\begin{array}{l}\text { Affect -awareness, attitude, } \\
\text { values, affective skills } \\
\text { (moral reasoning), locus of } \\
\text { control, assumption of } \\
\text { personal responsibility }\end{array}$ & $\begin{array}{l}\text { Participation - } \\
\text { environmentally } \\
\text { responsible } \\
\text { behavior }\end{array}$ \\
\hline Roth $(1992,1996)$ & $\begin{array}{l}\text { Knowledge skills } \\
\text { (decision-making, } \\
\text { critical thinking, } \\
\text { knowledge application) }\end{array}$ & $\begin{array}{l}\text { Affect-locus of control, } \\
\text { assumption of personal } \\
\text { responsibility, curious, open } \\
\text { to new ideas, environmental } \\
\text { ethics (awareness, } \\
\text { understanding), affective } \\
\text { skills (recognize problems) }\end{array}$ & $\begin{array}{l}\text { Behavior action skills } \\
\text { (stewardship, } \\
\text { voluntary } \\
\text { simplicity, "green" } \\
\text { consumerism) }\end{array}$ \\
\hline Wilke (1995) & $\begin{array}{l}\text { Cognitive (content } \\
\text { knowledge), cognitive } \\
\text { skills (critical thinking, } \\
\text { problem solving, } \\
\text { environmental action } \\
\text { strategies) }\end{array}$ & $\begin{array}{l}\text { Affective (awareness, empathy, } \\
\text { attitude), additional } \\
\text { determinants of } \\
\text { environmentally responsible } \\
\text { behavior (individual and } \\
\text { group locus of control, } \\
\text { assumption of personal } \\
\text { responsibility) }\end{array}$ & $\begin{array}{l}\text { Environmentally } \\
\text { responsible } \\
\text { behavior (personal } \\
\text { or group } \\
\text { involvement) }\end{array}$ \\
\hline $\begin{array}{l}\text { Simmons (1995); Volk \& } \\
\text { McBeth (1997); NAAEE } \\
(2004)\end{array}$ & $\begin{array}{l}\text { Ecological knowledge, } \\
\text { socio-political } \\
\text { knowledge, knowledge } \\
\text { of environmental issues, } \\
\text { cognitive skills }\end{array}$ & $\begin{array}{l}\text { Affect additional determinants } \\
\text { of environmentally } \\
\text { responsible behavior }\end{array}$ & $\begin{array}{l}\text { Environmentally } \\
\text { responsible } \\
\text { behavior }\end{array}$ \\
\hline Hollweg et al. (2012) & $\begin{array}{l}\text { Knowledge competence } \\
\text { (cognitive skills, critical } \\
\text { thinking skills) }\end{array}$ & $\begin{array}{l}\text { Dispositions (sensitivity; } \\
\text { attitudes, concern; personal } \\
\text { responsibility; self-efficacy; } \\
\text { motivations), competence } \\
\text { (evaluate, judgments) }\end{array}$ & $\begin{array}{l}\text { Environmentally } \\
\text { responsible } \\
\text { behaviour, action }\end{array}$ \\
\hline
\end{tabular}

Note. Published as "Previously Identified Components of Environmental Education Outcomes and Environmental Literacy" in "Establishing Measurement Criteria for an Energy Literacy Questionnaire," by J. D. DeWaters and S. Powers, 2013, The Journal of Environmental Education, 44, p. 44. 


\subsubsection{Environmental Education in Canada}

In Canada there is no federal department of education. Instead each of the 10 provinces and three territories are responsible for organizing, delivering, and assessing elementary and secondary education falling within their province or territory; postsecondary institutions have slightly more autonomy from provincial or territorial management (i.e., more control over curriculum) but still need to conform to provincial standards for degree programs. In lieu of a federal body, Canada has the less formal Council of Ministers for Education Canada (CMEC) that provides provincial education ministers with a forum for discussing educational matters (Nazir, Pedretti, Wallace, Montemurro, \& Inwood, 2009). While not directly responsible for Canadian education policy, the CMEC has produced several key documents (e.g., CMEC, 2015) and was principally involved in producing the Report to UNECE and UNESCO on Indicators for Sustainable Development, in collaboration with Environment Canada and The Canadian Commission for UNESCO (2007). Produced by all member states, this document reported on the implementation of the Strategy for Education for Sustainable Development (i.e., environmental education and sustainability initiatives) in formal, non-formal, and informal settings within the context of the United Nations Decade of Education for Sustainable Development (DESD) 2005-2014 (CMEC, 2007).

While it is beyond the scope of study to examine these initiatives by jurisdiction, a glance at Ontario's environmental educational initiatives fit well within DeWaters and Powers' (2013) conceptualization of environmental education and literacy. Specifically, the CMEC (2007) reports on the Government of Ontario's creation of the Curriculum Council who developed the 2007 report Shaping Our Schools, Sharing Our Future, in which environmental education is defined as challenging students to develop:

the knowledge, skills, and attitudes they will need to cope with an increasingly complex world and [will] enable them to find new solutions in building a healthy society. (p. 17).

There is clearly some overlap between the use of Education for Sustainable Development (ESD) and Environmental Education (EE) terminologies. It appears that conceptualization of ESD, EE, and Climate Change Education (CCE) have developed and continue to develop together, with several meanings coexisting for key terms such as 'environment' and 'sustainable' 
(Blum, Nazir, Breiting, Goh, \& Pedretti, 2013). Blum et al. (2013) use the term 'development' to demonstrate this conceptualization variability, especially by user and geography (emphasis in original). For example, in Ontario, development generally has an economic focus so that ESD is associated with sustainable economies or green economies (Government of Ontario, as in Blum et al. 2013). In contrast, in Nunavut, development has a socio-cultural and post-colonial focus so that ESD is associated with "living within the bounds of traditional Aboriginal wisdom" (Government of Nunavut, as in Blum et al., 2013, p. 208). Generally, ESD and EE are conceptualized and used similarly and in countries like Canada, where EE has a longer history (Palmer, 1998), the discussion of meaning continues (Blum et al., 2013). In the current research, meaning differences are acknowledged while simultaneously recognizing that EE, ESD, CCE, and energy education tend to be highly interrelated; so discussion of energy literacy will often include discussion of the other related terms, such as sustainability and environmentalism.

\subsubsection{Informal Learning}

DeWaters and Powers' (2013) conceptualizations of scientific, technological, and environmental literacies have mostly been influenced or realized by bodies concerned with education, specifically elementary and secondary education. As a result, their conceptualizations of energy literacy are in large part tied to student populations. Although the current research focuses on general public populations, literacy conceptualizations based on student populations are considered to be a relevant component of energy literacy in an adult population. Energy literacy in students is, after all, related to or likely to influence literacy in adults. Therefore, DeWaters and Powers' (2013) work was deemed acceptable for the purposes of this research on the grounds that their instrument conceptualized energy literacy at a fundamental level, from which the present work could build. Furthermore, DeWaters and Powers' literacy conceptualizations are being considered for the current research because there is little work on literacy in nonstudent populations (i.e., it is difficult to use a framework of public literacy when one does not exist). That being said, it is worthwhile to briefly discuss informal learning, generally (i.e., non student learning), as well as some related initiatives, as these are likely to influence public energy literacy.

Generally, education involves the transfer of knowledge from a teacher to a learner and can be classified by type (Livingstone, 2007). Formal education, specifically, 
constitutes a pre-established body of knowledge that is delivered by an authority figure (i.e., someone possessing a lot of knowledge) (Livingstone, 2006). It is organized by age and provides credentials establishing one's knowledge competencies (Livingstone, 1999). In contrast, knowledge pursued voluntarily in the form of courses, training programs, or workshops is known as further or non-formal education (Livingstone, 1999, 2006, 2007). The CMEC's (2007) definition of non-formal education includes non-certificate education and training. According to Livingstone (1999), the increasing number of individuals moving between further education, paid work, part-time education, and part-time employment is blurring the lines between formal and further education.

Pertinent here, education classified as informal involves learning occurring outside of the "sustained reference to an intentionally organized body of knowledge" (Livingstone, 2006, p. 204). The objectives, content, length, applications, and processes for knowledge acquisition are determined by the learner (Livingstone, 1999). Informal learning can be explicit (i.e., conscious awareness of significant learning) or tacit (i.e., learning through everyday perceptions and socializations) (Livingstone, 1999). Of tacit learning, Livingstone (2006, p. 204) remarks it may be "coterminous with life experience itself". The CMEC (2007) also maintains that informal learning is a part of everyday living and supports it as tacit, claiming that it often occurs without the intent of the learner.

Though the majority of adults engage in various forms of learning, only formal and further education appear to be documented (Livingstone, 2006). Other types of adult learning are "ignored or devalued by dominant authorities and researchers" (Livingstone, 2006, p. 205). In 1999, Livingstone and the National Research Network in New Approaches to Lifelong Learning (NALL) conducted the first large scale Canadian survey of adult informal learning practices. Respondents were asked about their knowledge, skills, or understanding about health or hobbies, household tasks or paid work, or other interests. The research found that more than 95 percent of respondents reported being involved in some type of significant informal learning activity (Livingstone, 1999). Of those involved in informal learning related to general interests (i.e., one of the broad informal learning categories), 75 percent were learning about health and well-being; 60 percent about environmental issues; 60 percent about finances; and over half about hobby skills, social skills, public issues, computers, sports, and recreation (Livingstone, 1999). Even more, the survey found respondents aged 65 and over to spend a similar amount of hours on 
informal learning as respondents between the ages of 25 and 34, supporting the notion that learning is a lifelong endeavor (Livingstone, 1999). A 2004 follow up study found that 40 percent of adults were participating in further education, annually, but even more (over 90\%) were participating in informal learning activities (Livingstone, 2007). Total informal learning hours per week in 1999 and 2004 were 16 and 14 hours, respectively (Livingstone, 1999, 2007).

\subsubsection{Informal Learning Initiatives}

As previously noted, the 2007 Report to UNECE and UNESCO on Indicators for Sustainable Development was prepared by the Council of Ministers of Education to inform country-wide ESD strategies, including those in informal environments. Some of the leading initiatives from this report will be described, along with others not in the report but considered to be equally influential for public learning in sustainability, the environment, and energy. Further, some of these initiatives launched subsequent to the 2007 CMEC report.

One government supported initiative is Environment Canada's Biosphere, in Montreal, Quebec. This environmental museum is a place for the exchange of information, education, and ideas on environmental issues related to water, air, climate change, sustainable development and consumption practices (CMEC, 2007). Another government supported initiative, was the World Urban Forum (WUF) in June 2006 in Vancouver, British Columbia which Canada hosted to discuss urban development and sustainable urbanization in cities (CMEC, 2007). In the context of this event, Western Economic Diversification Canada funded forty-three projects that focused on capacity building and research, including the Regional Vancouver Urban Observatory project, the Global Sustainability Solutions Exchange, and the Green Guide, which highlighted Vancouver urban sustainability (CMEC, 2007). Ten thousand participants from over 100 countries attended this event (CMEC, 2007).

A current energy-specific Government of Canada supported initiative is Let's Talk Energy at the Canada Science and Technology Museum in Ottawa, Ontario. This initiative is designed to improve Canadian energy literacy; increase dialogue surrounding Canada's energy future; and engage Canadians on the role of science and technology in Canada's energy past, present, and future (Canada Science and Technology Museums Corporation, 2016). Further, this initiative is realized through an informative and resource-full website, events, programming, and forums for those with energy-related interests (Canada Science and Technology Museums 
Corporation, 2016).

The International Centre for Sustainable Cities (ICSC) is the result of a partnership between three levels of government, the private sector, and civil society organizations. ICSC was founded in British Columbia and undertakes practical demonstration projects that show how urban sustainability can be implemented (CMEC, 2007). Demonstrations deal with issues such as solid waste, water, sewage, land use, transportation, housing, energy efficiency, social conflict, and poverty. Further, ICSC creates and supports learning and idea networks (CMEC, 2007).

A substantial number of informal initiatives for public engagement or "active community learning" (CMEC, 2007) occur via nonprofit, nongovernmental, and civil society organizations. These vary in their objectives however several have educational components or less formal learning opportunities by means of public awareness campaigns and project involvement for adults. Over the last few decades several Canadian nonprofit, nongovernmental, and civil society organizations have been active, with some contributing significantly. Pollution Probe, for example, has been instrumental in shaping Canadian environmental policies through restricting DDT use in Canada; developing recycling programs in Ontario; helping foster legislation for limited phosphate use in detergents; and supporting mandatory vehicle emissions testing in Ontario (Pollution Probe, 2016). This is just a sample of their work. Recently Energy Exchange was created as a division of Pollution Probe with the objective of advancing energy literacy in Canada. They provide several learning opportunities like their Primer on Energy Systems in Canada and Energy Exchange magazine, which provides readers with an introduction to basic concepts, conventions, and vocabulary related to energy and energy systems (Energy Exchange, 2014).

Similarly, the Energy program and Energy IQ website provide 'all' Canadians with access to energy content researched, created, and vetted by Canadian Geographic Education and funded by the Canadian Association of Petroleum Producers (The Royal Canadian Geographical Society, 2016). The program aims to increase energy and geographic literacy in Canada by providing the public and educators with easy-to-find information, and easy-to-adopt teaching tools such as activities, news articles, and videos (The Royal Canadian Geographical Society, 2016).

There are myriad other organizations operating in Canada that promote environmental and energy literacy in various ways, such as the David Suzuki Foundation (DSF), Student 
Energy, Learning for a Sustainable Future (LSF), Toronto Environmental Association (TEA), Environmental Studies Association of Canada (ESAC), Toronto Atmospheric Fund (TAF), Toronto and Region Conservation Authority (TRCA), and Greenpeace, among others. Some of these have a very general scope (e.g., providing information and other educational resources), while others engage more narrowly (e.g., informing policy). Livingstone (1999) uses the metaphor of an iceberg to describe adult learning. That is, what we know about adult learning (i.e., further education and non-formal education) exists above surface, however, below surface, exists the vast amount of informal learning adults are engaging in (Livingstone, 1999); approximately 90 percent of an iceberg is found underwater. Learning occurring below the surface is likely to be influencing public energy literacy.

\subsection{Conceptualizing Energy Literacy}

The parallels across scientific, technological, and environmental literacy contributed to DeWaters and Powers' (2013) conceptualization of energy literacy and their subsequent energy literacy IDF. In particular, the components found in these literacies and their potential for being organized into cognitive, affective, and behavioural dimensions contributed to the researchers' holistic conceptualization. Using the conceptualizations of scientific, technological, and environmental literacy and review of curricular materials, educational standards, energy education and literacy literature, DeWaters and Powers (2013) define an energy literate individual as one who:

has a basic understanding of how energy is used in everyday life; understands the impacts that energy production and consumption have on all spheres of environment and society; is cognizant of the impacts of individual, collective, and corporate energy-related decisions and actions on the global community; is aware of the need for energy conservation and the need to develop alternatives to fossil fuel-based energy resources; and strives to make choices, decisions, and take actions that reflect these understandings and attitudes with respect to energy resource development and energy consumption, and is equipped with the necessary skills to do so. (p. 45).

This working definition was used by DeWaters and Powers (2013) to determine the 
characteristics of an energy literate individual. According to the researchers, the affective and behavioural characteristics of an energy literate individual are not overly difficult to imagine (DeWaters \& Powers, 2013). In particular, DeWaters and Powers (2013) claim that there is clear consensus that an energy literate individual acknowledges the existence of global energy problems and shows willingness to help with these (Salmon, 2000; St. Clair, 2003). In contrast, aspects of the cognitive dimension, such as content knowledge, appear to be more contentious (Hofman, 1980; Roth, 1996; Solomon, 1992). Knowledge is without a doubt an important aspect of literacy and linked to cognitive skills (DeWaters \& Powers, 2013). According to Pearson and Young (2002), increased knowledge increases an individual's feelings of self-confidence to ask questions, think critically, and to participate in decision-making. Therefore the question is not whether or not knowledge is important, but rather what type and depth of knowledge is necessary for an individual to be considered energy literate (DeWaters \& Powers, 2013).

The topic of energy is vast, ranging from scientific concepts to general issues to environmental issues (DeWaters \& Powers, 2013). For example, general issues include knowledge about appliance ratings and automobile fuel requirements and "lies at the intersection between knowledge, consumer decisions and actions and is deeply entrenched in societal context" (DeWaters \& Powers, 2013, p. 45). Solomon (1992) stresses a "citizen understanding of energy" whereby individuals have a basic understanding of energy concepts and can critically analyze information in order to make energy-related decisions (p. 79). Hofman (1980) stresses practical and technical knowledge. Solomon also distinguishes between formal and informal knowledge, therefore distinguishing between knowledge important for everyday people and knowledge required by an energy scientist or professional, respectively (1992). For example, with respect to power generation and fuel shortages, Solomon argues that citizens need to know that electricity is generated from an energy source and that fossil fuels are finite (Solomon, 1992). A professional or scientist's knowledge, however, would include knowing the specific processes for generating electricity from fossil fuels (Solomon, 1992).

DeWaters and Powers (2013) claim that energy literacy should empower and lead to action and, subsequently, the cognitive characteristics should stress "the informal or practical, citizenship knowledge of energy" (p. 46). They used this approach in combination with their former definition, to develop the characteristics of an energy literate individual—for all dimensions. They then generated question areas (what they call benchmarks) that align with each 
of these characteristics (DeWaters \& Powers, 2013). In general, the characteristics and benchmarks relate to 1) what an energy literate person should know and understand; 2) their attitudes, values, and concerns; and 3) their predispositions as well as actual energy-related behaviours (DeWaters \& Powers, 2013). These characteristics and question areas were based on their review of curricula, textbooks, educational literature, published energy polls and surveys, and were approved by a validity panel (DeWaters \& Powers, 2013). Their IDF (Appendix 1) demonstrates the characteristics of an energy literate individual according to dimension and specifically includes eight general characteristics and 33 measurable benchmarks related to the cognitive dimension; three general characteristics and 11 measurable benchmarks related to the affective dimension; and a behavioural dimension that is subdivided into predispositions to behave (three general characteristics and six measurable benchmarks) and behaviours (two general characteristics, two measurable benchmarks) (DeWaters \& Powers, 2013). The authors note that there is some overlap such as with their benchmark, "importance and effectiveness of personal decisions and actions for reducing energy consumption" found in the cognitive dimension and "internal locus of control" found in the affective dimension (DeWaters \& Powers, 2013). That is, these two benchmarks (i.e., question areas) share commonality.

It should be quickly noted that the term domain and dimension appear to be used interchangeably in the literature. Specifically, DeWaters \& Powers (2013) use both interchangeably while others show preference for either dimension (e.g., Pearson \& Young, 2002) or domain (e.g., Bloom et al., 1956). A recent paper examining dimensional comparison theory distinguishes between domains (e.g., Math versus English) but calls their comparison, dimensional comparison (Moller \& Herb, 2013). For the purposes of this work and to remain consistent, from here onwards the term dimension will be used to refer to both dimensions and domains.

\subsubsection{Conceptualizing Public Energy Literacy}

In this research, public energy literacy is being defined as the possession of general knowledge regarding energy, energy-related issues, and the use of energy in everyday life. It is believed that energy literacy is influenced in various manners, including both formal and informal learning. An energy literate individual will value the impact of energy and energy systems on the environment and society and will engage in behaviours and decision-making that align with an 
informed use of energy. Therefore, similar to DeWaters and Powers (2013), a public energy literacy instrument will assess 1) what an energy literate person should know and understand; 2) their attitudes, values, and concerns; and 3) actual energy-related behaviours. Further, this instrument will be broad, because the emphasis is on public energy literacy and because it is believed that specific and/or expert knowledge is unnecessary for everyday individuals. This instrument will also be general, because the goal is to examine general energy literacy, unlike literacy tied to curricular objectives or particular research questions (e.g., how much do people know about energy production, only). In fact, according to St. Clair (2003), an emphasis on scientific knowledge narrows the understanding of energy and environmental literacy and assumptions of literacy being tied to high levels of scientific training can create an "elite of [environmentally] literate citizens, and a mass of people who either follow along or are completely excluded from informed environmental action" (St. Clair, 2003, p. 74). This is not the goal here.

\subsection{Methodology and Analysis}

An overview of the methodology is presented in Figure 4.1. My approach began with first defining public energy literacy (above). Second, an item pool was generated using the IDF, newly written items, and existent surveys (DeWaters et al., 2013; Gill, Tierney, Pegg, \& Allan, 2010; Tashchian, Slama, \& Tashchian, 1984; Office of Energy Efficiency, 2014). Many, but not all, of the IDF characteristics and benchmarks were used and decisions for keeping or omitting these will be elaborated on in subsequent sections. Items were generated recognizing the limitations of online surveys and were administered to homeowners twice: first in a pretest and second to generate data used for validation. The pretest provided a means for selecting items from an item pool, revising items, and demonstrating whether or not new items were needed. To complement the pretest and to obtain in-depth opinions, interviews were also conducted. The final assessment was used to examine the second iteration of the public energy literacy instrument and to also assess energy literacy among a sample of homeowners. To ensure that the resulting instrument was both valid and reliable, instrument development followed established procedures from psychology, sociology, and education (e.g., Collins, 2003; Czaja \& Blair, 2005; DeVellis, 2003; Koballa, 1984). Approval from the Ryerson Ethics Board for this project was sought and approved. 
Figure 4.1 Methodology for Developing a Public Energy Literacy Instrument 


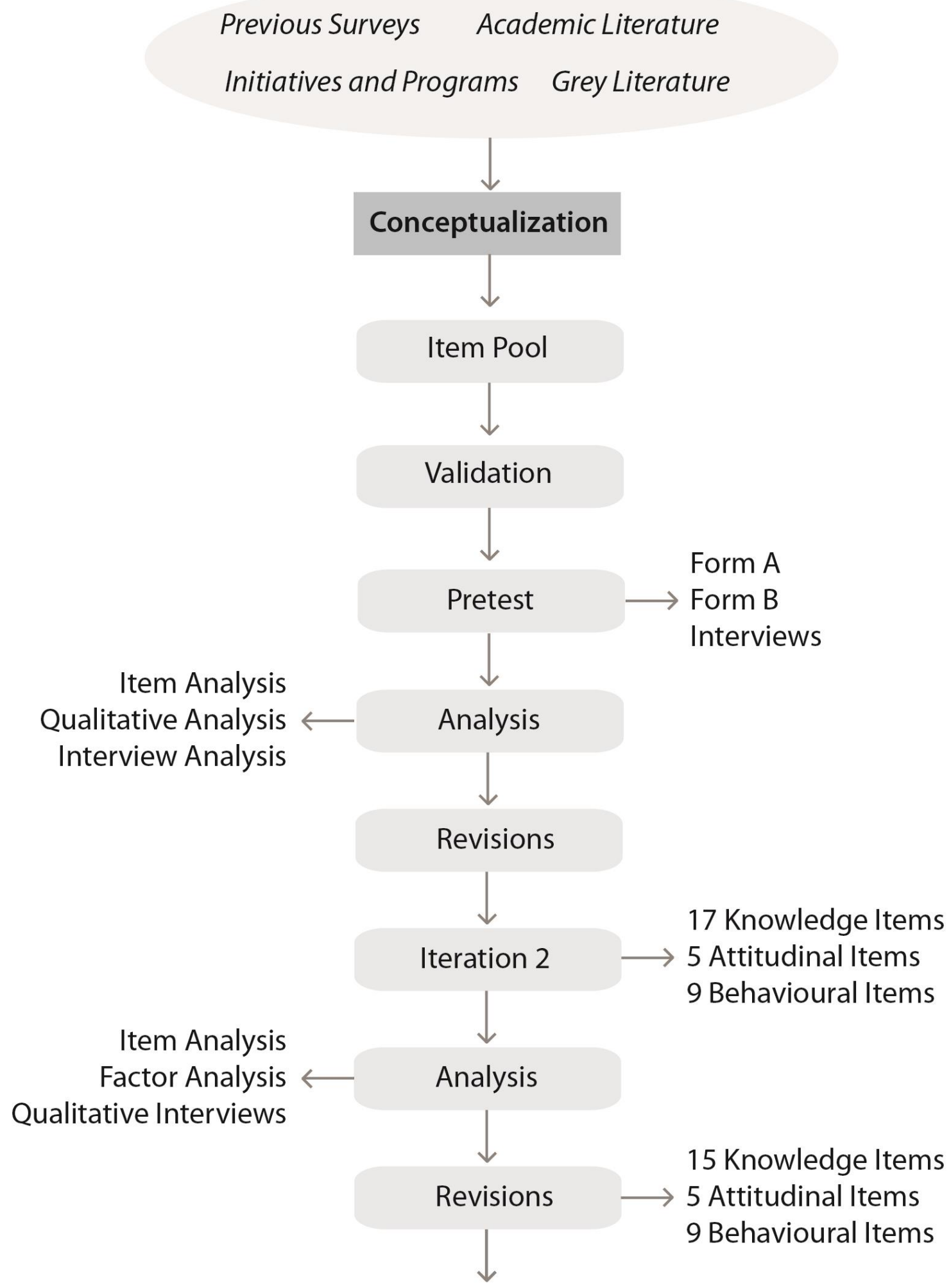

Public Energy Literacy Instrument

Overall, this chapter will address the following research questions: 
1. How can public energy literacy be conceptualized and used to guide development of an instrument?

2. How can established psychometric principles, educational, and survey methodologies be used to create a valid and reliable questionnaire for measuring energy literacy?

\subsubsection{Pretest - $1^{\text {st }}$ Iteration}

Newly written items and items drawn from previous surveys resulted in 106 knowledge, attitudinal, and behavioural items (corresponding to the cognitive, affective, and behavioural dimensions of energy literacy), with the majority of these coming from previous surveys. Several demographic questions were also added. Knowledge was measured using five-option multiplechoice questions with one correct choice. Attitudes and behaviours were measured using fivepoint Likert-type scales and included one neutral option.

The item pool was distributed to four individuals comprising the validity panel (i.e., two academics specializing in energy research, an energy educator, and an energy consultant) and three members of the dissertation supervisory committee (i.e., all academic researchers) with instructions to assess items for language, difficulty, and relevance to the overarching construct of public energy literacy. Some made suggestions for new items but most provided feedback on question type and wording. Additionally, some items were suggested for removal. For example, the following question was suggested to be problematic:

Which of the following statements best defines energy?
A. The rate at which work is done;
B. A force that moves something;
C. The ability to do work;
D. Potential and kinetic;
E. Fossil Fuels.

This question originally appeared in DeWaters et al.'s (2013) questionnaire for middle and high school youth and was criticized as such. That is, it was appraised for being typical of a question 
appearing in middle school textbooks and therefore presented a validity concern for an instrument purporting to measure public energy literacy. Although DeWaters et al. (2013) emphasize a 'citizenship' understanding of energy and energy-related issues, their target population makes several of their items more appropriate for students. Therefore, in agreement with the validity panel member's feedback, this and similar questions were either removed or updated. Also, multiple-choice questions were changed from being five-option multiple-choice to four-option multiple-choice questions in lieu of feedback suggesting that "a and b" or "all of the above" or "none of the above" type answer choices can appear tricky, at least by students, and therefore potentially by community members. Limiting answers choices to four also allowed them to be more meaningful (i.e., fewer 'throw-away' choices).

After revisions, the pretest (i.e., $1^{\text {st }}$ iteration) of the public energy literacy instrument consisted of 39 knowledge, 28 attitudinal, and 16 behavioural items. Given the number of items and to increase response rates, two forms were created (A and B) and can be found in Appendix 2 and Appendix 3. Form A consisted of 20 knowledge, 14 attitudinal, 8 behavioural items while Form B consisted of 19 knowledge, 14 attitudinal, and 8 behavioural items. The same demographic questions appeared on both.

\subsubsection{Participants and procedure}

The first iteration was administered to a convenience sample of twenty-eight homeowners, with twenty-three respondents living in detached homes and five respondents living in semi-detached homes. English was the first language for 25 participants, with the remaining three reporting Hindi, Punjabi, and Dutch as their first language. Levels of education varied, but the most common level of education was a bachelor's degree (32 percent). Income ranged from less than $\$ 40,000$ to more than $\$ 150,000$. Between December 2014 and February 2015 participants filled out either Form A or Form B of the energy literacy questionnaire, online, and were then contacted to participate in a cognitive interview.

\subsubsection{Pretest analysis}

Item analysis was based on Classical Test Theory (CTT), which dominates measurement theory (Kline, 2005) and has weak theoretical assumptions, making it easy to use (Fan, 1998). CTT assumes that an observed score is composed of an individual's true score and some random error (Kline, 2005). The focus of the "true score theory" then becomes the analysis of the total test 
score, frequency of responses, reliability of the test, and item-total correlations (Lucey, 2005; Magno, 2009), with difficulty level and discrimination indices also providing valuable information (Kline, 2005).

Analyses were carried out using SPSS version 21 and the CTTITEM SPSS syntax for classical item analysis, developed by Lei and Wu (2007). For knowledge items, missing values were treated as incorrect and for attitudinal and behavioural items, the program used listwise deletion. Each of the two forms was analyzed separately with the knowledge, attitude, and behaviour 'subscales' also analyzed separately (technically, these are not subscales, given the levels of measurement, but this is the conventional terminology). Item analysis included statistical analysis as well as qualitative evaluation.

\subsubsection{Pretest results}

Knowledge. Descriptive statistics and results of the item analysis are summarized in Table 4.2. The knowledge subscale was examined using the proportion who answered each item correctly, also known as item difficulty. Item difficulty is denoted using the $p$ value (not to be confused with the probability level for a calculated statistic given a specific sample size) and is calculated using the formula: $p=\mathrm{R} / \mathrm{T}$, where $p=$ item difficulty, $\mathrm{R}=$ the number of correct responses, $\mathrm{T}=$ the total number of responses (both correct and incorrect) (Sabri, 2013). Item difficulty also corresponds to a dichotomous item's mean (Kline, 2005). Difficulty on Forms A and B ranged from 0.25 to 1.00 and 0.08 to 1.00 , respectively, with higher values indicating easier items.

The discrimination index $(D)$ can be calculated for each dichotomous item, with higher $D$ values indicating stronger discriminating power (Kline, 2005). It measures how those who do well compare to those who do poorly. For each item, $D$ is calculated by 1) taking the difference between the number of correct answers from the upper group and the number of correct answers from the lower group and 2) dividing the difference by the number of individuals in the largest group (either the upper or lower group) (Escudero, Reyna, \& Morales, 2000). Generally, the upper group consists of the top 25 to 33 percent (i.e., have the highest overall scores) while the lower group consists of the bottom 25 to 33 percent (i.e., have the poorest overall scores) (Kline, 2005). Ds for the knowledge subscale ranged from -0.05 to 0.52 and -0.17 to 0.80 on Forms A and B, respectively. Higher values indicate stronger discrimination. Table 4.2 Descriptive and Item Analysis Statistics for Iteration 1 


\begin{tabular}{|c|c|c|c|c|c|c|c|c|}
\hline Item & $p$ or $M$ & $S D$ & $D$ & $\mathrm{r}_{p b i s}$ or $r$ & $p$ & $S D$ & $D$ & $r_{p b i s}$ or $r$ \\
\hline & Form A & & \multicolumn{3}{|c|}{ Knowledge Questions } & \multicolumn{2}{|c|}{ Form B } & \\
\hline 1 & 1.00 & 0.00 & 0.00 & - & $* 0.67$ & 0.47 & 0.43 & 0.131 \\
\hline 2 & $* * * 0.44$ & 0.49 & 0.07 & -0.134 & $* 0.33$ & 0.47 & 0.67 & 0.587 \\
\hline 3 & 0.94 & 0.24 & 0.17 & 0.000 & 1.00 & 0.00 & 0.00 & - \\
\hline 4 & 0.94 & 0.24 & 0.00 & 0.000 & 0.92 & 0.27 & -0.17 & -0.255 \\
\hline 5 & 0.69 & 0.46 & 0.07 & 0.243 & 1.00 & 0.00 & 0.00 & - \\
\hline 6 & $* * 0.94$ & 0.24 & 0.17 & 0.390 & 0.58 & 0.49 & 0.43 & 0.226 \\
\hline 7 & $* * 0.94$ & 0.24 & 0.17 & 0.000 & $* * 0.67$ & 0.47 & 0.80 & 0.587 \\
\hline 8 & $* 0.25$ & 0.43 & 0.52 & 0.138 & 1.00 & 0.00 & 0.00 & - \\
\hline 9 & $* * * 0.88$ & 0.32 & 0.17 & -0.240 & 1.00 & 0.00 & 0.00 & - \\
\hline 10 & $* * 0.31$ & 0.45 & 0.17 & -0.362 & 0.92 & 0.27 & 0.20 & 0.053 \\
\hline 11 & 1.00 & 0.00 & 0.43 & - & 0.83 & 0.37 & 0.03 & 0.101 \\
\hline 12 & 1.00 & 0.00 & 0.02 & - & $* * 0.08$ & 0.27 & 0.17 & 0.482 \\
\hline 13 & 0.69 & 0.46 & -0.05 & -0.073 & 0.92 & 0.27 & 0.20 & 0.053 \\
\hline 14 & 0.81 & 0.39 & 0.00 & 0.044 & 1.00 & 0.00 & 0.00 & - \\
\hline 15 & 0.75 & 0.43 & 0.00 & 0.081 & 0.08 & 0.27 & -0.20 & -0.328 \\
\hline 16 & 0.94 & 0.24 & 0.36 & -0.177 & 0.92 & 0.27 & 0.20 & 0.218 \\
\hline 17 & 1.00 & 0.00 & 0.19 & - & $* 0.42$ & 0.49 & 0.47 & 0.387 \\
\hline 18 & 1.00 & 0.00 & 0.19 & - & 1.00 & 0.00 & 0.00 & - \\
\hline 19 & $* * 0.63$ & 0.48 & 0.00 & 0.307 & 0.92 & 0.27 & 0.20 & 0.392 \\
\hline \multirow[t]{2}{*}{20} & $* * * 0.81$ & 0.00 & 0.00 & -0.281 & - & - & - & - \\
\hline & Form A & & \multicolumn{3}{|c|}{ Attitudinal Items } & \multicolumn{3}{|c|}{ Form B } \\
\hline 1 & 1.47 & 0.52 & & 0.199 & 4.17 & 0.84 & & 0.776 \\
\hline 2 & 4.60 & 0.63 & & -0.107 & 1.58 & 0.52 & & 0.769 \\
\hline 3 & 2.27 & 0.88 & & -0.503 & 1.58 & 0.52 & & 0.814 \\
\hline 4 & 1.93 & 0.80 & & 0.802 & 4.50 & 0.52 & & 0.767 \\
\hline 5 & 4.47 & 0.74 & & 0.280 & 2.50 & 0.91 & & 0.808 \\
\hline 6 & $* 1.60$ & 0.73 & & 0.769 & 1.58 & 0.52 & & 0.783 \\
\hline 7 & $* 2.27$ & 0.59 & & 0.235 & 3.25 & 0.97 & & 0.808 \\
\hline 8 & 1.87 & 0.35 & & 0.552 & 4.42 & 0.67 & & 0.755 \\
\hline 9 & 3.97 & 0.64 & & 0.099 & 4.25 & 0.97 & & 0.748 \\
\hline 10 & 3.93 & 0.46 & & 0.348 & 4.42 & 0.79 & & 0.751 \\
\hline 11 & 3.80 & 1.01 & & -0.137 & $* 3.67$ & 1.16 & & 0.821 \\
\hline 12 & 3.93 & 0.70 & & 0.612 & $* 1.50$ & 0.52 & & 0.767 \\
\hline 13 & 1.93 & 0.70 & & 0.141 & 4.08 & 0.10 & & 0.772 \\
\hline \multirow[t]{2}{*}{14} & 4.20 & 0.78 & & 0.576 & 2.67 & 1.16 & & 0.827 \\
\hline & Form A & & \multicolumn{3}{|c|}{ Behavioural Items } & \multicolumn{3}{|c|}{ Form B } \\
\hline 1 & $* 1.67$ & 0.82 & & -0.206 & 2.17 & 0.84 & & 0.293 \\
\hline 2 & $* * * 2.80$ & 1.42 & & 0.539 & 2.83 & 1.27 & & -0.484 \\
\hline 3 & 4.47 & 0.99 & & 0.284 & $* * 2.00$ & 0.60 & & -0.068 \\
\hline 4 & 3.40 & 1.30 & & 0.338 & *1.83 & 0.84 & & -0.116 \\
\hline 5 & 2.13 & 1.19 & & 0.430 & 3.17 & 1.95 & & -0.496 \\
\hline 6 & 3.47 & 0.92 & & 0.557 & 1.92 & 0.79 & & 0.255 \\
\hline 7 & $* * 2.33$ & 0.90 & & 0.361 & $* * 1.50$ & 0.80 & & -0.201 \\
\hline 8 & $* * 1.33$ & 0.49 & & 0.258 & $* * 2.75$ & 1.36 & & -0.428 \\
\hline
\end{tabular}

Note. Values corresponding to $r_{\mathrm{pbis}}$ or $\mathrm{r}$ depend on item level measurement ( $r_{\mathrm{pbis}}$ for knowledge items, $r$ for attitudes and behaviours). Both are corrected correlations. Bolded statistics represent items that were retained for the second iteration, *indicates an item that was retained in its original form, ** indicates that response options for an item were changed for iteration two, *** indicates that major modifications were made to an item for iteration two.

Discrimination can also be examined via correlations and has the advantage of taking into account scores from all participants and not only scores from those in the lower and upper 
groups, as with $D$ (Escudero et al., 2000). The $\mathrm{r}_{\text {pbis }}$ (i.e., point-biserial correlation) describes the relationship between an answer to a dichotomous measure (0) or (1) and the test scores of all persons (i.e., a continuous measure). Further 'corrected' item-total correlations correspond to the calculation of total scores without the item in question, as this would inflate the correlation (Kline, 2005). Therefore, corrected point-biserial correlations were calculated for all items in the knowledge subscale. Values for $\mathrm{r}_{\mathrm{pbis}}$ varied substantially, on both forms, with point-biserial correlations missing for items having no variability (i.e., $S D=0$ ). This makes sense because items with no variability cannot be used in computing correlations. Generally, higher correlations indicate stronger discriminating power. That is, an individual doing well on one item should theoretically do well on other items.

Attitudes and behaviours. Descriptive statistics were calculated for all items as they appeared on both forms (i.e., prior to reverse coding). However, corrected item-total correlations were computed on items after reverse coding. For attitudes, corrected item-total correlations varied from -0.50 to 0.80 and 0.75 to 0.83 , for Forms $\mathrm{A}$ and $\mathrm{B}$, respectively. For behaviours, corrected item-total correlations ranged from -0.206 to 0.539 for Form A and -0.596 to 0.293 for Form B. Higher positive correlations are associated with stronger discrimination.

Reliability. Subscale reliability was examined using Cronbach's alpha, with $\alpha=0.56$ and 0.62 for Form A attitudes and behaviours, respectively. For Form B attitudes, Cronbach's $\alpha=$ 0.78. Reliability analysis could not be calculated for the other subscales (i.e., knowledge subscales on both forms and Form B behaviour), since they did not produce a positive definite matrix. Common reasons for not obtaining a positive definite matrix include: 1) too many variables and few cases of data, which makes the correlation matrix unstable and 2) multicollinearity (i.e., highly correlated variables) (Field, p. 656). It should be noted that the use of Cronbach's alpha is often discouraged with dichotomous variables or ordinal variables and it is suggested that ordinal alpha be used instead (Gadermann, Guhn, \& Zumbo, 2012). The small sample size, stage of instrument development, and variable levels of measurement, all contributed to reliability not being stressed at this point. More involved reliability analyses occurred with the second iteration of the instrument.

\subsubsection{Cognitive interview}

Cognitive interviews are meant to complement a survey. They help to make sure that respondents understand questions, that respondents understand questions in the same way, and 
that respondents are willing and able to answer survey questions (Collins, 2003). Following the pretest, twenty-four individuals volunteered to participate in cognitive interviews. These were conducted face-to-face and over the telephone. Some of main highlights are briefly presented.

For Form A, several individuals claimed that they guessed the answer to the fill in the blank question on efficient lighting (Q.2), therefore indicating a cognitively difficult question. The question was modified and fill in the blanks were removed from the survey. For the question on time-of-use rates (Q.10), some individuals noted they believed the answer was "when they got home from work", and were not sure why it was not an option. This confirmed the inclusion of this question in iteration two of the instrument. The question on the causes of global warming was interesting for many. Some explained their method for answering this question as if it were a contentious issue (e.g., discussing religion, or being "sciencey"). It was therefore decided to adjust and move this question to the attitudes section. On Form B, while many individuals confirmed their ability to compute electricity use, not everyone understood the difference between $\mathrm{kW}$ and $\mathrm{kWh}$ prompting the retention of this question (Q.2). For the question on standby power (Q.4), the terms vampire, standby, and phantom power were not known to everyone. The most popular terms, standby and phantom power, were retained. The question on photovoltaic (solar) cells (Q.9) was too easy and was removed. Interestingly, the question on the advantages of nuclear power (Q.14) was debated. Respondents were unsure what the objectives were. For example, did the survey mean health or economic benefits? The question on specific pipelines (Q.18) was considered too difficult by everyone and it was removed.

\subsubsection{Qualitative analysis}

Each item was evaluated for its individual value, its consistency with the rest of the subscale, and its contribution to the overall instrument. Due to the sample size, it is plausible that some of the observed correlations are unreliable (along with the estimates of reliability themselves).

Therefore, in addition to statistical analysis, qualitative analysis on an item-by-item basis was equally valuable.

Four knowledge items were retained from the pretest, with these being neither too easy nor too difficult $(M=0.47)$. Discarded items included those that all participants answered correctly and those believed to be somewhat ambiguous such as: 
Scientists say that the fastest and most cost-effective way to address our energy needs is to...
A. Develop all possible domestic sources of fossil fuels;
B. Build nuclear power plants;
C. Develop more power plants that use renewable energy sources;
D. Promote energy conservation.

The correct response option could be debatable, depending on the scientist. Also, respondents may be unclear whether a technological solution versus a behavioural solution is "desired". Another question that was dropped:

Most of the electricity produced in Canada comes from...
A. Burning coal;
B. Nuclear power;
C. Solar energy;
D. Water (hydro) power.

A similar question on electricity generation in Ontario was asked on Form A. The use of both versions was considered unnecessary, so the Ontario based question was retained. Six items were retained with minor revisions because they were considered to be important to the overall instrument. For example, "In the winter, the most expensive rate that electrical utilities charge their customers happens at a time of day when..." aligns with time-of-use rates, i.e., electricity pricing that reflects use by demand. Understanding time-of-use (TOU) rates is considered important because a) several jurisdictions have implemented time-of-use pricing, and b) TOU is an indicator of understanding electricity demand - that is, it can be difficult to meet electricity demands when requests for electricity occur at the same time. For this question, the response option, "People are getting up and getting ready to go to work" was changed to "People are getting up and getting ready to go to work and when they come home from work". The latter half of the response option was initially omitted because it was considered too lengthy. It was afterwards decided that the full response option was more accurate and that prior omission may have resulted in its negative discrimination index. It is also possible that respondents had 
difficulty with this question because it assumes that people work standard eight-hour 9am to $5 \mathrm{pm}$ shifts. Increasingly, these "regular" work shifts are becoming less typical and therefore the ability to answer this question might have to do with a person's occupational status (e.g., taxi drivers, doctors, retail workers). Three questions from Forms A and B provided the foundation for new questions. Changes here were considered to be more substantial than those made above. For example, the following question was changed in order to encourage deeper thinking:

Which organization sets the price of electricity in Ontario?
A. The Ministry of Environment and Climate Change;
B. The National Energy Board;
C. The Ontario Energy Board;
D. Toronto Hydro Electric Systems Limited.

It was changed to:

In Canada, the price of electricity is determined at which jurisdictional level?
A. International;
B. National;
C. Provincial;
D. Municipal.

For attitudes, four items were retained. Several discarded items demonstrated extreme skew. Also, many of the items that were not discarded were conceptually similar to items found in the New Ecological Paradigm (NEP) scale, a measure of environmental concern (Dunlap, Van Liere, Mertig, \& Jones, 2000). Given that the NEP is an established scale and widely used, it was incorporated into the assessment of energy literacy and is discussed in Chapter 5.

For behaviours, two items were retained, five items were retained with revisions, and one item was completely modified. Items that were discarded included skewed items, such as asking respondents whether or not they, "put plastic film on windows in the winter", which most people indicated not doing. Decisions for keeping or modifying items were based on Gardner and Stern's short list (2008), wherein the most effective household actions for reducing energy use 
are outlined. Item modification included changing, "use energy efficient compact fluorescent light" to "use energy efficient lighting (LEDS or CFLs)".

\subsubsection{Second Iteration}

Retained items, revisions, and additions to the pretest resulted in the second iteration of the public energy literacy instrument (Appendix 4). It consisted of 17 knowledge items, five attitudinal items, nine behavioural items, and the NEP scale. Most items, excluding NEP items, were written by the researcher. Several of these are however very similar to questions appearing on other surveys, and were inspired by previous works.

\subsubsection{Participants and procedure}

Toronto neighbourhood profiles, accessible through the City of Toronto (1998-2016), served as reference for sampling criteria and household selection. Based on census tracts, profiles include maps for each of the 140 Toronto neighbourhoods as well as profiles on age, gender, language, family and dwelling, ethnicity, and income; minimum neighbourhood populations range from 7,000 to 10,000 . After examining several neighbourhoods, Stonegate Queensway was selected as the target neighbourhood due to having a high percentage of single-detached homes (56\%) compared to other neighbourhoods (e.g., Junction; $16 \%$ ) and for having a high percentage of working age individuals (i.e., 25-64). In order to control for differences between the energy use behaviours of apartment dwellers and homeowners, this study targeted homeowners of singlefamily dwellings (i.e., those not residing in multi-unit residential buildings such as apartment buildings).

On October 2015, 5046 recruitment notices (Appendix 5) were mailed to residents living in Toronto's Stonegate Queensway neighbourhood. Notices were delivered using Canada Post's Unaddressed Admail service, which allows for building ownership (i.e., homeowners) and building type (i.e., non apartments) to be specified as delivery parameters. Notices provided residents with a brief overview of the study and directed them to a URL where they could find more information, online consent forms, and the survey. Recruitment via admail resulted in 15 responses. Due to the extremely low response rate, door-to-door recruitment was adopted for a second phase of participant recruitment.

Between November 16, 2015 and February 16, 2016, the researcher and research assistants went door-to-door in several Toronto neighbourhoods such as Riverdale, the Annex, 
Dovercourt, Dufferin Grove, Christie Pitts, Bloor West Village, Cabbagetown, Little Italy, Little Korea, Bloordale, Davisville, the Beaches, Roncesvalles, and High Park. Typical weekday recruitment sessions lasted from 5:00 to 7:00 p.m. and weekend sessions from 11:00 a.m. to 2:00 p.m. Neighbourhoods were chosen based on profile variability with respect to sociodemographics (e.g., income) and their proximity to local transit (making travel to sites easier). In total, 6200 recruitment notices were delivered and, in several cases, the research team was able to recruit households face-to-face. Door-to-door recruitment resulted in 203 responses. Of these, eight respondents indicated not owning their home. Six respondents partially completed the survey, and data for these participants were considered incomplete.

Low response rates are likely tied to the nature of the appeals for participation. Specifically, participants were asked to consent to participating in the online survey, provide their electricity and natural gas account information, and consent to releasing their electricity and natural gas data. The latter two requests related to analyses that will be discussed in Chapter 5 . During door-to-door recruitment, several households expressed extreme discomfort with providing their utility information, generally. Several households also expressed discomfort with the use of the online platform, Qualtrics, which routes information through the US. Collecting utility data as well as using an online platform that routes data through the US were major barriers to recruitment.

Overall, data for 204 participants were analyzed. Most household representatives were males (58\% compared to females, $42.5 \%$ ). Almost 79 percent of respondents had either an undergraduate degree, certificate, or diploma, or a master's or doctorate degree. English was the first language for 93 percent of respondents. Household income ranged from less than $\$ 40,000$ to more than $\$ 200,000$ and respondent age ranged from 32 years of age to 87 years of age $(M=56$ years, $S D=12.89)$. Most people lived in single-detached homes $(49.5 \%)$ but several lived in semi-detached homes $(39.2 \%)$ and some lived in row $(6.9 \%)$ or town $(5.4 \%)$ homes.

\subsubsection{Iteration 2 analysis}

First, item analysis was based on Classical Test Theory (CTT), as with the pretest. CTTITEM SPSS syntax was used in the same manner as in the pretest. Each subscale was analyzed separately. Second, exploratory factor analysis was used as the method of data reduction to uncover the underlying structure of the subscales. Factor analysis assumptions include: variables are measured continuously, have multivariate normal distributions, and have linear relationships 
(Tabachnick, \& Fidell, 2013). Interval data are often treated as continuous and subsequently the product-moment (Pearson) correlation matrix is used as the basis for factor analysis (Hofstee, Ten Berge, \& Hendriks, 1988). However, this approach is heavily debated (Lorenzo-Seva \& Ferrando, 2015). Similarly, dichotomous variables are not recommended for factor analysis, unless the correlation matrix is 'adjusted' for tetrachoric correlations (Pearson, 1900; LorenzoSeva \& Ferrando, 2012). Both the tetrachoric and polychoric correlation matrix are based on the assumptions that 1) observations come from the 'separation' of continuous and unobservable latent responses at specific thresholds and 2) the joint distribution of the latent responses is bivariate normal (Rigdon, 2010). The tetrachoric correlation (which is just a special case of the polychoric correlation) and the polychoric correlation estimate the Pearson correlation and can be likened to transforming the data so that the response scale is "stretched" (Lorenzo-Seva \& Ferrando, 2015, p. 885). Uses of polychoric correlations include minimizing floor and ceiling effects, linearity of factor regressions, and being robust, which contribute to its wide use (Lorenzo-Seva \& Ferrando, 2015). Polychoric correlations are not without limitation: it is not a direct correlation but a model-based estimate, making it less stable than the Pearson correlation obtained from true continuous data, especially with fewer than 200 observations (Chen \& Choi, 2009; Guilford \& Frutcther, 1973).

POLYMAT-C and TETRA-COM SPSS programs were used for estimating polychoric and tetrachoric correlations (Lorenzo-Seva \& Ferrando, 2012, 2015). Both programs check the positive definiteness of the correlation matrix and, if there is a problem, a nonlinear smoothing procedure is used; this enables the matrix to be used with any factor analysis estimation procedure (Lorenzo-Seva \& Ferrando, 2012, 2015).

\subsubsection{Iteration 2 results}

Item analysis. Item analysis confirmed the performance of retained and revised items from the pretest in addition to a few new items. Difficulty varied, with $p$ ranging from 0.37 to 0.94 . Where guessing may be a possibility, an ideal $p$ value results from calculating $0.50+(0.50 / k)$, where $k$ is the number of multiple-choice options, and $0.50 / \mathrm{k}$ is added to compensate for random guessing (e.g., Crocker \& Algina, 1986, p. 313). According to Wei and Lu (2007), most individuals do not randomly guess but eliminate options first, making ideal $p$ slightly higher than $0.50+(0.50 / k)$. For iteration 2, average difficulty $(M=0.67)$ is in line with the slightly higher ideal $p$ value of 
0.63 , based on four multiple-choice options.

Statistical analysis revealed one item (question 8 on heating equipment) that discriminated poorly between those who did well and those who did poorly $(D=0.05)$ but can be attributed to most people answering this question correctly. Answers to question 4 (on petrochemical products) were also well below the recommended $D$ value of 0.20 (Ebel \& Frisbie, 1991). Corrected point-biserial correlations ranged from 0.014 to 0.350 and were positive, demonstrating that items discriminated in the proper direction. Emslie and Emslie (2002) suggest discriminating items should have corrected point-biserial correlations of 0.30 or larger, which is approximately equivalent to biserial correlations of 0.40 or larger. Varma (2002) suggests pointbiserial correlations of at least 0.15 with good items having point-biserial correlations above 0.25 . Thus a good corrected point-biserial correlation may be approximately 0.15 . Importantly, Kline (2005) points out that items with low or high $p$ values have a restricted range, contributing to low item-total correlations. At least half of the knowledge items were close to 0.15, with several low correlations associated with high $p$ values. Potentially problematic questions are 4, 8, 10, (on petrochemicals, heating systems, energy pricing jurisdiction, respectively), and 14 (on transportation fuels). For some questions, interesting changes occurred between the first and the second iteration. When respondents were asked to determine the electricity use for an electric heater, if used for two hours, 33 percent of respondents chose correctly during the pretest, and 64 percent chose correctly on the second iteration. Nevertheless, several questions remained relatively consistent with respect to difficulty on both iterations. Problematic questions with respect to $D$ were also problematic in terms of their corrected item-total correlations. This makes sense as both are measures of discrimination. For example, question 4, overall, did not appear unusually problematic ( $p=0.72$ ), however, an approximately equivalent number of people from both the low and high scoring groups answered this question correctly. With the exception of one attitudinal item (item 4) and one behavioural item (item 1), corrected item-total correlations were above 0.15. Again, all correlations were positive. All descriptive and item analysis statistics for iteration two are shown in Table 4.3.

Table 4.3 Descriptive and Item Analysis Statistics for Iteration 2

\begin{tabular}{|c|c|c|c|c|}
\hline Item & $p$ or $M$ & $S D$ & $D$ & $\mathrm{r}_{p b i s}$ or $r$ \\
\hline \multicolumn{5}{|c|}{ Knowledge Questions } \\
\hline
\end{tabular}




\begin{tabular}{|c|c|c|c|c|}
\hline 1 & .64 & 0.48 & .46 & .249 \\
\hline 2 & .63 & 0.48 & .19 & .102 \\
\hline 3 & .58 & 0.49 & .51 & .266 \\
\hline 4 & .72 & 0.45 & .14 & .031 \\
\hline 5 & .70 & 0.46 & .31 & .171 \\
\hline 6 & .89 & 0.32 & .18 & .243 \\
\hline 7 & .70 & 0.46 & .25 & .074 \\
\hline 8 & .94 & 0.24 & .05 & .030 \\
\hline 9 & .57 & 0.50 & .45 & .212 \\
\hline 10 & .84 & 0.37 & .17 & .014 \\
\hline 11 & .72 & 0.45 & .22 & .085 \\
\hline 12 & .70 & 0.46 & .32 & .171 \\
\hline 13 & .37 & 0.48 & .43 & .232 \\
\hline 14 & .37 & 0.48 & .26 & .055 \\
\hline 15 & .56 & 0.50 & .56 & .350 \\
\hline 16 & .57 & 0.50 & .33 & .144 \\
\hline 17 & .67 & 0.47 & .42 & .275 \\
\hline \multicolumn{5}{|c|}{ Attitudinal Items } \\
\hline 1 & 1.31 & .635 & - & .250 \\
\hline 2 & 2.03 & .974 & - & .220 \\
\hline 3 & 1.45 & .653 & - & .335 \\
\hline 4 & 3.98 & .775 & - & .139 \\
\hline 5 & 1.60 & .885 & - & .168 \\
\hline \multicolumn{5}{|c|}{ Behavioural Items } \\
\hline 1 & 2.24 & .884 & - & .093 \\
\hline 2 & 1.73 & .669 & - & .183 \\
\hline 3 & 1.85 & .818 & - & .182 \\
\hline 4 & 1.63 & 1.206 & - & .267 \\
\hline 5 & 1.75 & .807 & - & .487 \\
\hline 6 & 1.84 & 1.00 & - & .434 \\
\hline 7 & 1.78 & 1.039 & - & .321 \\
\hline 8 & 1.95 & .896 & - & .336 \\
\hline 9 & 2.80 & 1.228 & & .196 \\
\hline
\end{tabular}

Note. Values corresponding to $r_{\mathrm{pbis}}$ or $\mathrm{r}$ depend on item level measurement $\left(r_{\mathrm{pbis}}\right.$ for knowledge items, $r$ for attitudes and behaviours). Both are corrected correlations.

Reliability. Debate surrounds the use and misuse of Cronbach's alpha (Gaderman et al., 2012).

Reliability calculations involving Cronbach's alpha rely on Pearson correlations. Therefore using this conventional alpha is fine when variables are measured continuously (Gaderman et al., 2012). However, if variable measurement is not continuous, using Cronbach's alpha can distort interpretations. Instead, ordinal coefficients are recommended (i.e., ordinal alpha). In particular, ordinal alpha is recommended when data come from measurements based on ordinal response 
scales (e.g., rating scales or Likert-type response formats) (Gaderman et al., 2012). As such, ordinal alpha is akin to the nonparametric version of reliability coefficients (Lewis, 2007). Using tetrachoric and polychoric correlations, ordinal alpha was calculated for all three subscales. In general, literature recommends that alpha for a scale should not be less than 0.70 when used for research purposes, at least 0.80 for applied settings, and greater than 0.90 for "high-stake", individual-based educational, diagnostic, or clinical purposes (Gaderman et al., 2012). Further, according to Benson and Clark (1982), alpha values should be at least 0.70 for a set of items in social science scales. For education assessment scales, alpha can be as low as 0.60 (Linn \& Gronlund, 2000; Qaqish, 2006). As shown in Table 4.4, ordinal alphas align with these conventional recommendations.

Table 4.4 A Comparison of Reliability for Iteration 2 Subscales

\begin{tabular}{lcrr}
\hline & Knowledge & Attitudes & Behaviour \\
Cronbach's alpha & 0.49 & 0.42 & 0.58 \\
Polychoric ordinal alpha & 0.63 & 0.68 & 0.69 \\
\hline
\end{tabular}

Factor Analysis. Based on tetrachoric correlations, exploratory factor analysis by unweighted least squares was carried out for the knowledge items. Examination of initial eigenvalues, demonstrated seven factors with eigenvalues over Kaiser's criterion of 1 and in combination explained $69.10 \%$ of the variance. The scree plot was slightly ambiguous and showed inflexions that justified a 2 to 4 factor solution. Further, questions 8 and 14 on heating systems and transportation fuels did not confer well to factor analysis and had high communalities for more than 2 factors. These items were discarded from the analysis. A 15-item factor analysis with orthogonal rotation (varimax) was carried out. The Kaiser-Meyer-Olkin measure meets the bare minimum for sampling adequacy for this analysis, KMO =.497 (Field, 2009). Bartlett's test of sphericity $\chi^{2}(105)=640.28, p<0.001$, indicated the correlations were sufficiently large enough for factor analysis, i.e., there were significant correlations among enough of the variables. Six factors had eigenvalues over 1 , however, examination of the scree plot, again, pointed to a three factor solution and this was the number of factors that was retained in the final analysis. Table 4.5 shows the factor loadings after rotation. The items that cluster on the same factors suggest that factor 1 represents questions to do with electricity (except question $13 \& 4$ on the second 
iteration, i.e., questions on pipelines and petrochemical products), factors 2 and 3 represent broad questions and it is difficult to distinguish between the two.

Factor analysis demonstrated subscale multidimensionality and this is reasonable given various types of knowledge questions. These results further support an adapted framework for this work as shown in Appendix 6, however, the categories of the adapted framework apply to groupings that make more sense compared to the categories produced using factor analysis.

After removal of questions 8 and 14 (heating equipment and transportation fuels, respectively), ordinal alpha increased to 0.64 , thereby improving the reliability of the knowledge subscale. The removal of question 8 on heating equipment is further justified given that most answered this question correctly therefore minimizing variability. Removal of the question on transportation fuels is supported by the fact that it is cognitively difficult. Asking people to recall percentages can be very difficult and can contribute to guessing and low discrimination. Average difficulty based on the 15 knowledge questions equals 0.66 and is therefore still consistent with ideal $p$ values (Crocker and Algina, 1986; Wei \& Lu, 2007). To reiterate, according to Wei and Lu (2007), most individuals do not randomly guess but eliminate options first, making ideal $p$ slightly higher than $0.50+(0.50 / k)$.

Exploratory factor analysis by alpha extraction based on polychoric correlations was carried out on the 5 attitude items with orthogonal rotation (varimax). Examination of initial eigenvalues, demonstrated one factor with an eigenvalue of 2.20 and explained $44 \%$ of the variance. The scree plot showed inflexions that justified a 1 to 2 factor solution. The KaiserMeyer-Olkin measure, meets criteria for sampling adequacy for the analysis, $\mathrm{KMO}=.671$ (Field, 2009). Bartlett's test of sphericity $\chi 2(10)=166.54, p<0.001$, indicating the correlations were sufficiently large enough for factor analysis. Analysis ended here, because finding a factor solution for five items did not appear very meaningful, especially after confirmation of eigenvalues and examination of the scree plot. 
Table 4.5 Rotated Factor Loadings for the Knowledge Subscale

Factor

$\begin{array}{llll}\text { Item } & 1 & 2 & 3\end{array}$

Which of the following light bulbs uses the least amount of energy to produce light

In Canada, whose responsibility is it to negotiate the right to use a landowner's property for a pipeline once the pipeline has been approved?

The best way to limit standby power or "phantom loads" is to ....

If you use a 1-kilowatt $(\mathrm{kW})$ electric heater for two hours how much electricity will it use?

Which product is NOT made from petrochemicals derived from oil or natural gas?

When you turn on a light bulb in your house, the electricity it uses was produced how long ago?

In which province can you drive an electric car and produce the fewest greenhouse gas emissions?

In Canada which of the following methods for shipping crude oil is becoming more popular?

In 2014, which jurisdiction in North America became the first to completely eliminate coal as a source of electricity generation?

Ontario gets the majority of its electricity from which energy source

In Canada, the price of electricity is determined at which jurisdictional level?

Who is the primary regulatory body for the oil sands

Which uses the most energy in the average Canadian home each year?

During winter, electricity is most expensive for Toronto households when...

Which of the following statements best describes the relationship between Canada's energy imports and exports?

Extraction Method: Unweighted Least Squares.

Rotation Method: Varimax with Kaiser Normalization; loadings of less than .2 are not shown. 
For behaviours, exploratory factor analysis by alpha extraction based on polychoric correlations was carried out on 9 behaviour items with orthogonal rotation (varimax). Examination of initial eigenvalues, demonstrated two factors with eigenvalues over 1 and explained $44 \%$ of the variance. The scree plot showed inflexions that justified a 1 to 2 factor solution. The Kaiser-Meyer-Olkin measure, meets the level of good criteria for sampling adequacy for the analysis, $\mathrm{KMO}=.762$ (Field, 2009). Bartlett's test of sphericity $\chi^{2}(36)=$ 216.24, $p<0.001$, indicating the correlations were sufficiently large enough for factor analysis. Table 4.6 shows the factor loadings after rotation. The items that cluster on the same factors suggest that factor 1 represents questions on household behaviours and factor 2 represents questions on transportation.

Table 4.6 Rotated Factor Loadings for the Behaviour Subscale

\begin{tabular}{|c|c|c|}
\hline \multirow[b]{2}{*}{ Item } & \multicolumn{2}{|c|}{ Factor } \\
\hline & 1 & 2 \\
\hline In the summer use AC sparingly & .701 & \\
\hline $\begin{array}{l}\text { Put on more clothes, such as a sweater instead of } \\
\text { adjusting the temperature }\end{array}$ & 670 & \\
\hline $\begin{array}{l}\text { Use cold water settings for wash or rinse settings to wash } \\
\text { clothing }\end{array}$ & .545 & \\
\hline Turn the heat down at night & .521 & \\
\hline Use energy efficient lighting (LEDs or CFLs) & .425 & .270 \\
\hline Use a clothesline or drying rack to dry clothing & .306 & \\
\hline Maintain correct tire pressure & .260 & \\
\hline Carpool or use public transportation & & .555 \\
\hline Walk or bike short distances & & .536 \\
\hline
\end{tabular}




\subsection{Discussion and Conclusion}

Using a rigorous methodology, an instrument was developed for measuring public energy literacy in the Canadian residential sector. Instrument development included pretesting, cognitive interviews, and quantitative and qualitative analysis of instrument items; these aligned with psychometric, educational, and survey design principles. The instrument subscales performed adequately on measures of reliability, and validity was supported by an expert panel review.

This instrument is an improvement over the few existing measures of public energy literacy. In particular, previous measures of public energy literacy have neither clearly defined energy literacy nor provided a sound conceptual basis for their measures (i.e., questions and items). In contrast, in the present research, an in-depth systematic literature review of both academic literature and grey literature was conducted and therefore informed a comprehensive approach for arriving at a conceptualization of public energy literacy — a task which has yet to be performed in other research. Materials that were reviewed included theories and frameworks on education and literacy in various areas (e.g., environment, science, technology, sustainability) as well as the initiatives that have been advanced to support higher levels in both of these (i.e., education and literacy). Frameworks, theories, and initiatives were examined for both student and adult populations.

It is likely that student energy literacy and public energy literacy are highly related. That is, both are likely to be influenced by similar phenomena (e.g., being knowledgeable about energy and energy-related issues). However, assessing students and members of the general public on similar energy-related knowledge questions would not be considered valid assessments of energy-related knowledge. This argument also applies to attitudinal and behavioural items. That is, students and adults should not be assessed on their energy-related attitudes and behaviours using similar items. This study thus demonstrated the importance of differentiating between students and adults (i.e., the general public) and used this differentiation for generating questions and items that align with and are suitable for an assessment of public energy literacy.

A major strength of this instrument is that conceptualization of public energy literacy was broad (but not too broad) and therefore the questions and items on this instrument will be able to provide a general assessment of public energy literacy. That is, this instrument is able to provide a broad assessment of energy-related knowledge, attitudes, and behaviours rather than specialize in one specific area of energy literacy (e.g., knowledge of renewable energy). Further, by being 
broad, this instrument can provide a foundation for future energy literacy studies. That is, the questions and items on this instrument can be developed for specific populations or even specific geographic areas (e.g., question on what energy source is dominant for electricity in Ontario can be changed to reflect the fuel mix of a different province).

It seems reasonable to think that one of the reasons a sufficient tool had not been created is that doing so calls forth the dual challenges of a) the academic rigor required to create a robust instrument, and b) the sprawling nature of the concept of energy literacy. Because the tools were lacking, it is not surprising to see that research studies which could be derived from examining public energy literacy, are also lacking. For example, it is difficult to assess changes in energy literacy without a proper instrument. Another example, it is difficult to assess the influence of energy literacy on household energy use if an adequate measure of energy literacy is lacking.

The public energy literacy instrument was developed to contribute to an underrepresented area of study. This instrument demonstrates that it is possible to measure energy literacy as a way of understanding more about the variation in energy-related knowledge, attitudes, and behaviours and therefore fill an important research gap in the Canadian energy context. 


\section{Chapter 5: Energy Literacy and Household Energy Usage}

\subsection{Introduction}

Studies show that providing people with information on different energy sources can affect their levels of support for different sources of energy generation (e.g., Hobman \& Ashworth, 2013). Further, providing feedback on energy use via bills and energy monitors (e.g., smart meters) can reduce household energy use (e.g., Faruqui, Sergici, \& Sharif, 2010; Van Houwelingen \& Van Raaij, 1989; McClelland and Cook, 1979-1980). In recent qualitative research, consumers reported that energy monitors made energy more visible and therefore contributed to their increased awareness and knowledge of energy use (Buchanan, Russo, \& Anderson, 2014).

As previously mentioned, there has been limited research on public energy literacy assessments, such as the examination of energy-related knowledge, attitudes, and behaviourseither individually or together. Further, only a few studies have mapped energy literacy onto actual energy use, likely due to the difficulty of acquiring energy use data. Of the few studies connecting energy literacy with actual energy use, most have focused on energy or environmental attitudes. That is, most have focused on one of the subscales belonging to energy literacy (i.e., attitudes), leaving little to no examination of energy-related knowledge and behaviours. It should be noted, however, that Abrahamse and Steg (2009) examined relationships between attitudes, perceived behavioural control, personal norms, awareness of consequences, ascription of responsibility, and direct and indirect energy use; therefore examining variables relating to the theory of planned behaviour and the norm activation model. With the exception of energy-related attitudes, the variables examined by Abrahamse and Steg (2009) are different than those belonging to energy literacy.

Some studies have reported finding weak or no relationships between attitudes and energy use (e.g., Ritchie, Mcdougall, \& Claxton, 1981). However, several studies have found positive connections between attitudes and energy use. Recently, Sapci and Considine (2014) found that environmental and energy attitudes significantly predicted electricity use among a sample of 612 households. In particular, the researchers used four items to measure environmental and energy attitudes (Sapci \& Considine, 2014). Two items assessed respondent beliefs regarding the relationship between conserving electricity and emissions reductions and the relationship between conserving electricity and preserving the environment (Sapci \& 
Considine, 2014). The other two items assessed respondent beliefs regarding whether or not humans have the right to modify the natural environment and whether or not environmental laws have become too strict (Sapci \& Considine, 2014). In order to examine the relationship between environmental and energy attitudes and household electricity use, the researchers ran four separate linear regressions using each attitudinal item as a unique predictor variable (Sapci \& Considine, 2014). For each regression, attitudes significantly predicted household electricity use, controlling for heating type, size of home (i.e., area), and household income (Sapci \& Considine, 2014). For beliefs that electricity conservation reduces emissions, high scoring respondents, compared to low scoring respondents, were predicted to use less electricity (Sapci \& Considine, 2014). Similarly, for beliefs that electricity conservation preserves the natural environment, high scoring respondents, compared to low scoring respondents, were predicted to use less electricity (Sapci \& Considine, 2014). Respondents with high belief scores on the item measuring whether or not humans have the right to modify their natural environment were predicted to use more electricity than respondents with low scores on this item (Sapci \& Considine, 2014). Similarly, respondents with high belief scores on the item measuring whether or not environmental laws have become strict were predicted to use more electricity than respondents with low scores on this item (Sapci \& Considine, 2014).

Dull and Janky (2011) also found a relationship between environmental attitudes and electricity bills. In particular, the researchers used the New Ecological Paradigm (NEP) scale (i.e., a measure of environmental concern) to predict household electricity bills (Dull \& Janky, 2011). The researchers also examined several other independent variables: demand constraints (e.g., financial problems), employment status, socio-demographics, consumer purchasing decisions (i.e., choice of appliances), and two items measuring energy efficient behaviours (e.g., use of energy efficient light bulbs) (Dull \& Janky, 2011). In their simplest model, the researchers found that environmental attitudes (i.e., NEP scale) significantly predicted four percent of the variance in household electricity bills. The effect of environmental attitudes remained statistically significant even when the researchers controlled for demand constraints, employment status, and socio-demographics. However, after controlling for appliance type and energy efficient behaviours, the effect of environmental attitudes did not remain statistically significant (Dull \& Janky, 2011). 
Two older studies also found a statistically significant relationship between attitudes and household energy use. In particular, in both winter and summer months, attitudes were found to explain 18 percent of the variance in winter natural gas consumption and 60 percent of the variance in summer energy consumption, among 207 households (Becker, Lawrence, Seligman, Fazio, \& Darley, 1981; Seligman, Darley, \& Becker, 1978). It should be noted that the researchers measured attitudes broadly and therefore examined attitudes on comfort, family finances, optimism, the legitimacy of the energy crisis, household savings, an individual's role in energy conservation, and general health (Becker, Lawrence, Seligman, Fazio, \& Darley, 1981; Seligman, Darley, \& Becker, 1978).

It is possible that research on the relationship between public energy literacy and household energy use is lacking because there are so few measures of public energy literacy. The focus of this chapter is to use the measure of public energy literacy that was developed in Chapter 4 to assess the relationship between public energy literacy and household energy use. This chapter first presents an assessment of energy literacy, followed by an analysis of its relationship to household energy use.

\subsection{Methods}

\subsubsection{Participants}

The participants were those sampled for iteration two of the development of the public energy literacy instrument (see Chapter 4, section 4.5.2.1), resulting in a sample size of 204 households. Therefore this research was conducted among a sample of homeowners living in Toronto.

\subsubsection{Measures}

The complete energy literacy questionnaire can be found in Appendix 7. This survey was distributed online, but was converted to a text based version to be included in the Appendices. Therefore, some of the computer coding that was used for skip questions and for the overall online survey can be seen.

\subsubsection{Energy literacy}

Energy literacy was assessed using a public energy literacy instrument; development of this instrument is discussed in Chapter 4. This measure consisted of 15 knowledge items, five 
attitudinal items, and nine behavioural items. Ordinal alpha reliability coefficients of these subscales are $0.64,0.68$, and 0.69 , respectively.

\subsubsection{Environmental concern}

Using the revised 15-item NEP scale, participants were asked about their environmental concern; revisions include a more balanced scale and limited use of outdated terminology (Dunlap, Liere, Mertig, \& Jones, 2000). According to Dunlap et al. (2000), the NEP scale is used as a measure of worldview, environmental attitudes, beliefs, and values. The researchers acknowledge that the scale's use in measuring these various psychological variables "reflect the ambiguity inherent in measuring these phenomena" (Dunlap et al., 2000, p. 427). Further, according to Dunlap et al. (2000), items found on the NEP scale draw on 'primitive beliefs' (author's emphasis) about the "nature of the earth and humanity's relationship with it" (p. 427). It has been theorized that primitive beliefs form the basis of a person's belief system (e.g., Rokeasch, 1968). Further, social psychologists view primitive beliefs as influencing broader beliefs and attitudes relating to environmental issues (Stern, Dietz, \& Guagnano, 1995a). As such, NEP items like "the so called ecological crisis facing humankind has been greatly exaggerated" and "the earth has plenty of natural resources if we just learn how to develop them" examine fundamental beliefs about nature and the relationship humans have with it (Dunlap et al., 2000). In environmental psychology, the NEP is commonly used to measure general environmental concern (Poortinga, Steg, \& Vlek, 2004).

\subsubsection{Household and dwelling characteristics}

Participants answered socio-demographic questions (e.g., level of education, number of household residents, household income) and questions on their dwelling characteristics (e.g., dwelling size, dwelling type, energy source used for heating, energy source used for hot water, energy source used for a cookstove).

\subsubsection{Conservation and efficiency programs}

An index was created to measure knowledge of common conservation and efficiency programs. In particular, on the survey, respondents were asked to indicate their knowledge/awareness of conservation and efficiency programs, with several of these being specific to Toronto. These included: Smartmeter, Peaksaver, PowerShift, Energy Star, Heating and Cooling, and Fridge and 
Freezer Pickup programs. The index was created by summing the number of programs participants were aware of.

\subsubsection{Major renovations}

Another index was created to reflect household conservation and efficiency behaviours. Major renovations consisted of insulating an attic, insulating walls, upgrading windows, and upgrading appliances. The index was created by summing the number of major renovations participants had performed over the past several years. No weighting was applied; that is, each major renovation behaviour received a score of one. Although, these renovations were not performed at the same time as performance on the energy literacy questionnaire they are being considered here because major renovations are behaviours that are not performed regularly and can provide a crude assessment of a household's interest in performing renovation behaviours.

\subsubsection{Electricity}

During recruitment participants were asked to release their electricity consumption records if they purchased electricity from Toronto Hydro-Electric System Limited. Consenting participants provided their account numbers and account holder names and data were obtained for these individuals for the period covering May 1, 2012 to May 1, 2015. Toronto Hydro provided data

per billing period, thus electricity use was calculated by pro-rating electricity use. Specifically, three measures of electricity use were obtained by summing household electricity use across twelve months for each year of analysis and dividing this sum by the number of billing days in that period. For each household, the summed values were then multiplied by 365 to find average electricity use per year.

\subsubsection{Natural gas}

During recruitment participants were also asked to release their natural gas consumption records through Enbridge Gas Distribution. For consenting participants, natural gas use, measured in cubic meters, was obtained for each month covering the period from May 1, 2012 to May 1, 2015. Three measures of natural gas consumption were obtained by summing gas consumption across twelve months for each year of analysis. Data was originally provided in cubic meters but was converted to gigajoules ${ }^{6}$.

\footnotetext{
${ }^{6} 1$ cubic meter $=0.038$ gigajoules.
} 


\subsection{Analysis and Results}

\subsubsection{Energy Literacy}

Energy literacy was assessed by examining performance on each instrument subscale (i.e., knowledge, attitudes, behaviours) as well as on the measure of environmental concern (i.e., NEP scale). Similar to previous studies on energy literacy (Comeau et al., 2015; Southwell et al., 2012), the relationship between energy literacy and socio-demographic variables (i.e., gender, age, and level of education) were examined. The relationship between socio-demographic variables and environmental concern was also examined. Further, the relationships between the energy literacy subscales, environmental concern, knowledge of energy conservation programs, and performance of major and minor behaviours were examined. Thus the following research questions were addressed:

1. How well do Toronto homeowners fare on an assessment of energy literacy? What do Toronto homeowners know about energy and energy-related issues? What are the energy attitudes of Toronto homeowners? Are Toronto homeowners environmentally concerned? What energy-saving behaviours are Toronto homeowners performing?

2. What household characteristics (i.e., socio-demographic variables) are associated with higher levels of energy-related knowledge, more positive attitudes, higher levels of environmental concern, and performance of self-reported energy conserving behaviours?

3. Is there a relationship between the different subscales of the energy literacy instrument? In what way are the different subscales of the energy literacy instrument related with environmental concern? In what way is energy literacy and environmental concern related to knowledge of energy conservation programs, performance of major repairs, and performance of minor repairs?

Performance on the 15-item knowledge subscale reflect a satisfactory understanding of energy and energy-related issues. Scores ranged from 3 correct to 15 correct with the median score being $10(M=9.85, S D=2.46)$, meaning half of respondents scored less than 66 percent on the questions. As shown in Table 5.1, performance on the individual knowledge items ranged considerably. A high of 85 percent correctly identified that electricity pricing is determined at the provincial level whereas a low of 37 percent correctly identified the "pipeline company" as the 
body responsible for negotiating the rights to use a landowner's property for oil or gas development. Findings that are concerning include only 64 percent of respondents correctly calculating electricity use. This implies that some households may be unsure of how they are getting billed for their electricity use. Also concerning is the number of respondents (63\%) who did not know that space heating uses the most energy in Canadian homes, especially given our cold climate. Another concern, only 58 percent of respondents were able to correctly identify "nuclear" as Ontario's main source of energy for generating electricity. A means comparison found that women $(\bar{x}=9.25)$ were less successful than men $(\bar{x}=10.37)$ on the knowledge subscale.

On the 25-point attitude subscale, scores ranged from 13 to 25 , with a mean of 21.59 ( $S D$ $=2.18$ ). Therefore many participants demonstrated having positive attitudes towards energy and energy-related issues. Interestingly, as shown in Table 5.2, the most popular endorsed items included, "causes of global warming include human activities like burning fossil fuels" and "energy education should be included in every school's curriculum". The least endorsed item was "I am reluctant to conserve material goods and services when it affects my daily life".

On the 75-point NEP scale, scores could range from 15 (low environmental concern) to 75 (high environmental concern); participant scores ranged from 30 to 74 . In order to distinguish between respondents with low environmental concern and respondents with high environmental concern, the median-split procedure was used (median = 59) (Poortinga, Steg, Vlek, \& Wiersman, 2003). Respondents with low environmental concern had scores of 59 or less and respondents with high environmental concern had scores higher than 59. A noteworthy finding for this subscale includes that 75 percent of respondents strongly agreed that causes of global warming include human activities like burning fossil fuels, leaving 25 percent of respondents who are not absolutely sure about anthropocentric climate change. It is worth considering that fewer people are sure about global warming than about climate change, however, during the cognitive interviews (discussed in the previous chapter), participants were asked about this. Most people were able to differentiate between global warming and climate change but given the small number of interviews that were conducted, it may be worth revisiting this issue. Also noteworthy is that the majority of respondents agreed or strongly agreed with the statement, "individuals are just as responsible as governments and organizations for protecting and maintaining the 
environment", indicating that individuals may be taking onus for environmental issues. The NEP scores are shown in Table 5.3.

Table 5.1 Performance on individual knowledge items $(N=204)$

\begin{tabular}{|c|c|c|}
\hline Knowledge item & Correct answer & $\begin{array}{c}\text { \% respondents } \\
\text { answering } \\
\text { correctly }\end{array}$ \\
\hline $\begin{array}{l}\text { In Canada, the price of electricity is determined at } \\
\text { which jurisdictional level? }\end{array}$ & Provincial & 85 \\
\hline $\begin{array}{l}\text { Which product is NOT made from petrochemicals } \\
\text { derived from oil or natural gas? }\end{array}$ & Baking soda & 73 \\
\hline $\begin{array}{l}\text { During winter, electricity is most expensive for } \\
\text { Toronto households when ... }\end{array}$ & $\begin{array}{l}\text { People are getting up } \\
\text { and getting ready... }\end{array}$ & 72 \\
\hline $\begin{array}{l}\text { The best way to limit standby power or "phantom } \\
\text { loads" is to... }\end{array}$ & $\begin{array}{l}\text { Use power bars with } \\
\text { on/off switches }\end{array}$ & 71 \\
\hline $\begin{array}{l}\text { In which province would driving an electric car } \\
\text { result in the fewest greenhouse gas emissions? }\end{array}$ & Ontario & 71 \\
\hline $\begin{array}{l}\text { Which of the following statements best describes the } \\
\text { relationship between Canada's energy imports... }\end{array}$ & $\begin{array}{l}\text { Canada exports more } \\
\text { than it imports }\end{array}$ & 70 \\
\hline $\begin{array}{l}\text { Who is the primary regulatory body responsible for } \\
\text { the oil sands? }\end{array}$ & Alberta Government & 67 \\
\hline $\begin{array}{l}\text { If you use a 1-kilowatt }(\mathrm{kW}) \text { electric heater for two } \\
\text { hours, how much electricity will it use? }\end{array}$ & $\begin{array}{l}2 \text { Kilowatt-hours } \\
(\mathrm{kWh})\end{array}$ & 64 \\
\hline $\begin{array}{l}\text { Which uses the MOST ENERGY in the average } \\
\text { Canadian home each year? }\end{array}$ & Space heating & 63 \\
\hline $\begin{array}{l}\text { When you turn on a light bulb in your house, the } \\
\text { electricity it uses was produced how long ago? }\end{array}$ & $\begin{array}{l}\text { The electricity was } \\
\text { produced seconds ago }\end{array}$ & 58 \\
\hline $\begin{array}{l}\text { Ontario gets the majority of its electricity from } \\
\text { which energy source? }\end{array}$ & Nuclear & 58 \\
\hline $\begin{array}{l}\text { In } 2014 \text {, which jurisdiction in North America } \\
\text { became the first to completely eliminate coal... }\end{array}$ & Ontario & 57 \\
\hline $\begin{array}{l}\text { In Canada, which of the following methods for } \\
\text { shipping crude oil is becoming MORE popular? }\end{array}$ & Rail & 57 \\
\hline $\begin{array}{l}\text { In Canada, whose responsibility is it to negotiate the } \\
\text { right to use a landowner's property for oil and... }\end{array}$ & $\begin{array}{l}\text { The pipeline } \\
\text { company }\end{array}$ & 37 \\
\hline
\end{tabular}


Table 5.2 Frequency distributions (in percentages) for energy attitudinal items $(N=204)$

\begin{tabular}{lccccc}
\hline \multicolumn{1}{c}{ Item } & SA $^{\text {a }}$ & A & U & D & SD \\
\hline Causes of global warming include... & 75 & 22 & 2 & 1 & 1 \\
$\begin{array}{l}\text { Energy education should be included in every } \\
\text { school's curriculum }\end{array}$ & 62 & 33 & 3 & 2 & 0 \\
$\begin{array}{l}\text { Individuals are just as responsible as governments } \\
\text { and businesses for protecting ... }\end{array}$ & 57 & 35 & 1 & 6 & 2 \\
$\begin{array}{l}\text { I would do more to save energy if I knew how } \\
\text { I am reluctant to conserve material goods and }\end{array}$ & 31 & 49 & 9 & 9 & 2 \\
service when it affects my daily life ................ R
\end{tabular}

${ }^{\mathrm{a}} \mathrm{SA}=$ Strongly Agree, $\mathrm{A}=$ Agree, $\mathrm{U}=$ Unsure, $\mathrm{D}=$ Disagree, and SD = Strongly Disagree.

Note. Row percentages may not sum to 100 due to rounding.

Table 5.3 Frequency distributions (in percentages) for NEP items $(N=204)$

\begin{tabular}{|c|c|c|c|c|c|}
\hline Item & $\mathrm{SA}^{\mathrm{a}}$ & MA & $\mathrm{U}$ & MD & SD \\
\hline $\begin{array}{l}\text { Despite our special abilities, humans are still subject to the laws of } \\
\text { nature }\end{array}$ & 78 & 19 & 2 & 1 & 1 \\
\hline Humans are seriously abusing the environment & 66 & 22 & 2 & 4 & 6 \\
\hline Plants and animals have as much right as humans to exist & 59 & 27 & 2 & 7 & 5 \\
\hline $\begin{array}{l}\text { The so called ecological crisis facing humankind has been greatly } \\
\text { exaggerated } \ldots \ldots \ldots \ldots \ldots \ldots \ldots \ldots \ldots \ldots \ldots . . .\end{array}$ & 4 & 8 & 6 & 20 & 62 \\
\hline Humans were meant to rule over the rest of nature.....R & 3 & 9 & 7 & 23 & 56 \\
\hline $\begin{array}{l}\text { If things continue on their present course, we will soon experience a } \\
\text { major ecological catastrophe }\end{array}$ & 47 & 34 & 6 & 8 & 5 \\
\hline $\begin{array}{l}\text { The balance of nature is strong enough to cope with impacts of } \\
\text { modern industrial notions......................R }\end{array}$ & 1 & 9 & 8 & 39 & 43 \\
\hline $\begin{array}{l}\text { When human interfere with nature it often produces disastrous } \\
\text { consequences }\end{array}$ & 47 & 28 & 5 & 13 & 6 \\
\hline The balance of nature is very delicate and easily upset & 38 & 39 & 5 & 17 & 2 \\
\hline $\begin{array}{l}\text { Humans will eventually learn enough about how nature works to be } \\
\text { able to control it......................... R }\end{array}$ & 3 & 13 & 19 & 34 & 31 \\
\hline The Earth is like a space ship with very limited room and resources. & 36 & 32 & 6 & 20 & 6 \\
\hline $\begin{array}{l}\text { We are approaching the limit of the number of the people the Earth } \\
\text { can ... }\end{array}$ & 27 & 38 & 8 & 20 & 9 \\
\hline 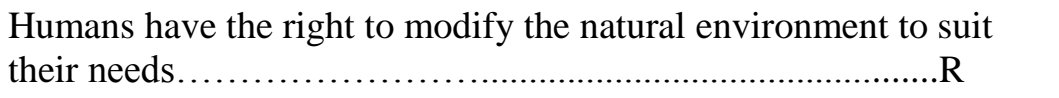 & 5 & 33 & 4 & 36 & 23 \\
\hline $\begin{array}{l}\text { Human ingenuity will ensure that we do not make the Earth } \\
\text { unlivable...................................... }\end{array}$ & 10 & 31 & 18 & 26 & 14 \\
\hline $\begin{array}{l}\text { The earth has plenty of natural resources if we just learn how to } \\
\text { develop them................................... }\end{array}$ & 23 & 38 & 10 & 19 & 14 \\
\hline
\end{tabular}

${ }^{\mathrm{a}} \mathrm{SA}=$ Strongly Agree, MA = Mildly Agree, U = Unsure, MD = Mildly Disagree, and SD = Strongly

Disagree. Note. Row percentages may not sum to 100 due to rounding.

${ }^{7}$ Items marked with a R were reverse coded prior to analysis. 
Participant scores on self-reported energy saving behaviours ranged from 17 to 44 ( $M=$ $36.43, S D=4.33$ ); scores could range from 9 (low self-reported behaviours) to 45 (high selfreported behaviours). Many people reported "always" engaging in most of the behaviours on the behavioural subscale (with the exception of using a clothesline) and there is a possibility that these high scores reflect, at least in part, a social desirability bias. That is, it is possible that respondents reported performing a lot of the conservation and efficiency behaviours "always" because they thought it would be the most "appropriate" answer. Respondent scores on the behavioural subscale are shown in Table 5.4.

Table 5.4 Frequency distributions (in percentages) of behavioural items $(N=204)$

\begin{tabular}{lccccc}
\hline \multicolumn{1}{c}{ Item } & $\mathrm{A}^{\mathrm{a}}$ & $\mathrm{O}$ & $\mathrm{S}$ & $\mathrm{R}$ & $\mathrm{N}$ \\
\hline Use a clothesline or drying rack to dry clothing & 13 & 36 & 23 & 16 & 13 \\
$\begin{array}{l}\text { Put on more clothes such as a sweater, instead } \\
\text { of raising the temperature }\end{array}$ & 42 & 46 & 8 & 3 & 1 \\
Use cold water wash or rinse settings & 53 & 28 & 10 & 7 & 3 \\
Use energy efficient lighting & 34 & 45 & 15 & 5 & 2 \\
Maintain correct tire pressure & 38 & 41 & 17 & 3 & 0 \\
Carpool or use public transportation & 14 & 57 & 20 & 6 & 2 \\
Walk or bike short distances & 38 & 53 & 8 & 2 & 0 \\
Turn the heat down at night & 73 & 10 & 5 & 6 & 6 \\
Use AC sparingly & 48 & 30 & 15 & 5 & 2 \\
\hline
\end{tabular}

${ }^{\mathrm{a}} \mathrm{A}=$ Always, $\mathrm{O}=$ Often, $\mathrm{S}=$ Sometimes, $\mathrm{R}=$ Rarely and $\mathrm{N}=$ Never.

Note. Row percentages may not sum to 100 due to rounding.

Participants were also asked to indicate their knowledge of six Toronto energy conservation and efficiency programs. Scores on the index ranged from 0 to 6 and, on average, participants were familiar with four of the programs. Participant scores on the other indicator of energy efficiency behaviour (i.e., the major renovation index) demonstrated that, on average, participants had performed two major renovations (out of a possible number of four).

In order to better gauge the relationship between the energy literacy subscales (i.e., energy-related knowledge, attitudes, and behaviours), environmental concern, knowledge of conservation programs, and performance of major renovations, correlational analyses were performed. As shown in Table 5.5, knowledge was positively correlated with the conservation ( $r$ $=.17)$ and the major renovation $(r=.20)$ index. Therefore, higher scores on the knowledge 
subscale were associated with higher scores on the conservation index. Also, higher scores on the knowledge subscale were associated with performing behaviours such as insulating an attic, insulating walls, upgrading windows, and upgrading appliances. Similarly, higher levels of knowledge on the conservation index were associated with higher scores on major renovation $(r$ $=.23)$ index.

The attitude subscale was positively correlated with the behaviour subscale $(r=.32)$ and the NEP scale $(r=.47)$. Therefore, people with positive energy-related attitudes were associated with being more environmentally concerned and also performing more energy saving behaviours.

Table 5.5 Pearson correlations between energy literacy, conservation knowledge, and renovation behaviour $(N=202)$

\begin{tabular}{lcccccc}
\hline \multicolumn{1}{c}{ Measure } & 1 & 2 & 3 & 4 & 5 & 6 \\
\hline 1. Knowledge scale & - & & & & & \\
2. Attitude scale & -.05 & - & & & & \\
3. Behaviour scale & -.01 & $.32^{* *}$ & - & & & \\
4. NEP scale & -.04 & $.47^{* *}$ & $.30^{* *}$ & - & & \\
5. Conservation index & $.17 *$ & .03 & .11 & -.04 & - & \\
6. Major renovation index & $.20^{*}$ & -.04 & -.10 & .02 & $.23^{* *}$ & - \\
\hline
\end{tabular}

Note. Significance tests are not possible to interpret because a non-probability sample was used. $* p<.05, * * p<.001$.

\subsubsection{Energy Literacy and Household Energy Use}

The next section is concerned with examining the relationship between energy literacy and household energy use. In particular, research questions that motivated the analysis were:

1. What effect do energy literacy variables have on electricity and natural gas use?

2. What variables have the largest effect on electricity and gas use?

Electricity and natural gas data were unavailable for the full sample completing the energy literacy questionnaire. That is, not all survey respondents consented to releasing their data. Further, for natural gas use, a few households were missing natural gas data on some months. 
Households missing data on four or more months were left as missing. For households having three or less months missing $(n=5)$, monthly natural gas means were imputed. Further the sample was limited to participants who did not use an electric furnace: respondents who indicated using an electric furnace $(n=6)$ or not knowing the energy source of their furnace $(n=$ $5)$, were left out of the analysis. This decision was based on the sample comprising very few households that used electricity for heating. These households did not represent a large enough group to allow comparison of households using electricity for heating to households using natural gas for heating and their inclusion could have biased the results. The unit of analysis is the household, given that data were obtained at the household level; a member of the household who was considered to be the household representative completed the energy literacy questionnaire; this approach has been used in other research on household energy use (e.g., Sapci \& Considine, 2014).

As previously mentioned, measures of electricity and natural gas use were calculated for three time periods. As shown in Tables 5.6 and 5.7, electricity and natural gas use were highly correlated among all three years. For this analysis, the measures of electricity and natural gas use were based on year three data, i.e., data collected between March 2014 and April 2015 and representing the most recent dataset. Between March 2014 and April 2015 households in this sample used, on average, $7939.24 \mathrm{kWh}(S D=3857.54)$ of electricity and $112.83 \mathrm{GJ}$ ( $S D=$ 41.11) of natural gas.

Table 5.6 Pearson correlations between natural gas use

\begin{tabular}{lcc}
\hline \multicolumn{1}{c}{ Measure } & 1 & 2 \\
\hline 1. Gas year 1 & - & \\
2. Gas year 2 & .97 & - \\
3. Gas year 3 & .96 & .99 \\
\hline
\end{tabular}

Table 5.7 Pearson correlations between electricity use

\begin{tabular}{ccc}
\hline Measure & 1 & 2 \\
\hline 1. Electricity year 1 & - & \\
2. Electricity year 2 & .96 & - \\
3. Electricity year 3 & .94 & .96 \\
\hline
\end{tabular}


Several independent variables were included in the analysis. In particular, these were the various subscales belonging to energy literacy: knowledge, behaviour, as well as environmental concern; the attitudes subscale was removed due to multicollinearity issues. Knowledge, behaviours, and environmental concern were re-scaled in order to more easily interpret their effect on the dependent variables. All the scales were re-scaled from their original scale ranges to new scales ranging from 1 to 10 .

Dwelling characteristics and household characteristics were also included in the analysis based on previous research (e.g., Abrahamse \& Steg, 2009; Brounen et al., 2013; Steemers \& Yun, 2009) and the findings reported in Chapter 3. The following dwelling characteristics were included in the electricity and natural gas models: heated floor area, the energy source used for a cookstove, the energy source used for hot water, whether or not households used air conditioning, use of energy efficient appliances, dwelling type (i.e., detached versus not detached), and vintage (i.e., year dwelling was built). The following household characteristics were included in the analysis: household income and number of residents. Household income was re-scaled to interpret its effect in tens of thousands of dollars. With smaller data sets it is important to consider sample size when running a regression. According to Tabachnick and Fidell (2013), ideal sizes are $N \geq 104$ + number of predictors, for testing individual predictors, and $N \geq 50+8$ multiplied by the number of predictors, for testing variance. For these regression models the ideal number of predictors in somewhere in the 9 to 10 range. Table 5.8 provides the measurement of all model variables.

All analyses were carried out using SPSS version 21. To examine the effect of the independent variables on the continuous measures of energy use, ordinary least squares regressions were used. Block loading was used to examine the effects of dwelling and household characteristics. Since the distribution of electricity use was highly skewed, it was transformed by taking the natural log of electricity use. As such, explanation of the dependent variable is based on percentage change. An increase of one unit in a continuous independent variable would result in $\left(e^{\beta}-1\right) * 100$ percentage change in Y (Cornell Statistical Consulting, 2012). Multicollinearity was assessed by examining variance inflation factors (VIFs) as well as tolerance, with the NEP and the attitudes scale having high and low values on these, respectively. Outliers were examined by looking at Cook's and Mahalanobis distances and three cases were removed based on exceeding a critical $X^{2}$ value of for $29.59, p<.001$. Missing data were also examined. With the 
exception of household income, the variables in the model have less than $5 \%$ of cases missing for an unknown reason, and therefore were not significant concerns. Tables 5.9 and 5.10 provide the descriptive statistics of the model variables.

Table 5.8 List of variables and measurement

\begin{tabular}{|c|c|}
\hline Variables & Measurement \\
\hline Electricity use year $3(\ln )$ & Scale variable \\
\hline Natural gas use year 3 & Scale variable \\
\hline Knowledge scale & $\begin{array}{l}\text { Scale constructed based on knowledge items ranging from } 0 \text { to } \\
15 \text { (low scores }=\text { low knowledge). Re-scaled }(1-10) . \text { Scale } \alpha= \\
0.64\end{array}$ \\
\hline Attitudes scale & $\begin{array}{l}\text { Scale constructed based on attitudinal items ranging from } 5 \text { to } \\
25 \text { (high scores = positive energy attitudes). Re-scaled (1-10). } \\
\text { Scale } \alpha=0.68\end{array}$ \\
\hline $\begin{array}{l}\text { Environmental concern (NEP) } \\
\text { scale }\end{array}$ & $\begin{array}{l}\text { Scale ranging from } 15 \text { to } 75 \text { (high scores = environmental } \\
\text { concern). Re-scaled (1-10). Scale } \alpha=0.82\end{array}$ \\
\hline Behaviour scale & $\begin{aligned} \text { Scale ranging from } 9 \text { to } 45 \text { (high scores } & =\text { pro-environmental } \\
\text { behaviour). Re-scaled (1-10). Scale } \alpha & =0.69\end{aligned}$ \\
\hline Heated floor area & $\begin{array}{l}\left.\text { Dummy variables: Less than } 140 \mathrm{~m}^{2} \text { (reference) }\right)^{8} / 141 \text { to } 185 \\
\mathrm{~m}^{2} / 186 \text { to } 230 \mathrm{~m}^{2} / \text { more than } 231 \mathrm{~m}^{2}\end{array}$ \\
\hline Cookstove energy source & Dichotomous variable: $1=$ electricity $/ 0=$ natural gas \\
\hline Hot water energy source & Dichotomous variable: $1=$ electricity $/ 0=$ natural gas \\
\hline Air conditioning & Dichotomous variable: $1=$ yes $/ 0=$ no \\
\hline Efficient appliance (s) & Dichotomous variable: $1=$ yes $/ 0=$ no \\
\hline Detached & Dichotomous variable: $1=$ yes $/ 0=$ no \\
\hline Vintage & $\begin{array}{l}\text { Dummy variables: Before 1900/1900-1909/1910-1919/1920- } \\
\text { 1929/1930 or later (reference) }\end{array}$ \\
\hline Household income & Interval proximate \\
\hline Number of residents & Scale variable \\
\hline
\end{tabular}

\footnotetext{
${ }^{8}$ Categories are based on measurement of heated floor area in Statistics Canada surveys.
} 
Table 5.9 Descriptive statistics of all electricity model variables

\begin{tabular}{|c|c|c|c|}
\hline Variable & Categories & Percentage/M (SD) ${ }^{\mathrm{a}}$ & $\begin{array}{c}\text { Valid } \\
\text { Responses }\end{array}$ \\
\hline Ln electricity year3 & Scale & $8.88(0.49)$ & 134 \\
\hline Knowledge scale & (scale from $1-10$ ) & $10.05(2.31)$ & 134 \\
\hline NEP scale & (scale from $1-10)$ & $58.63(8.68)$ & 134 \\
\hline Behaviour scale & (scale from $1-10$ ) & $36.90(3.97)$ & 134 \\
\hline \multirow[t]{4}{*}{ Heated floor area } & Less than $140 \mathrm{~m}^{2}$ & $21.5 \%$ & 130 \\
\hline & 141 to $185 \mathrm{~m}^{2}$ & $31.5 \%$ & \\
\hline & 186 to $230 \mathrm{~m}^{2}$ & $23.1 \%$ & \\
\hline & More than $231 \mathrm{~m}^{2}$ & $23.8 \%$ & \\
\hline \multirow[t]{2}{*}{ Cookstove energy source } & Electricity & $35.1 \%$ & 131 \\
\hline & Natural gas & $64.9 \%$ & \\
\hline \multirow[t]{2}{*}{ Hot water energy source } & Electricity & $11.0 \%$ & 127 \\
\hline & Natural gas & $89.0 \%$ & \\
\hline \multirow[t]{2}{*}{ Air conditioning } & Yes & $87.3 \%$ & 134 \\
\hline & No & $12.7 \%$ & \\
\hline \multirow[t]{2}{*}{ Efficient appliances } & Yes & $73.4 \%$ & 123 \\
\hline & No & $25.8 \%$ & \\
\hline Household income & Scale & $\$ 141,803(56,671)$ & 122 \\
\hline Number of residents & Scale & $2.78(1.06)$ & 127 \\
\hline
\end{tabular}

Table 5.10 Descriptive statistics of all natural gas model variables

\begin{tabular}{|c|c|c|c|}
\hline Variable & Categories & Percentage/M (SD) $^{\mathrm{a}}$ & $\begin{array}{c}\text { Valid } \\
\text { Responses }\end{array}$ \\
\hline Gas (GJ) year 3 & Scale & 112.83(41.11) & 128 \\
\hline Knowledge scale & (scale from $1-10$ ) & $10.06(2.40)$ & 128 \\
\hline NEP scale & (scale from $1-10$ ) & $57.92(8.96)$ & 128 \\
\hline Behaviour scale & (scale from $1-10$ ) & $36.61(4.32)$ & 128 \\
\hline \multirow[t]{2}{*}{ Detached } & Yes & $52.3 \%$ & 128 \\
\hline & No & $47.7 \%$ & \\
\hline \multirow[t]{4}{*}{ Heated floor area } & Less than $140 \mathrm{~m}^{2}$ & $23.4 \%$ & 124 \\
\hline & 141 to $185 \mathrm{~m}^{2}$ & $31.5 \%$ & \\
\hline & 186 to $230 \mathrm{~m}^{2}$ & $22.6 \%$ & \\
\hline & More than $231 \mathrm{~m}^{2}$ & $22.6 \%$ & \\
\hline \multirow[t]{5}{*}{ Vintage } & Before 1900 & $8.6 \%$ & 128 \\
\hline & 1900-1909 & $21.9 \%$ & \\
\hline & 1910-1919 & $28.9 \%$ & \\
\hline & $1920-1929$ & $14.8 \%$ & \\
\hline & 1930 or later & $25.8 \%$ & \\
\hline \multirow[t]{2}{*}{ Cookstove energy source } & Electricity & $36.8 \%$ & 125 \\
\hline & Natural gas & $63.2 \%$ & \\
\hline \multirow[t]{2}{*}{ Hot water energy source } & Electricity & $10.7 \%$ & 121 \\
\hline & Natural gas & $89.3 \%$ & \\
\hline Household Income & Scale & $\$ 141,315(57,941)$ & 115 \\
\hline Number of residents & Scale & $2.79(1.07)$ & 121 \\
\hline
\end{tabular}


Table 5.11 Linear regression predicting household electricity use $(n=102)$

\begin{tabular}{|c|c|c|c|c|c|c|c|c|c|}
\hline & \multicolumn{3}{|c|}{ Model 1} & \multicolumn{3}{|c|}{ Model 2} & \multicolumn{3}{|c|}{ Model 3} \\
\hline & $\beta$ & $S E$ & beta & $\beta$ & $S E$ & beta & $\beta$ & $S E$ & beta \\
\hline Knowledge scale & 0.01 & 0.03 & & 0.02 & 0.03 & & 0.00 & 0.03 & \\
\hline NEP scale & -0.07 & 0.04 & -0.16 & -0.02 & 0.04 & & -0.02 & 0.04 & \\
\hline Behaviour scale & -0.15 & 0.06 & -0.28 & -0.16 & 0.05 & -0.29 & -0.13 & 0.05 & -0.24 \\
\hline \multicolumn{10}{|l|}{ Heated Floor area ${ }^{a}$} \\
\hline 141 to $185 \mathrm{~m}^{2}$ & & & & 0.29 & 0.12 & 0.27 & 0.25 & 0.11 & 0.23 \\
\hline 186 to $230 \mathrm{~m}^{2}$ & & & & 0.44 & 0.13 & 0.38 & 0.38 & 0.12 & 0.34 \\
\hline More than $231 \mathrm{~m}^{2}$ & & & & 0.39 & 0.12 & 0.34 & 0.38 & 0.12 & 0.33 \\
\hline Cookstove & & & & 0.08 & 0.09 & & 0.12 & 0.09 & \\
\hline Hot water & & & & 0.45 & 0.13 & 0.29 & 0.49 & 0.13 & 0.32 \\
\hline Air conditioning & & & & 0.38 & 0.13 & 0.25 & 0.33 & 0.13 & 0.21 \\
\hline Efficient appliances & & & & 0.13 & 0.09 & & 0.12 & 0.09 & \\
\hline $\begin{array}{l}\text { Household income } \\
\text { (tens of thousands) }\end{array}$ & & & & & & & 0.01 & 0.01 & \\
\hline Number of residents & & & & & & & 0.12 & 0.04 & 0.25 \\
\hline Constant & & 10.56 & & & 9.45 & & & 8.89 & \\
\hline Adjusted $\mathrm{R}^{2}$ & & 0.109 & & & 0.316 & & & 0.386 & \\
\hline
\end{tabular}

${ }^{a}$ Reference group $=$ Less than $140 \mathrm{~m}^{2}$.

Table 5.11 present the results of the linear regression predicting household electricity use. With the first model, the effects of energy literacy and environmental concern were examined. Together, energy-related knowledge, environmental concern and self-reported behaviours explain $10.9 \%$ of the variance in electricity use. In particular, for each point increase on the NEP scale, electricity use decreases by $7 \%$, controlling for knowledge and behaviours.

For each point increase on the behaviour scale, electricity use decreases by $15 \%$, controlling for knowledge and environmental concern. With the second model, dwelling characteristics were added to the model and these increase the variance explained in household electricity use (Adj. $\mathrm{R}^{2}=31.6 \%$ ). In this model, increasing household area is associated with using more electricity and supports findings from Chapter 3. Interestingly, households using an electric cookstove do not use more electricity than households using a natural gas cookstove. It is possible that using electric cookstoves do not greatly contribute to household electricity use. However, it would be best to control for how often cookstove appliances are used; potentially households in this sample eat a lot of their meals outside of home. Households using electric domestic hot water use more electricity than households using natural gas for domestic hot water. These results show that behaviours associated with domestic hot water (i.e., bathing, showering) are important and stable (compared to using a cookstove, for example). That is, behaviours associated with 
domestic hot water use such as bathing and showering are performed reliably compared to, potentially, cooking types of behaviours. As expected, households who used air conditioning used more electricity than households who did not use air conditioning. In the final model household income and number of residents were added. In particular, each additional household member increases electricity use by $12 \%$, controlling for all other model variables and is very similar to the findings from Chapter 3 wherein each additional household member increased electricity use by $13 \%$, controlling for all other model variables. The final model accounts for $38.6 \%$ of the variance in household electricity use, in this sample.

Table 5.12 Linear regression predicting household natural gas use $(n=95)$

\begin{tabular}{|c|c|c|c|c|c|c|c|c|c|}
\hline & \multicolumn{3}{|c|}{ Model 1} & \multicolumn{3}{|c|}{ Model 2} & \multicolumn{3}{|c|}{ Model 3} \\
\hline & $\beta$ & $S E$ & beta & $\beta$ & $S E$ & beta & $\beta$ & $S E$ & beta \\
\hline Knowledge scale & 1.47 & 2.63 & & -1.04 & 2.24 & & -.714 & 1.45 & \\
\hline NEP scale & -3.02 & 3.73 & & -1.28 & 3.38 & & 0.77 & 0.45 & \\
\hline Behaviour scale & -5.02 & 4.81 & & -6.99 & 4.09 & & -7.65 & 0.88 & -0.18 \\
\hline Detached & & & & 16.07 & 7.86 & 0.19 & 17.99 & 7.60 & 0.22 \\
\hline \multicolumn{10}{|l|}{ Heated Floor area ${ }^{a}$} \\
\hline 141 to $185 \mathrm{~m}^{2}$ & & & & 35.20 & 10.10 & 0.39 & 33.33 & 9.96 & 0.37 \\
\hline 186 to $230 \mathrm{~m}^{2}$ & & & & 44.27 & 11.32 & 0.46 & 40.08 & 11.20 & 0.42 \\
\hline More than $231 \mathrm{~m}^{2}$ & & & & 66.03 & 11.11 & 0.67 & 58.43 & 11.03 & 0.59 \\
\hline \multicolumn{10}{|l|}{ Vintage $^{b}$} \\
\hline Before 1900 & & & & 24.05 & 13.64 & & 22.62 & 13.21 & \\
\hline 1900-1909 & & & & 32.95 & 10.72 & 0.33 & 35.28 & 10.51 & 0.35 \\
\hline $1910-1919$ & & & & 18.03 & 10.40 & & 15.27 & 10.14 & \\
\hline 1920-1929 & & & & 21.74 & 12.72 & & 26.13 & 12.35 & 0.22 \\
\hline Cookstove & & & & -2.05 & 8.44 & & -1.21 & 8.12 & \\
\hline Hot water & & & & -7.73 & 12.21 & & -9.38 & 11.75 & \\
\hline $\begin{array}{l}\text { Household income } \\
\text { (tens of thousands) }\end{array}$ & & & & & & & 1.74 & 0.70 & 0.24 \\
\hline Number of residents & & & & & & & -7.87 & 3.46 & -0.21 \\
\hline Constant & & 69.37 & & & 28.11 & & & 115.06 & \\
\hline Adjusted $\mathrm{R}^{2}$ & & .004 & & & .329 & & & 0.381 & \\
\hline
\end{tabular}

${ }^{\mathrm{a}}$ Reference group $=$ Less than $140 \mathrm{~m}^{2}$.

${ }^{\mathrm{b}}$ Reference group $=1930$ or later.

Table 5.12 presents the results of the linear regression predicting household natural gas use. It is immediately apparent that energy literacy and environmental concern do not predict a large amount of the variance in natural gas use. As expected, the proportion of variance in the dependent variable that is explained increases with the addition of dwelling characteristics (i.e., Adj. $\mathrm{R}^{2}$ increases from .004 to .329$)$. The proportion of variance explained increases with the 
addition of household income and number of residents variables (i.e., household characteristics). In particular, with every $\$ 10,000$ increase in household income, yearly natural gas use increases by $1.74 \mathrm{GJ}$, controlling for the number of residents, dwelling characteristics, and energy literacy and is similar to findings in Chapter 3 (though not as nuanced). Interestingly, when controlling for household income and the number of residents in a household, performing self-reported behaviours is associated with decreased natural gas use. For the full model, examination of the standardized beta coefficients confirms the importance of area on natural gas use (betas range from .37 to .59$)$.

\subsection{Discussion}

The results show that respondents in this sample performed generally well on the various measures of energy literacy. Respondents answered a fair amount of questions correctly on the knowledge subscale, demonstrated positive energy-related attitudes, demonstrated environmental concern, and performed many of the behaviours on the behavioural subscale. It is important to note that these results may reflect self-selection bias. Particularly, those individuals who have more energy-related knowledge, more pro-environmental attitudes, higher levels of environmental concern, and perform more energy saving behaviours may have participated in this study.

On average, the participants in this study answered 66 percent of questions correctly. The National Environmental Education and Training Foundation (2002), for example, found that only 12 percent of Americans were able to pass a basic energy quiz. On the Energy Behavior, Knowledge, and Opinions Survey, Southwell et al. (2012) found that respondents answered less than 60 percent of knowledge items correctly. Results of the 2010 RBC Energy Literacy Quiz, completed by 2871 individuals, revealed that, on average, people answered 3.5 out of 9 questions correctly (Pollution Probe, personal communication, October 11, 2011). More recently, Comeau et al. (2015) found both perceived and actual levels of energy-related knowledge to be low. In particular, respondents were asked to answer four questions with one of these asking participants to estimate the percentage of hydro-electricity they believed contributed to their provincial electricity supply (Comeau et al., 2015). They found that over 40 percent of respondents answered correctly in Alberta, Prince Edward Island and Quebec and less than 20 percent of respondents answered correctly in New Brunswick, Ontario, and Saskatchewan (Comeau et al., 
2015). This is one of the topic areas that participants in the present study had difficulty with as well. Particularly, respondents had difficulty answering correctly when asked about Ontario's main source of electricity. Comeau et al. (2005) also asked participants questions on thermodynamics, household lighting, and power plant efficiency-topics that were not investigated here given that they did not align with the objective on the public energy literacy instrument.

Similar to the present study, Comeau et al. (2015) found that women, compared to men, were less successful on energy-related questions, opening up numerous research questions to explore why this is. For example, is this somehow related to women participating less in science, technology, engineering, and mathematics (STEM) compared with men? According to the 2011 National Household Survey (NHS), women accounted for 39\% of university graduates aged 25 to 34 with a STEM degree, compared with $66 \%$ of university graduates in non-STEM programs (2011). Further, young women with a high level of mathematical ability are significantly less likely to enter STEM fields than young men, this includes young men with lower levels of mathematical ability (Hango, 2013). Possibly then, the results of the present study reflect lower levels of women educated in STEM-related fields compared with men. But of course, numerous other avenues of further research exist as well.

Participants in the present study were not explicitly asked about their beliefs regarding barriers to public engagement, however, it is possible that a lack of energy-related knowledge is associated with low levels of participation in energy-related discussions and decision-making. In their national study, Comeau et al. (2015) found that people perceived a lack of knowledge as a barrier to participating in energy-related discussions and decision-making, suggesting that levels of knowledge may be related to public engagement. It is possible that some people perceive energy-related issues, and the discussions surrounding them, as specialized and thus feel that a lack of knowledge excludes them from participating. If Canada wants more people to become involved in discussions surrounding transitioning to a low carbon future, then barriers to public engagement, including low levels of knowledge, need to be addressed.

Many interesting relationships were found with respect to the subscales belonging to the public energy literacy instrument. First, energy-related knowledge was not related with energyrelated attitudes nor energy-saving behaviours. Second, energy-related attitudes were positively correlated with energy-saving behaviours. DeWaters and Powers (2011) reported similar 
findings for their measure of student energy literacy wherein student attitudinal and behavioural scores were more closely correlated than knowledge and behavioural scores. According to Bob Oliver of Pollution Probe:

Canada's future rests significantly on effective strategies to develop its energy opportunities. Improving energy literacy must be viewed as a priority in every part of Canada. The lack of alignment between what we know, how we think and feel, and how we behave when confronted with energy issues and choices constitutes a deficiency in energy literacy. (Policy, June 2012-2013, p. 51).

As such, the lack of a relationship between the knowledge and attitudes subscales, and the knowledge and behaviours subscales points towards a need for more action to support energyrelated initiatives. Further, the role of energy-related attitudes in affecting energy-saving behaviours should be supported through educational programs and initiatives to foster positive attitudes towards energy conservation and energy efficiency. Behavioural theories (e.g., theory of planned behaviour) as well as theories from social psychology (Gardner \& Stern, 1995; Stern et al., 1995), connecting attitudes, behaviours, and environmental concern are supported by the positive relationships that were found between the attitudinal and behavioural subscales and the environmental concerns scale.

An examination of the correlations between the measures of energy literacy, environmental concern, knowledge of conservation programs, and performance of major renovations demonstrates that energy is a complex and multi-faceted phenomenon. Overall, energy-related knowledge appears to be connected to specific and, more or less, efficiencyfocused behaviours, rather than curtailment behaviours, as evidenced by the positive correlations that were found between both measures of knowledge (i.e., the knowledge subscale and the index of conservation knowledge) and performance of major renovations. Highly visible behaviours, also known as curtailment behaviours, are behaviours that must be continued repeatedly over time in order to achieve optimal effects. In contrast, poorly visible behaviours, also known as efficiency behaviours, can be performed once or infrequently with little or no maintenance to have lasting effects (Abrahamse et al., 2005). Although both curtailment and efficiency behaviours have the potential to decrease energy consumption (Pacala \& Socolow, 
2004), comparisons reveal that energy efficiency, rather than curtailment behaviours, can save and reduce energy and carbon emissions the most (Gardner \& Stern, 2008). In the present study, knowledge does not appear to be connected with curtailment types of behaviours, evidenced by the odd correlations between the knowledge subscale, the conservation index, and behavioural subscales. Therefore broader types of knowledge as well as knowledge of specific energy saving programs appear to be connected with people performing focused and planned behaviours such as insulating walls, or upgrading windows, rather than using air conditioning sparingly or putting on a sweater when it is too cold. The latter behaviours can be conceptualized as being more practice-based behaviours that require habit formation. This theory is further supported by examining the relationship between the behavioural subscale and the major renovation index, which were not correlated. Further, as demonstrated in previous studies (e.g., Guagnano et al., 1995), attitudes can be related to behaviours when the behaviours are not "hard" or "high-cost". So the correlation between the attitudinal subscale with the behavioural subscale compared to the attitudinal subscale and the major renovation index reflects this relationship. That is, attitudes and behaviour relationships may be dependent on context, providing support for the $\mathrm{ABC}$ model of behaviour that discusses the importance of context in determining the factors that predict behaviour.

The complex nature of energy consumption is further shown in the regressions predicting household electricity and natural gas use. Participant levels of knowledge, measured using the energy literacy instrument, were not found to be associated with actual electricity or natural gas use. However, as in other studies (e.g. Abrahamse \& Steg, 2009; Dull \& Janky, 2011; Sapci \& Considine, 2014; Seligman et al., 1978), the more people demonstrated pro-environmental attitudes (i.e., NEP scale), the less electricity they used. Further, the more energy-saving behaviours (i.e., behavioural subscale) people reported performing, the less electricity and natural gas they used. These relationships do not undermine the relationships that were previously discussed with respect to knowledge (both measures), attitudes, and behaviours (including renovation behaviour). Instead, electricity or natural gas use, can be viewed as complex and "noisy". Particularly, electricity use and natural gas use are broad, and predicting their determinants needs to be extensive. That is, a lot of factors likely explain overall energy use, therefore teasing electricity and natural gas into smaller categories may help identify predictors more easily. For example, instead of examining overall electricity use, one could look 
at plug loads, or appliance use. As in Chapter 3, electricity use appears to be explained more by household characteristics than dwelling characteristics, in contrast to natural gas use. Excluding psychological variables, household area and the number of residents were both influential predictors in the model explaining electricity use. For, natural gas use, dwelling characteristics accounted for more of the variance than household characteristics.

An important finding to come out of this study is the relationship between self-reported behaviours and actual electricity and natural gas use. In past studies, behaviours have been measured using several scales (Markle, 2013) with researchers often wondering about their validity. That is, often there is a worry with using measures of self-reported behaviours that the self-reporting of behaviours become inflated. Studies which rely on self-reported data are casually dismissed by people who presume that self-reports cannot be accurate. Indeed, there are many instances where respondents self-report behaviours in such a way as to make them congruent with certain normative expectations. However, this study adds weight to the argument that self-reported behaviours, if collected correctly, are an important tool for social scientists.

\subsection{Conclusion}

Energy literacy among a sample of Toronto homeowners was assessed with overall performance being satisfactory on the knowledge subscale and people demonstrating positive attitudes, environmental concern and performance energy saving behaviours. However, there is room for improvement. Particularly, performance on certain questions highlights the gaps in people's understanding of some energy-related concepts. Low levels of knowledge will potentially affect how everyday individuals make decisions with regards to energy related issues and may also affect their public participation. The findings suggest energy use is a complex phenomenon. Knowledge appears to be related to specific energy saving behaviours such as performing major renovations, however, does not appear to be related to overall electricity or natural gas use. However, energy-saving behaviours, as found on the energy literacy instrument, were found to predict both electricity use and natural gas use. Thus, energy literacy helps to explain more of the variation in energy use, on top of characteristics that were accounted for previously in Chapter 3. As such, future studies of energy use should include measures of energy literacy.

Energy literacy helps to explain more of the variation in energy use, on top of the characteristics that were accounted for previously. 


\section{Chapter 6: Concluding Chapter}

\subsection{Summary of Dissertation Objectives}

The overarching objective of this dissertation was to conduct research in an interdisciplinary manner in order to explore and better understand households and the relationships occupants have with energy. Broadly, this can be understood by examining people and their understanding of energy and energy-related issues. More specifically, this can be understood by looking at occupants of households and their energy consumption. Therefore the conceptual framework that guided the present study benefitted from examining various theories, models, and frameworks of environmental behaviour, with these rooted in several disciplines. This study operationalized household energy use as a form of environmental behaviour given that energy use — and reducing energy use - is commonly considered to be pro-environmental behaviour.

This study aimed to 1) examine the relationship between household characteristics, dwelling characteristics, electricity use, and natural gas use; 2) establish criteria for measuring public energy literacy; 3) develop a valid and reliable instrument to measure energy literacy; 4) address performance on a measure of energy literacy and; 5) examine the relationship between energy literacy and household energy use. Each chapter investigated and presented a different facet of household energy use. That is, each chapter explored the relationship between people, their understanding of energy and their use of energy. Further, this was done using different measures and methods. Although these approaches seem to be different and juxtaposed, they were complimentary and connected. The major findings of each chapter are presented in what follows.

\subsection{Resolved Research Questions}

\subsubsection{Chapter 3 - Canadian Residential Energy Consumption}

The most recent Statistics Canada dataset on Canadian residential energy use (i.e., 2013 HES and EUS) was analyzed in order to better understand the determinants of Canadian household energy use. The areas of focus included dwelling characteristics and household characteristics, with the specific research questions being: 
1. In what way do household and dwelling characteristics contribute to electricity use?

2. In what way do household and dwelling characteristics contribute to natural gas use?

3. How much variation in energy use can be explained by household and dwelling characteristics?

Both household and dwelling characteristics significantly impact household energy use, however, the effects of each depend on the type of energy that is being examined. Household characteristics, such as household income and number of residents, have greater impact than dwelling characteristics on electricity use. In contrast, dwelling characteristics, such as heated floor area and the year a dwelling was built (i.e., vintage), have greater impact than household characteristics on natural gas use. Overall, approximately $20 \%$ of the variation in household electricity and natural gas can be explained by the household and dwelling characteristics that were examined here.

\subsubsection{Chapter 4 - Development of Public Energy Literacy Instrument}

In order to better understand the potential determinants of household energy use, the development of a public instrument proceeded. The following research questions were used to guide the work that was presented in this chapter:

1. How can public energy literacy be conceptualized and used to guide the development of an instrument?

2. How can established psychometric principles, educational, and survey methodologies be used to create a valid and reliable questionnaire for measuring energy literacy?

Public energy literacy was conceptualized in a comprehensive manner using previous surveys as well as frameworks and models from academic literature, grey literature, as well as literacy and educational initiatives and programs. Conceptualization of public energy literacy created the parameters within which survey items could be developed, created, and therefore generated. Items on the energy literacy instrument were reviewed by a validity panel. Further, instrument development included pretesting, cognitive interviews, and quantitative and 
qualitative analysis of instrument items. The resulting instrument is a good measure of public energy literacy that can be used or adapted by researchers and practitioners alike.

\subsubsection{Chapter 5 - Energy Literacy and Household Energy Use}

Energy-related knowledge, attitudes, and behaviours, along with environmental concern were assessed among a sample of Toronto homeowners. These variables were additionally incorporated into an examination of household energy use, given that a large percentage of Canadian residential energy use remained unexplained, after accounting for the effects of dwelling characteristics and socio-demographics. The following research questions guided the direction of this chapter:

1. How well do Toronto homeowners fare on an assessment of energy literacy? What do Toronto homeowners know about energy and energy-related issues? What are the energy attitudes of Toronto homeowners? Are Toronto homeowners environmentally concerned? What energy-saving behaviours are Toronto homeowners performing?

2. What household characteristics (i.e., socio-demographic variables) are associated with higher levels of energy-related knowledge, more positive attitudes, higher levels of environmental concern, and performance of self-reported energy conserving behaviours?

3. Is there a relationship between the different subscales of the energy literacy instrument? In what way are the different subscales of the energy literacy instrument related with environmental concern? In what way is energy literacy and environmental concern related to knowledge of energy conservation programs, and performance of major repairs?

In general, a sample of Toronto homeowners demonstrated environmental concern, positive attitudes, and performed energy-saving behaviours. Participants also demonstrated a satisfactory understanding of energy-related knowledge; the average score on the knowledge subscale was 66 percent. But the lack of higher scores suggests that there is still room for future improvement. Further, men were more successful than women on the knowledge subscale and answered more questions correctly, indicating that more research needs to be conducted to investigate this relationship. 
Interesting relationships were found between the subscales of the public energy literacy instrument. In particular, the knowledge subscale was not correlated with the behavioural and attitudinal subscales. However, the attitudinal and behavioural subscales were correlated. These latter subscales were also correlated with environmental concern. Using a few additional measures from the energy literacy questionnaire (i.e., knowledge of conservation and efficiency programs and performance of major renovations), additional relationships between knowledge, attitudes, and behaviours were examined. It was found that general knowledge (i.e., knowledge measured using the knowledge subscale) and knowledge of conservation programs were related to performing major renovations. This contrasts with the absence of a relationship between the knowledge and behaviour subscales of the energy literacy instrument. Additionally, no relationship was found between the behavioural subscale and the performance of major renovations.

Environmental concern and the knowledge and behavioural items from the measure of energy literacy were used to examine the relationship between energy literacy and household energy use. The results demonstrated that the attitudinal and behavioural subscales predicted household electricity and natural gas use. However, attitudes did not predict energy use when controlling for dwelling of other household characteristics. Additionally, other household characteristics and dwelling characteristics also predicted electricity and natural gas use and findings were similar to those found in the Canadian residential sector.

It appears that general knowledge, as measured on the energy literacy instrument, might be related to specific energy-saving behaviours, such as the performance of major repairs, but not with less specific energy-saving behaviours, such as household electricity or natural gas use. However, it appears that the attitudinal and behavioural (i.e., self-reported curtailment behaviours) dimensions of energy literacy are important for predicting household electricity and natural gas use.

These findings suggest that energy use is a complex and multi-faceted phenomenon and that the effects of dwelling characteristics, socio-demographics, as well as energy literacy inform energy use in different ways. In particular, it appears that general knowledge is connected to specific energy-efficient behaviours, whereas attitudes and self-reported curtailment behaviours are connected with broader electricity and natural gas use. 


\subsection{Strengths and Limitations}

The primary objective of this research, i.e., to examine household energy use via interdisciplinary examination, was a major strength of this research. In particular, examining household energy consumption using different disciplinary perspectives resulted in a more thorough and 'holistic' examination of household energy use. What could be considered a clashing approach is in actuality the most connected approach and is supported by the findings: using variables from different disciplines that help to explain the variance in household electricity and natural gas use. Although direct comparisons cannot be made with respect to the study on Canadian household energy use and the study on Toronto homeowner energy use, dwelling characteristics and household characteristics, inclusive of socio-demographic and psychological variables were found to contribute to household energy use. Thus, examining household energy use, using only socio-demographics, psychological variables, or dwelling characteristics, will provide a limited understanding of household energy use.

Another strength of this research was the development of a public energy literacy instrument. Few measures of public energy literacy exist, and fewer are standardized. Therefore, the development of a public energy literacy instrument contributes substantially to this area. This instrument is important for two primary reasons. First, this instrument can be used, on its own, as an assessment tool to measure energy literacy. Second, this instrument can be combined with other measures to investigate energy-related phenomena, as was the case here. The development of this instrument was rigorous and comprehensive and has the ability to be useful in numerous settings.

In this research, household characteristics (i.e., socio-demographics and psychological variables) were used to predict actual household electricity and natural gas use. Several past studies have examined the link between socio-demographics, psychological variables, and environmental behaviour but many of these have used measures of self-reported behaviours to measure environmental behaviours. With the availability of metered data, more studies can use actual/real energy use data and this was the approach taken in this research. Using real energy use data, the present study was able to link socio-demographics and psychological variables to actual household energy use; few studies have done this, especially with respect to psychological variables. 
A related strength of this study is the finding that self-reported behaviours (as measured on the energy literacy instrument) and electricity and natural gas use, among a sample of homeowners, were correlated. This finding demonstrates that self-reported behaviours may be reliable measures, at least in the case of self-reported energy-saving behaviours, and that these may not be as biased as they are generally considered to be. This finding does not undermine the importance of examining actual energy use data as a measure of energy use behaviour, but gives some degree of license to future researchers to use 1) self-reported energy-saving behaviours when actual energy use data is unavailable 2) self-reported behaviours as a reliable measure of energy-saving behaviours and 3) self-reported measures to supplement energy use data.

There were some limitations in this study. The first involves the HES and EUS surveys that were used for examining Canadian residential energy use. In particular, these surveys were very limited in the number and types of questions they asked Canadians, with respect to household energy use. For example, respondents were not asked about the energy source they used for a cookstove or the energy source they used for domestic hot water. As such, several important control variables were left out and this represents a limitation for modeling household energy use. This is unfortunate given that the HES and EUS were distributed to thousands of Canadians and thus more in-depth knowledge of Canadian residential energy use could have potentially been explored. This limitation in the surveys represents a lost opportunity. Beyond basic control variables, the inclusion of various additional socio-demographic variables (e.g., age of household head) and behaviours (e.g., renovations, public engagement) would be ideal in order for a more complete understanding of Canadians' energy use.

Though a strength of this research is the comprehensive development of an energy literacy instrument, the form of the instrument (i.e., an online survey) may have limited its full potential. In particular, the public energy literacy instrument was designed for online distribution (or paper-based if requested) and this form limited the types of questions that were used to measure energy literacy. For example, Southwell et al. (2012), measured public energy literacy by asking households to interpret their energy bill and it is possible that a measure of public energy literacy should probe households at this level. In this study it was found that many participants were unable to calculate electricity use and therefore an applied understanding of their knowledge could potentially bolster understanding of public energy literacy. 
Last, the response rate and sampling for the development of the instrument as well as the study on energy literacy and household energy use were limitations. Generally, larger sample sizes benefit research and could have been the case here.

\subsection{Recommendations and Future Work}

In the overall study, both dwelling characteristics as well as household characteristics were used to predict household energy use and it was found that both affected household energy use. That is, dwelling characteristics and household characteristics (socio-demographics and energy literacy) predicted household energy use. As such, it is recommended that future work examine the determinants of household energy use by considering these types of variables in their examination. This recommendation is also being made for survey developers, including national survey developers. Surveys on household energy use need to incorporate more questions and gather more information on household related information. In not doing so, a great opportunity is lost. Without examining social and psychological variables, a complete understanding of household energy use will not be accounted for.

Future work should also consider testing the public energy literacy instrument with a larger sample. Here, the research was bound by cost and time and therefore it was impossible to keep sampling for testing the measure of public energy literacy. It is suggested that sampling for a next round not include asking potential participants for their energy use data. Therefore, the research should focus solely on developing this instrument. As previously mentioned in the strengths and limitations, there is room for adapting this instrument to include more applied measures (e.g., assess understanding of an energy bill) and this should be explored. Further, future testing of the instrument and revising has the possibility for making it a more valid and reliable instrument.

Given the relationships between the various energy literacy subscales as well as the measures of knowledge and behaviour outside of the energy literacy tool (i.e., knowledge of conservation programs, performance of major renovations, electricity use and natural gas use), future research should examine knowledge, attitudes, and behaviours in their various forms (major renovations versus everyday smaller behaviours such as turning off the lights). Even more, the relationships between these should be more closely examined. That is, how are they connected? 
The findings here support the need for more instruments to encourage households and individuals to save energy. As shown here, dwelling characteristics are important predictors of energy use and therefore policy regarding retrofits and building codes are important for helping people save energy. However, energy literacy is important too. Though they might be more difficult to conceptualize and design, focus needs to continue on promoting energy-saving behaviours (they matter!) and also on working to change people's attitudes. Even more, there is potential for market segmentation. For example, it was found that households with different incomes used energy differently. Thus, generic campaigns may not be overly useful for affecting change.

\subsection{Significance Of Work}

Canada is currently involved in a period of energy transition in order to progress towards a more sustainable energy path (e.g., Climate Change Action Plan, 2016). In transitioning, the public plays an important role and having a better understanding of their energy literacy is crucial as they, inarguably, have the ability to influence our energy future. Therefore this study breaks methodological ground by incorporating an understanding of people and their energy-related knowledge, attitudes, and behaviours into the examination of energy use and therefore into the examination of our energy future. Households are important for driving energy use but they also have the potential for driving energy conservation and energy efficiency and so research and initiatives directed at households need to continue. Further, the people who make up households need to be acknowledged as dynamic and so understanding them and working with them has the best potential for ensuring success. "Buildings don’t use energy, people do," (Janda, 2011). 


\section{Appendices}

\section{Appendix 1}

Instrument Development Framework by DeWaters and Powers (2013)

\footnotetext{
Cognitive outcomes

Knowledge of basic scientific facts

Definitions of energy

Forms of energy

First and second laws of energy (concepts of energy conservation, entropy)

Transfer of energy through living and non living systems

Relationship between energy and power

Units of energy and power

Knowledge of issues related to energy sources and resources

Sun as primary energy source, other sources of energy used by humans

Renewable and nonrenewable resources

Relationship between supply and demand, and energy resource discovery, development and use

Advantages and disadvantages of developing and using different energy resources (technical,

environmental, economic, societal

Limitations of particular energy resources for various end-use applications

Importance of fossil fuels for meeting needs of today's society and as components in many valuable products

Awareness of the importance of energy use for individual and societal functioning

Society's need for energy

Uses of energy in societies and households

Knowledge of general trends in US and global energy resources supply and use

Relationship between fossil fuel consumption patterns and quantities of remaining reserves

Relative abundance of existing energy resources, in the US and globally

Use and management of various energy resources, in the US and globally

Understanding of the impact energy resource development and use can have on society

Influence of energy resource supply and demand on relationships between states, regions, and nations

Societal and economic problems related to shortages in nonrenewable energy resources

Societal impacts related to energy resource development and use

Personal and community health and safety factors associated with energy resource development and use

Understanding of the impact energy resource development and use can have on the environment

Impact of developing and using energy from various renewable and nonrenewable resources on all spheres of the environment

Relationship between fossil fuel combustion and increasing levels of carbon dioxide in the atmosphere

Global climate change

Knowledge of the impact individual and societal decisions related to energy resources development and use can have on the ability of societies of effectively satisfy future energy needs

Importance of energy conservation and improved efficiency of energy use

Need for developing alternative to fossil fuel based energy resources

Importance and effectiveness of personal decisions and actions for reducing energy consumption

Connection between today's energy-related decision and the future availability of energy resources

Cognitive skills

Ability to assimilate and interpret current events relevant to energy issues

Ability to analyze and assess objective, reliable information relevant to energy issues

Ability to evaluate pros and costs related to energy consumption and energy resource development form
} 


\section{Framework Continued}

various renewable ad nonrenewable energy resources

Ability to evaluate the costs and benefits related to energy when making consumer purchases

Ability to examine one's own beliefs and values in light of new information

\section{Affective outcomes}

Awareness/concern with respect to global energy issues

Values energy education

Acknowledges seriousness of energy problem

Interested in current energy-related events

Concerned with potential debates with respect to sensitive energy-related issues and options that related to the environment, economics, personal choices and freedoms, personal responsibility, and technical developments

Positive attitudes and values regarding

Prevention and remediation of societal problems related to energy resource development and use

Prevention and remediation of environmental problems related to energy resource development and use

Economic responsibilities related to sustainable energy resource development and use

The potential for adapting our lifestyles in ways that contribute to solving the global energy problems

Strong efficacy beliefs

Internal locus of control

Assumption of personal responsibility in contributing, as an individual and collectively with others, toward development of sustainable energy resource development and use

Assumption of personal responsibility in contributing, as an individual and collectively with others, toward mitigating negative impacts associated with energy resource development and use

\section{Behavioural outcomes}

Predispositions to behave

Willingness to work toward energy conservation

Considers energy-related impacts of everyday decisions, choices, and actions

Thoughtful, effective decision-making

Assesses objective, reliable information relevant to energy issues

Evaluates pros and cons related to energy consumption and energy resource development from various

renewable and nonrenewable resources

Remains open to new ideas

Evaluates costs and benefits related to energy when making consumer purchases

Change advocacy

Remains open to new ideas

Behaviour

Willingness to work to work toward energy-conservation

Exhibits energy-savings habits at home, at work, and in school

Change advocacy

Encourages others to make wise-energy related decisions and actions

Note. From “Establishing Measurement Criteria for an Energy Literacy Questionnaire,” by J. D. DeWaters and S. Powers, 2013, The Journal of Environmental Education, 44, p. 49-50. 


\section{Appendix 2}

Knowledge Items

Pretest: Form A

1. In Ontario, households are billed for their electrical energy (electricity) using what unit of measurement?
A. Kilowatt-hours (kWh)
B. Kilowatts $(\mathrm{kW})$
C. British Thermal Units (BTU)
D. Volts (V)

2. Fill in the blank: Compact fluorescent light bulbs (CFLs) are energy efficient and use approximately
A. $5 \%$
B. $25 \%$
C. $50 \%$
D. $75 \%$

3. In Ontario, households are billed for their natural gas using what unit of measurement?
A. Kilowatt-hours (kWh)
B. Kilowatts $(\mathrm{kW})$
C. Cubic meters $\left(\mathrm{m}^{3}\right)$
D. British Thermal Units (BTU)

4. What type of home uses the most energy per square foot for heating?
A. Detached
B. Semi-detached
C. Row houses or townhouses
D. Condominiums

5. Which of the following items uses the MOST ELECTRICITY in the average Canadian home each year?
A. Lights
B. Refrigerator
C. Computer
D. Television

6. An effective way to limit standby power use or "phantom loads" is to...
A. Change batteries for electronics often
B. Use ENERGY STAR ® appliances
C. Use electronics and appliances during off-peak pricing hours
D. Plug all electronics into a powerbar that can be switched off when the electronics are not being used

7. What is the main type of heating system used in Canada?
A. Forced air furnace
B. Electric baseboards
C. Boiler with hot water or steam radiators
D. Wood fireplace 
8. Ontario gets the majority of its electricity from which energy source?
A. Hydro (water)
B. Nuclear
C. Coal
D. Wind

9. Which organization sets the price of electricity in Ontario?
A. The Ministry of Environment and Climate Change
B. The National Energy Board
C. The Ontario Energy Board
D. Toronto Hydro Electric Systems Limited

10. In the winter, the most expensive rate that electrical utilities charge their customers happens at a time of day when...
A. People are getting up and getting ready to go to work
B. People are at work
C. People are sleeping at night
D. People are at lunch meetings

11. When using electricity, a regional blackout (power outage) can occur...
A. If the electricity supply exceeds the demand for electricity
B. If the demand for electricity exceeds the electricity supply
C. If customer bills are overdue
D. If fossil fuels are used to generate electricity

12. The vast majority of scientists say the Earth's average temperature is increasing. The primary cause of this change is...
A. Acid rain
B. Rising ocean levels
C. The sun is moving closer to the earth
D. Increasing carbon dioxide $\left(\mathrm{CO}_{2}\right)$ concentrations from burning fossil fuels

13. Scientists say that the fastest and most cost-effective way to address our energy needs is to...
A. Develop all possible domestic sources of fossil fuels
B. Build nuclear power plants
C. Develop more power plants that use renewable energy sources
D. Promote energy conservation

14. Of the following countries, which country consumes the most energy per person?
A. Bangladesh
B. India
C. Canada
D. China

15. Renewable energy resources like wind can impact humans and the environment because...
A. Generating electricity with wind turbines creates air pollution
B. Wind turbines are too expensive for most people
C. It takes a lot of energy and material to manufacture wind turbines
D. Wind power causes global warming 
16. In Canada, there is a growing interest in ethanol-blended gasoline because...
A. Ethanol has a higher energy content than gasoline
B. Any excess ethanol that is not mixed with gasoline can be sold at the liquor store
C. Canada has the cropland to support the production of corn and wheat used for making ethanol
D. Regular gasoline is more expensive in Canada than in most other countries

17. What car sold in Ontario today produces the fewest greenhouse gas emissions when driving?
A. Diesel powered car
B. Hybrid car
C. Plug in electric car
D. Three-cylinder gas powered car

18. The process of mixing water with sand and chemicals and injecting the mixture at high pressure into a drill hole to create small fractures in shale rock for gas and petroleum extraction is known as...
A. Offshore drilling
B. Deep well drilling
C. Hydraulic fracturing (fracking)
D. Open pit mining

19. In Canada, whose responsibility is it to negotiate the right to use a landowner's property for a pipeline once a pipeline has been approved?
A. The pipeline company
B. The Government of Canada
C. Politicians
D. Natural Resources Canada

20. To date, what is the largest initiative for reducing greenhouse gases in North America?
A. The saveONenergy Fridge \& Freezer Pick Up program
B. Closure of Ontario's coal fired electricity generation stations
C. The Cash for Clunkers program
D. The saveONenergy coupons for discounts on a wide range of energy efficient products

\section{Attitude Items}

Energy Use Around the House - Strongly Agree, Agree, Neither Agree nor Disagree, Disagree, Strongly Disagree

1. Reducing electricity use at home is important to me

2. Reducing household energy consumption is only for eco-warriors and environmentalists

Energy and Technology - Strongly Agree, Agree, Neither Agree nor Disagree, Disagree, Strongly Disagree

3. If technology can develop the atom bomb, and put a man on the moon, it can surely solve the energy problem

4. Efforts to develop renewable energy technologies are more important than efforts to find and develop new sources of fossil fuels

Energy and Climate Change - Strongly Agree, Agree, Neither Agree nor Disagree, Disagree, Strongly Disagree

5. There is no point in doing anything about climate change because Mother Nature will do what it wants anyway 
6. Causes of global warming include human activities like burning fossil fuels

General Views on Energy and Energy Issues - Strongly Agree, Agree, Neither Agree nor Disagree, Disagree, Strongly Disagree

7. I would do more to save energy if I knew how

8. I believe that I can contribute to solving energy problems by making appropriate energy-related choices

9. The way I personally use energy does not make a difference to the energy problems that face our nation

10. I do not want to change my lifestyle to conserve energy because that will take a lot of effort

11. I have worked hard to get where I am and am entitled to the "good things" in life

12. There is no point in reducing my carbon footprint if others don't reduce theirs

Energy and Policy - Strongly Agree, Agree, Neither Agree nor Disagree, Disagree, Strongly Disagree

13. All electrical appliances should have a label that shows the resources used in making and operating costs

14. More oil fields should be developed as they are discovered, even if they are located in areas protected by environmental laws

\section{Behaviour Items}

Behaviors Around the House - Always, Most of the Time, Sometimes, Rarely, Never

Please indicate if you or anyone in your household does any of the following

1. Turn the heat down at night

2. Use fans for cooling in the summer instead of air conditioning

3. Put plastic film on windows in the winter

4. Unplug electronics when you are away from your electronics for an extended period of time

5. Encourage other occupants to reduce their household energy consumption

6. Purchase fewer goods in order to save energy

Energy and Transportation - Always, Most of the Time, Sometimes, Rarely, Never

Please indicate if you or anyone in your household does any of the following

7. Walk or bike to go short distances, instead of using other methods of transportation

8. Maintain correct tire pressure for the family vehicle(s)

\section{Profile Items}

Are you or a member of your household the owner of your house?

- Yes

- No

_ Don't know

What type of house do you live in?

Detached

- Semi-detached

— Row house

_ Condominium

_ Other - please indicate in the space provided 
What type of heating equipment provides most of the heat for your house?

_ Furnace

_ Boiler

- Heating stove

_ Electric radiant heating

_ Electric baseboards

_ Gas fireplace

_ Heat pump

_ Other - please indicate in the space provided

_ Don't know

What source(s) of energy does your furnace/boiler/heating stove use? Please exclude the energy used for running the fan and pump.

Electricity

- Natural gas

- Heating oil

- Wood

_ Propane

_ Other - please indicate in the space provided

_ Don't know

What source of energy does your cooking stove use?

_ Electricity

_ Natural gas

_ Heating oil

Wood

_ Propane

_ Other-please indicate in the space provided

_ Don't know

What is your first language?

English

French

_ Other - please indicate in the space provided

What is the highest level of education completed by any member of your household?

_ Less than high school (Grades 1-8)

_ High school diploma or equivalent

_ College, CEGEP or other non-university certificate or diploma

_ Undergraduate university degree, certificate or diploma

_ Master's degree

- Degree in medicine, dentistry, veterinary medicine or optometry

Doctorate

None of the above

_ Prefer not to answer

Within which of the following categories does your yearly total household income fall?

Less than $\$ 20,000$

$\$ 20,000$ to less than $\$ 40,000$

$\$ 40,000$ to less than $\$ 60,000$

$\$ 60,000$ to less than $\$ 80,000$

_ $\$ 80,000$ to less than $\$ 100,000$ 
$\$ 100,000$ to less than $\$ 120,000$

$\$ 120,000$ to less than $\$ 150,000$

_ $\$ 150,000$ and over

_ Prefer not to answer

Are you?

Male

_Female

What is your STREET NUMBER? Your answer will help us match your survey responses with the interview portion of this study. Please enter in the space provided.

Thank you for completing our survey.

Thank you for your participation. Could you please include your general impression of the questionnaire (e.g., things you would change, things you liked) in the box below. I can use these suggestions to prepare for our interview and to improve the survey. 


\section{Appendix 3}

Pretest: Form B

Knowledge Items

1. Which uses the MOST ENERGY in the average Canadian home each year?
A. Space heating
B. Water heating
C. Appliance use
D. Lighting

2. If you use a 1-kilowatt $(\mathrm{kW})$ electric heater for two hours, how much electricity will it use?
A. 1 Kilowatt-hour $(\mathrm{kWh})$
B. 2 Kilowatt-hours $(\mathrm{kWh})$
C. 1 Kilowatt $(\mathrm{kW})$
D. 2 Kilowatts $(\mathrm{kW})$

3. Fill in the blanks: Furnaces heat while boilers heat
A. Air, Water
B. Water, Air
C. Water, Water
D. Air, Air

4. Standby power also known as "vampire power" and "phantom loads" accounts for an average of 5 to 10 percent of all electricity used in the typical Canadian home. What is standby power?

A. Energy used by electronics and appliances when they are turned on

B. Energy used by electronics and appliances when they are turned off but still plugged into a power outlet

C. Standby power refers to a loss of power during a power outage (blackout)

D. Energy used by people when they are standing up and using electronics and appliances instead of sitting down

5. If a couple invests thousands of dollars in attic insulation with a 10-year payback period this means...
A. The couple will receive a cheque from the government for 10 years
C. The couple will receive free home energy audits for the next 10 years
D. The couple does not have to pay their energy bills for the next 10 years
B. Over 10 years, the amount of money saved on energy bills will exceed the amount of money spent on the renovation

6. Most of the electricity produced in Canada comes from ...
A. Burning coal
B. Nuclear power
C. Solar energy
D. Water (hydro) power

7. When you turn on a light bulb in your house, the electricity it uses was produced how long ago?
A. The electricity was produced seconds ago
B. The electricity was produced one day ago
C. The electricity was produced one month ago
D. The electricity was produced last year 
8. Some people think that if we run out of fossil fuels we can just switch over to electric cars. What is the flaw with this idea?
A. Most of the world's electricity is currently produced from fossil fuels (coal, oil, natural gas)
B. Switching to electric cars will make unemployment rates go up
C. It's difficult to build electric cars in great quantities
D. You can't use electricity to operate a car

9. Photovoltaic (solar) cells are used to convert...
A. Chemical energy into electrical energy (electricity)
B. Chemical energy into mechanical energy
C. Sunlight into chemical energy
D. Sunlight into electrical energy (electricity)

10. Which of the following is one reason why solar energy is an intermittent source of energy?
A. Solar energy is easily stored
B. Solar output varies throughout seasons
C. Sometimes there is not enough UV in sunlight to generate energy
D. Sometimes the sun's rays are too hot to use for generating energy

11. Which of the following energy resources is NOT renewable?
A. Coal
B. Solar
C. Biomass fuels (wood, waste, plants, alcohol fuels)
D. Hydro (water)

12. Which product is NOT made from petrochemicals derived from oil or natural gas?
A. Perfume
B. Aspirin
C. Lipstick
D. Rubber

13. How is climate change different from global warming?
A. Global warming applies to humans and climate change applies to plants and animals
B. Global warming is the increase in the average temperature near Earth's surface whereas climate change refers to broader changes such as changes in weather
C. Global warming is associated with increases in levels of carbon dioxide whereas climate change is associated with increases in levels of methane
D. Global warming is relevant for warm climate countries whereas climate change is relevant for all countries

14. One advantage to using nuclear power instead of coal or petroleum for generating energy is that...
A. Nuclear power plants are cheaper to build
B. Less greenhouse gases are emitted
C. Nuclear power is completely safe
D. Nuclear waste products are easy to store

15. Oil sands account for what percentage of Canada's total oil reserves?
A. $25 \%$
B. $50 \%$
C. $75 \%$
D. $95 \%$ 
16. Canada trades most of its petroleum with which country?
A. Venezuela
B. Saudi Arabia
C. United States
D. Iraq

17. Which of one of the following statements best describes the relationship between Canada's energy imports and exports?
A. Canada exports more energy than it imports
B. Canada imports more energy than it exports
C. Canada's energy imports and exports are roughly the same
D. Canada does not import energy and only exports energy

18. Which of the following projects proposes to deliver crude oil from Alberta to New Brunswick?
A. The Keystone XL Pipeline
B. The Energy East Pipeline Project
C. The Northern Gateway Pipeline
D. The Trans-Mountain Pipeline System

19. Moving crude oil using infrastructure like pipelines is needed because...
A. Crude oil needs to be moved to a refinery where it can be processed
B. Crude oil becomes thinner as it moves through a pipeline and turns into gasoline
C. Crude oil is less flammable when it travels through a pipeline
D. Crude oil increases its energy content after travelling through a pipeline

\section{Attitude Items}

Energy Use Around the House - Strongly Agree, Agree, Neither Agree nor Disagree, Disagree, Strongly Disagree

1. At home, I prefer having most of the lights turned on because it looks nice

2. Reducing heat use at home is important to me

3. I can influence how the other occupants in my house use electricity

Energy and Technology - Strongly Agree, Agree, Neither Agree nor Disagree, Disagree, Strongly Disagree

4. We do not have to worry about conserving energy, because new technologies will be developed to solve energy problems for future generations

5. Technological developments can help people to control physical, biological, and social processes for the benefit of future generations

6. Renewable energy resources should play a larger role in Canada's electricity

Energy and Climate Change - Strongly Agree, Agree, Neither Agree nor Disagree, Disagree, Strongly Disagree

7. Climate change is the result of ineffective energy policies and not the fault of individuals

8. The effects of climate change will happen in the future so there is no point in worrying about it now

9. I do not want to hear about issues surrounding climate change anymore because it is tiresome

10. There is no need to address climate change because my life is comfortable and I don't want that to change 
General Views on Energy and Energy Issues - Strongly Agree, Agree, Neither Agree nor Disagree, Disagree, Strongly Disagree

11. I am reluctant to conserve material goods and services when it affects my daily

12. Energy education should be included in every school's curriculum

Energy and Policy - Strongly Agree, Agree, Neither Agree nor Disagree, Disagree, Strongly Disagree

13. Laws protecting the natural environment should be made less strict in order to allow more energy to be produced

14. Oil companies will benefit from the energy problem because they will raise prices

\section{Behaviour Items}

Behaviors Around the House - Always, Most of the Time, Sometimes, Rarely, Never

1. Try to save water

2. Use dimmers on household lights

3. Use energy efficient compact fluorescent light

4. Put on more clothes, such as a sweater, instead of adjusting the temperature when it is cold

5. Turn the air conditioner temperature up when leaving the house

6. Close the blinds or drapes in the house during the hottest part of the day

7. Use cold-water settings to wash clothing, the majority of the time

8. Use a clothesline or drying rack, weather permitting

\section{Profile Items}

Are you or a member of your household the owner of your house?

Yes

No

— Don't know

What type of house do you live in?

Detached

_ Semi-detached

- Row house

_ Condominium

_ Other - please indicate in the space provided

What type of heating equipment provides most of the heat for your house?

- Furnace

_ Boiler

_ Heating stove

Electric radiant heating

Electric baseboards

_ Gas fireplace

_ Other - please indicate in the space provided

_ Heat pump

_ Don't know

What source(s) of energy does your furnace/boiler/heating stove use? Please exclude the energy used for running the fan and pump.

Electricity 
_ Natural gas

Heating oil

- Wood

_ Propane

_ Other - please indicate in the space provided

_ Don't know

What source of energy does your cooking stove use?

Electricity

_ Natural gas

_ Heating oil

- Wood

_ Propane

_ Other - please indicate in the space provided

Don't know

What is your first language?

_English

French

_ Other - please indicate in the space provided

What is the highest level of education completed by any member of your household?

_ Less than high school (Grades 1-8)

_ High school diploma or equivalent

_ College, CEGEP or other non-university certificate or diploma

_ Undergraduate university degree, certificate or diploma

— Master's degree

_ Degree in medicine, dentistry, veterinary medicine or optometry

_ Doctorate

_ None of the above

_ Prefer not to answer

Within which of the following categories does your yearly total household income fall?

Less than $\$ 20,000$

$\$ 20,000$ to less than $\$ 40,000$

_ $\$ 40,000$ to less than $\$ 60,000$

— $\$ 60,000$ to less than $\$ 80,000$

— $\$ 80,000$ to less than $\$ 100,000$

_ $\$ 100,000$ to less than $\$ 120,000$

— $\$ 120,000$ to less than $\$ 150,000$

— $\$ 150,000$ and over

_ Prefer not to answer

Are you?

Male

_ Female

What is your STREET NUMBER? Your answer will help us match your survey responses with the interview portion of this study. Please enter in the space provided.

Thank you for completing our survey 
Thank you for your participation. Could you please include your general impression of the questionnaire (e.g., things you would change, things you liked) in the box below. I can use these suggestions to prepare for our interview and to improve the survey. 


\section{Appendix 4}

Iteration 2 Items

Knowledge Items

1. If you use a 1-kilowatt (kW) electric heater for two hours, how much electricity will it use?

O 1 Kilowatt-hour $(\mathrm{kWh})$

O 2 Kilowatt-hours (kWh)

O 1 Kilowatt $(\mathrm{kW})$

O 2 Kilowatts $(\mathrm{kW})$

2. Which uses the MOST ENERGY in the average Canadian home each year?

O Space heating

O Water heating

O Appliance use

Lighting

3. When you turn on a light bulb in your house, the electricity it uses was produced how long ago?

The electricity was produced seconds ago

The electricity was produced hours ago

The electricity was produced one day ago

The electricity was produced one month ago

4. Which product is NOT made from petrochemicals derived from oil or natural gas?

O Pantyhose

O Baking soda

O Lipstick

O Aspirin

5. Which of the following statements best describes the relationship between Canada's energy imports and exports?

Canada exports more energy than it imports

O Canada imports more energy than it exports

O Canada's energy imports and exports are roughly the same

O Canada does not import energy and only exports energy

6. Which of the following light bulbs uses the least amount of energy to produce light?

C CFLs (Compact fluorescent light bulbs)

O Traditional incandescent light bulbs

LEDs (Light-emitting diode light bulbs)

Halogen light bulbs

7. The best way to limit standby power or "phantom loads" is to...

O Change batteries often

Use energy efficient appliances and electronics

Use electronics and appliances during off-peak pricing hours

Use power bars with on/off switc 
8. In Ontario, what is the MAIN type of heating equipment used by households?

O Heat Pump

Electric baseboard

O Boiler

O Furnace

9. Ontario gets the majority of its electricity from which energy source?

O Hydro (water)

O Nuclear

O Coal

O Wind

10. In Canada, the price of electricity is determined at which jurisdictional level?

O International

O National

O Provincial

O Municipal

11. In winter, electricity is most expensive for Toronto households when ...

People are getting up and getting ready to go to work and when they come home from work

O People are at work

People are sleeping at night

People are in lunch meetings

12. In which province would driving an electric car result in the fewest greenhouse gas emissions?

O Ontario

O Alberta

O Nova Scotia

O Saskatchewan

13. In Canada, whose responsibility is it to negotiate the right to use a landowner's property for oil and gas pipelines once the pipelines have been approved?

O The federal government

The provincial government of the province in which the pipeline is being negotiated

The municipal government of the city or township in which the pipeline is being negotiated

The pipeline company

14. In Canada, what percentage of refined petroleum products is used as transportation fuels?

O $15 \%$

O $25 \%$

○ $50 \%$

○ $75 \%$

15. In 2014, which jurisdiction in North America became the first to completely eliminate coal as a source of electricity generation?

O Ontario

O Saskatchewan

O New York

O California 
16. In Canada, which of the following methods for shipping crude oil is becoming MORE popular?

O Rail

P Pipelines

O Trucks

Boats

17. Who is the primary regulatory body responsible for the oil sands?

O Oil sands developers

O The federal government

O First Nations peoples

O The Alberta Government

\section{Attitude Items}

\begin{tabular}{|c|c|c|c|c|c|}
\hline & Strongly Agree & Agree & Unsure & Disagree & $\begin{array}{l}\text { Strongly } \\
\text { Disagree }\end{array}$ \\
\hline $\begin{array}{l}\text { 1. Causes of } \\
\text { global warming } \\
\text { include human } \\
\text { activities like } \\
\text { burning fossil } \\
\text { fuels }\end{array}$ & O & 0 & 0 & O & 0 \\
\hline $\begin{array}{l}\text { 2. I would do } \\
\text { more to save } \\
\text { energy if I knew } \\
\text { how }\end{array}$ & O & O & 0 & 0 & 0 \\
\hline $\begin{array}{l}\text { 3. Energy } \\
\text { education should } \\
\text { be included in } \\
\text { every school's } \\
\text { curriculum }\end{array}$ & 0 & O & 0 & O & 0 \\
\hline $\begin{array}{l}\text { 4. I am reluctant } \\
\text { to conserve } \\
\text { material goods } \\
\text { and services } \\
\text { when it affects } \\
\text { my daily life }\end{array}$ & 0 & 0 & 0 & O & O \\
\hline $\begin{array}{l}\text { 5. Individuals } \\
\text { are just as } \\
\text { responsible as } \\
\text { governments and } \\
\text { businesses for } \\
\text { protecting and } \\
\text { maintaining the } \\
\text { environment }\end{array}$ & O & O & O & O & 0 \\
\hline
\end{tabular}




\begin{tabular}{|c|c|c|c|c|c|}
\hline & Always & Often & Sometimes & Rarely & Never \\
\hline $\begin{array}{l}\text { 1.Carpool or } \\
\text { use public } \\
\text { transportation }\end{array}$ & 0 & $\mathrm{O}$ & 0 & $\mathrm{O}$ & O \\
\hline $\begin{array}{l}\text { 2.Walk or bike } \\
\text { short distances }\end{array}$ & 0 & $\mathrm{O}$ & 0 & O & O \\
\hline $\begin{array}{l}\text { 3. Maintain } \\
\text { correct tire } \\
\text { pressure for the } \\
\text { family } \\
\text { vehicle(s) (if } \\
\text { you do not have } \\
\text { a car, leave } \\
\text { blank) }\end{array}$ & O & O & $\mathrm{O}$ & O & O \\
\hline
\end{tabular}

\begin{tabular}{|c|c|c|c|c|c|}
\hline & Always & Often & Sometimes & Rarely & Never \\
\hline $\begin{array}{l}\text { 4. Turn the heat } \\
\text { down at night }\end{array}$ & 0 & $\mathrm{O}$ & O & $\mathrm{O}$ & 0 \\
\hline $\begin{array}{l}\text { 5. Put on more } \\
\text { clothes, such as } \\
\text { a sweater, } \\
\text { instead of } \\
\text { raising the } \\
\text { temperature }\end{array}$ & $\mathrm{O}$ & O & 0 & 0 & $\mathrm{O}$ \\
\hline $\begin{array}{c}\text { 6. In the } \\
\text { summer, use } \\
\text { air-conditioning } \\
\text { sparingly (if } \\
\text { you do not have } \\
\text { AC, leave } \\
\text { blank) }\end{array}$ & 0 & O & 0 & 0 & 0 \\
\hline $\begin{array}{l}\text { 7. Use cold- } \\
\text { water wash or } \\
\text { rinse settings to } \\
\text { wash clothing }\end{array}$ & 0 & 0 & 0 & 0 & 0 \\
\hline $\begin{array}{l}\text { 8. Use energy } \\
\text { efficient } \\
\text { lighting (LEDs } \\
\text { or CFLs) }\end{array}$ & O & O & 0 & 0 & $\mathrm{O}$ \\
\hline $\begin{array}{l}\text { 9. Use a } \\
\text { clothesline or } \\
\text { drying rack to }\end{array}$ & O & O & 0 & 0 & O \\
\hline
\end{tabular}


dry clothing

\section{Profile Items}

Are you OR a member of your household the owner of your house?

O Yes O No

Don't know

What type of house do you live in?

O Detached

Semi-detached

O Row house - end unit

Row house - non-end unit

O Town house - end unit

Town house - non-end unit

O Apartment

Other - please specify

O Don't know

How long have you or your household lived in your current house?

Please answer using only one of the response options.

O My date of move in was:

O Number of months:

O Number of years:

O Don't know

In what year was your house originally built?

$\begin{array}{llll}\text { O } & \text { Before } 1900 & \text { O } & 1940-1949 \\ \text { O } & 1900-1909 & \text { O } & 1950-1959 \\ \text { O } & 1910-1919 & \text { O } & 1960-1969 \\ \text { O } & 1920-1929 & \text { O } & 1970-1979 \\ \text { O } & 1930-1939 & \text { O } & 1980-1989\end{array}$

O $1990-1999$

O 2000-2009

O 2010 or later

O Don't know

Are you?

O Male

O Female

What is your marital status?

S Single/never been married

O Divorced

O Married/Common-law

O Widowed

O Separated

What is the highest level of education completed by any member of your household?

O Less than high school (Grades 1-8)

O Some high school

O None of the above

O High school diploma or equivalent

Prefer not to answer

O Some college

College, CEGEP or other non-university certificate or diploma

Undergraduate university degree, certificate or diploma

O Some university

O Master's or Doctorate degree

O Professional degree such as dentistry, veterinary medicine

Other - please specify 
What is the first language that you learned to speak and still understand?

O English

O French

Other - please specify

In which of the following categories does your yearly total household income fall?

Please include income from all sources, before taxes.

O Less than $\$ 20,000$

O $\$ 20,000$ to less than $\$ 40,000$

O $\$ 40,000$ to less than $\$ 60,000$

O $\$ 60,000$ to less than $\$ 80,000$

O $\$ 80,000$ to less than $\$ 100,000$

O $\$ 100,000$ to less than $\$ 120,000$

O $\$ 120,000$ to less than $\$ 140,000$

O $\$ 140,000$ to less than $\$ 160,000$

O $\$ 160,000$ to less than $\$ 180,000$

O $\$ 180,000$ to $\$ 200,000$

O More than $\$ 200,000$

O Prefer not to answer

Please specify the year you were born:

Including yourself, please indicate the number of people in each of the following age groups that live in your house.

O Infants 0-12 months

O 1 to 10 years old

O 11 to 20 years old

21 to 30 years old

31 to 40 years old

41 to 50 years old

O 51 to 65 years old

Age 65 years or older

Thank you for your participation! 


\section{Appendix 5}

\section{Recruitment Notice}

\section{RYERSON}

UNIVERSITY

Fall 2015

Dear Resident,

You are being invited to volunteer in a research opportunity. Ms. Runa Das and Dr. Russell Richman from Ryerson University are conducting a research study that will explore what Toronto homeowners know about energy related issues and how this affects electricity and gas consumption. Your participation will help us learn how to develop programs to assist homeowners with managing their energy consumption. You will also be assisting Ms. Das in completing her PhD.

We have sent out thousands of invitations for participation to residents in the Toronto area including your neighbourhood.

If you decide to volunteer, you will be asked to complete a 15 minute online survey that asks about your understanding of energy related issues, your attitudes towards energy and the environment, and your household behaviours. In order to connect your survey responses to your electricity and gas consumption, you will be asked for your Toronto Hydro and Enbridge account information. If you consent, Toronto Hydro and Enbridge have agreed to provide the researchers with your consumption data for the past three years.

It is important for you to know that any information you provide will be confidential, including your account numbers. Please also note that with your permission Toronto Hydro and Enbridge will only provide energy consumption records, not billing or payment information. All of the data will be summarized, making it impossible to identify individuals. Additional security information is provided online.

\section{If you wish to participate, please visit the Study Website at: www.bitly.com/energyliteracy}

This link is best viewed using Firefox, Safari, or Internet Explorer.

If you have any questions please contact Runa Das (rras@ryerson.ca) or Dr. Russell Richman (richman@ryerson) or 416-979-5000 extension 6489. Your email will not be shared. Requesting more information does not obligate you to participate in this study.

Thank you for considering participation in this study.

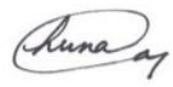

Runa Das

PhD Candidate

Environmental Applied Science and Management 


\section{Appendix 6}

A Modified Framework for Public Energy Literacy

\begin{tabular}{|c|}
\hline Cognitive outcomes \\
\hline Knowledge of basic scientific facts \\
\hline $\begin{array}{l}\text { Definitions of energy } \\
\text { - If you use a 1-kilowatt }(\mathrm{kW}) \text { electric heater for two hours, how much electricity will } \\
\text { you consume? } \\
\text { - When you turn on a light bulb in your house, the electricity it uses was produced how } \\
\text { long ago? }\end{array}$ \\
\hline $\begin{array}{l}\text { Relationship between energy and power } \\
\text { - If you use a 1-kilowatt }(\mathrm{kW}) \text { electric heater for two hours, how much electricity will } \\
\text { you consume? }\end{array}$ \\
\hline $\begin{array}{l}\text { Units of energy and power } \\
\text { • If you use a 1-kilowatt (kW) electric heater for two hours, how much electricity will } \\
\text { you consume? }\end{array}$ \\
\hline Knowledge of issues related to energy sources and resources \\
\hline $\begin{array}{l}\text { Renewable and nonrenewable resources } \\
\text { - In which province would driving an electric car result in the fewest greenhouse gas } \\
\text { emissions? } \\
\text { - Ontario gets the majority of its electricity from which energy source? } \\
\text { - Who is the primary regulatory body responsible for the oil sands? }\end{array}$ \\
\hline $\begin{array}{l}\text { Relationship between supply and demand, and energy resource discovery, development } \\
\text { and use } \\
\text { - When you turn on a light bulb in your house, the electricity it uses was produced how } \\
\text { long ago? } \\
\text { - Ontario gets the majority of its electricity from which energy source? }\end{array}$ \\
\hline $\begin{array}{l}\text { Advantages and disadvantages of developing and using different energy resources } \\
\text { (technical, environmental, economic, societal } \\
\text { - When you turn on a light bulb in your house, the electricity it uses was produced how } \\
\text { long ago? }\end{array}$ \\
\hline $\begin{array}{l}\text { Limitations of particular energy resources for various end-use applications } \\
\text { - When you turn on a light bulb in your house, the electricity it uses was produced how } \\
\text { long ago? }\end{array}$ \\
\hline $\begin{array}{l}\text { Importance of fossil fuels for meeting needs of today's society and as components in } \\
\text { many valuable products } \\
\text { - Which product is NOT made from petrochemicals derived from oil or natural gas? } \\
\text { - In Canada, which of the following methods for shipping crude oil is becoming more } \\
\text { popular? }\end{array}$ \\
\hline Awareness of the importance of energy use for individual and societal functioning \\
\hline $\begin{array}{l}\text { Uses of energy in societies and households } \\
\text { - The best way to limit standby power or "phantom loads" is to... } \\
\text { - In Canada, the price of electricity is determined at which jurisdictional level? }\end{array}$ \\
\hline
\end{tabular}




- In which province would driving an electric car result in the fewest greenhouse gas
- - Which uses the most energy in the average Canadian home each year?
- Which of the following light bulbs uses the least amount of energy to produce light?
Knowledge of general trends in Canada and global energy resources supply and use
Relationship between fossil fuel consumption patterns and quantities of remaining
reserves
- Which of the following statements best describes the relationship between Canada's
energy imports and exports?
Relative abundance of existing energy resources, in Canada and globally
- Which of the following statements best describes the relationship between Canada's
- energy imports and exports?
- Onse and management of various energy resources, in Canada and globally
- In Canada, the price of electricity is determined at which jurisdictional level?
- In Canada, whose responsibility is it to negotiate the right to use a landowner's
property for a pipeline once a pipeline has been approved?
- Which of the following statements best describes the relationship between Canada's
- In the winter, electricity is most expensive for Toronto households when...
- In 2014, which jurisdiction in North America became the first to completely eliminate
coal as a source of electricity generation?
popular?

Influence of energy resource supply and demand on relationships between states, regions, and nations

- In Canada, whose responsibility is it to negotiate the right to use a landowner's property for a pipeline once a pipeline has been approved?

- Who is the primary regulatory body responsible for the oil sands? Understanding of the impact energy resource development and use can have on the environment Impact of developing and using energy from various renewable and nonrenewable resources on all spheres of the environment

- In which province can you drive an electric car and produce the fewest greenhouse gas emissions?

Relationship between fossil fuel combustion and increasing levels of carbon dioxide in the atmosphere

- In which province can you drive an electric car and produce the fewest greenhouse gas emissions?

\section{Global climate change}

- In which province can you drive an electric car and produce the fewest greenhouse gas emissions?

Knowledge of the impact individual and societal decisions related to energy resource development and use can have on the ability of societies to effectively satisfy future energy needs 
Importance of energy conservation and improved efficiency of energy use

- In winter, electricity is most expensive for Toronto households when ... Need for developing alternative to fossil fuel based energy resources

Importance and effectiveness of personal decisions and actions for reducing energy consumption

- In which province can you drive an electric car and produce the fewest greenhouse gas emissions

- The best way to limit standby power or "phantom loads" is to....

- Which of the following light bulbs uses the least amount of energy to produce light?

Ability to assimilate and interpret current events relevant to energy issues

- In Canada, which of the following methods for shipping crude oil is becoming more popular?

Ability to analyze and assess objective, reliable information relevant to energy issues

- Who is the primary regulatory body responsible for the oil sands?

Ability to evaluate pros and cons related to energy consumption and energy resource development from various renewable and nonrenewable energy resources

- When you turn on a light bulb in our house, the electricity it uses was produced how long ago?

Ability to evaluate costs and benefits related to energy when making consumer purchases

- If you use a 1-kilowatt (kW) electric heater for two hours, how much electricity will it use?

\begin{tabular}{|c|}
\hline Affective outcomes \\
\hline Awareness/concern with respect to global energy issues \\
\hline Values energy education \\
- I would do more to save energy if I knew how. \\
- Energy education should be an important part of every school's curriculum.
\end{tabular}

Acknowledges seriousness of energy problem

- I would do more to save energy if I knew how .

- I am reluctant to conserve material goods and services when it affects my daily life.

- Energy education should be an important part of every school's curriculum.

Interested in current energy-related events

- Causes of global warming include activities like burning fossil fuels Form

Concerned with potential debates with respect to sensitive energy-related issues and options that related to the environment, economics, personal choices and freedoms, personal responsibility, and technical developments

- I am reluctant to conserve material goods and services when it affects my daily life.

- Individuals are just as responsible as governments and businesses for protecting and maintaining the environment.

Positive attitudes and values regarding

Prevention and remediation of societal problems related to energy resource development and use

- I would do more to save energy if I knew how

- I am reluctant to conserve material goods and services when it affects my daily life.

Prevention and remediation of environmental problems related to energy resource development and use 
- I would do more to save energy if I knew how

Economic responsibilities related to sustainable energy resource development and use

- I am reluctant to conserve material goods and services when it affects my daily life.

The potential for adapting our lifestyles in ways that contribute to solving global energy problems

- I would do more to save energy if I knew how.

- I am reluctant to conserve material goods and services when it affects my daily life. Strong efficacy beliefs

\section{Internal locus of control}

- Individuals are just as responsible as governments and businesses for protecting and maintaining the environment.

Assumption of personal responsibility in contributing, as an individual and collectively with others, toward development of sustainable energy resource development and use

- Causes of global warming include human activities like burning fossil fuels

- Individuals are just as responsible as governments and businesses for protecting and maintaining the environment.

Assumption of personal responsibility in contributing, as an individual and collectively with others, toward mitigating negative impacts associated with energy resource development and use

- Individuals are just as responsible as governments and businesses for protecting and maintaining the environment.

\begin{tabular}{|l|}
\hline \multicolumn{1}{|c|}{ Behavioral outcomes } \\
\hline Willingness to work toward energy conservation \\
\hline Exhibits energy-saving habits at home, at work \\
- Turn down the heat down at night . \\
- In the summer, use air conditioning sparingly. \\
- Walk or bike to go short distances \\
- Maintain correct tire pressure for the family vehicles \\
- Use energy efficient compact fluorescent light B3 \\
- Use on more clothes, such as sweater, instead of raising the temperature \\
- Use a clothesline or drying rack \\
- Use energy efficient lighting (LEDs or CFLs).
\end{tabular}




\section{Appendix 7}

Online Energy Literacy Instrument

Welcome to the Online Survey

Thank you for your interest in Ryerson University's Energy Literacy Study! In this 15 minute survey, researchers at Ryerson University want to explore your understanding of energy and energy related issues. We also want to learn how this may be connected to your electricity and natural gas use. In order to participate you must first provide your consent at the bottom of this page. By providing consent you will be able to complete the online energy literacy survey. It is preferable that the person who takes care of the electricity and gas bills completes this survey. Second, we are asking for your consent to access your electricity and gas data. With your consent, we obtain this information directly from Toronto Hydro and Enbridge. On the next page you will be asked to provide your Toronto Hydro and Enbridge account numbers and account holder names. This information can be found on your Toronto Hydro and Enbridge bills. With your permission, Toronto Hydro and Enbridge will provide the researchers with your electricity use in (kWh) and natural gas use (in meters 3) for the period covering May 1, 2012 to May 1, 2015. Even if you have lived at your current residence for less than 3 years, we still want you to participate! Though we encourage all participants to include their Toronto Hydro and Enbridge account information, those who decide not to can still complete the survey. It is important for you to know that any information you provide will be confidential, including your account numbers and account holder name. All of the results will be presented in a way that makes it impossible to identify individuals. Participation in this survey is voluntary and your decision to participate or not will not influence your future relations with Ryerson, Toronto Hydro, or Enbridge. There are no foreseeable risks to participating in this study. Also, there are no direct benefits from participating in this study but your participation can help us determine how to manage energy consumption. Data is being collected using an encrypted survey website called Qualtrics, that maintains rigorous privacy controls. This survey company is located in the USA and as such, is subject to US laws; in particular, the US Patriot Act, which allows authorities access to the records of Internet service providers. If you choose to participate in the survey, you need to be aware that your responses to the survey questions may be accessed in the USA. The security and privacy policy for the web survey company can be found at the following link: http://www.qualtrics.com/security-statement/. Once surveys are complete, all data will be stored securely at Ryerson University, and will only be accessible to the research team. You may skip any questions that make you uncomfortable or stop your participation at any time. You can also stop participating by closing the browser before submission, thereby stopping the collection of information. If you have any questions about this study please contact:

Runa Das, PhD Candidate

Email: rras@ryerson.ca

OR her supervisor

Russell Richman, PhD

Email: richman@ryerson.ca Telephone: 416-979-5000 ext.6489

Ryerson University's Research Ethics Board has approved this study. If you have questions regarding your rights as a human subject you many contact them for more information: 416-979-5042. 
Do you agree to participate in this survey?

Yes, I agree

No, I will not participate

Answer: If Do you agree to participate in this survey? <span style="font-family:verdana,geneva, sans-

serif;"><span style="font-size: 16px;">No, I will not participate $</$ span $></$ span $>$ Is Selected

You have clicked "No" to participating in this survey. Please click "No" again to confirm that you don't wish to participate. Do you agree to participate in this survey?

Yes, I agree

No, I will not participate

If No, I will not participate Is Selected, Then Skip To End of Survey

Toronto Hydro Waiver

By providing your Toronto Hydro Account Number and checking the 'Yes, I agree' box, you are authorizing Toronto Hydro to release your household's electricity consumption data from May 1, 2012 to May 1, 2015 to The Energy Literacy Study. If you have lived at your current residence for less than 3 years you can still participate! Do you agree to this waiver?

Yes, I agree

No, I do not agree

I am not a Toronto Hydro customer

Toronto Hydro Customer Information

- Toronto Hydro Account Number - please enter Your account number is a 10-digit number that identifies your unique customer information profile with Toronto Hydro. This number is located in large bold numbers in the top left corner of your bill.

- Toronto Hydro Account Holder Name - please enter This information is being used to link the account number to the account holder. This name will not be used for any other purposes. Please enter First and Last name. Example: Jane Doe

- I confirm that I am the account holder

Enbridge Waiver By providing your Enbridge Account Number and checking the 'Yes, I agree' box, you are authorizing Enbridge to release your household's natural gas consumption data from May 1, 2012 to May 1, 2015 to The Energy Literacy Study. If you have lived at your current residence for less than 3 years you can still participate! Do you agree to this waiver?

Yes, I agree

No, I do not agree

I am not an Enbridge customer 
Enbridge Customer Information

Enbridge Account Number - please enter Your account number is a unique number that identifies your customer information profile with Enbridge. This number is located under the section 'Account Number' on your bill.

- Enbridge Account Holder Name - please enter This information is being used to link the account number to the account holder. This name will not be used for any other purposes. Please enter First and Last name. Example: Jane Doe

- I confirm that I am the account holder

Thank you Let's Begin the Survey!

\section{WHAT DO YOU KNOW ABOUT ENERGY?}

For the following statements please select the choice that BEST corresponds to your answer. If you use a 1-kilowatt $(\mathrm{kW})$ electric heater for two hours, how much electricity will it use?

1 Kilowatt-hour (kWh)

2 Kilowatt-hours (kWh)

1 Kilowatt $(\mathrm{kW})$

2 Kilowatts $(\mathrm{kW})$

Which uses the MOST ENERGY in the average Canadian home each year?

Space heating

Water heating

Appliance use

Lighting

When you turn on a light bulb in your house, the electricity it uses was produced how long ago?

The electricity was produced seconds ago

The electricity was produced hours ago

The electricity was produced one day ago

The electricity was produced one month ago

Which product is NOT made from petrochemicals derived from oil or natural gas?

Pantyhose

Baking soda

Lipstick

Aspirin 
Which of the following statements best describes the relationship between Canada's energy imports and exports?

Canada exports more energy than it imports

Canada imports more energy than it exports

Canada's energy imports and exports are roughly the same

Canada does not import energy and only exports energy

Which of the following light bulbs uses the least amount of energy to produce light?

CFLs (Compact fluorescent light bulbs)

Traditional incandescent light bulbs

LEDs (Light-emitting diode light bulbs)

Halogen light bulbs

The best way to limit standby power or "phantom loads" is to...

Change batteries often

Use energy efficient appliances and electronics

Use electronics and appliances during off-peak pricing hours

Use power bars with on/off switches

In Ontario, what is the MAIN type of heating equipment used by households?

Heat Pump

Electric baseboard

Boiler

Furnace

Ontario gets the majority of its electricity from which energy source?

Hydro (water)

Nuclear

Coal

Wind

In Canada, the price of electricity is determined at which jurisdictional level?

International

National

Provincial

Municipal

In winter, electricity is most expensive for Toronto households when ...

People are getting up and getting ready to go to work and when they come home from work

People are at work

People are sleeping at night

People are in lunch meetings 
In which province would driving an electric car result in the fewest greenhouse gas emissions?

Ontario

Alberta

Nova Scotia

Saskatchewan

In Canada, whose responsibility is it to negotiate the right to use a landowner's property for oil and gas pipelines once the pipelines have been approved?

The federal government

The provincial government of the province in which the pipeline is being negotiated

The municipal government of the city or township in which the pipeline is being negotiated

The pipeline company

In Canada, what percentage of refined petroleum products is used as transportation fuels?

$15 \%$

$25 \%$

$50 \%$

$75 \%$

In 2014, which jurisdiction in North America became the first to completely eliminate coal as a source of electricity generation?

Ontario

Saskatchewan

New York

California

In Canada, which of the following methods for shipping crude oil is becoming MORE popular?

Rail

Pipelines

Trucks

Boats

Who is the primary regulatory body responsible for the oil sands?

Oil sands developers

The federal government

First Nations peoples

The Alberta government 
Please indicate how much you agree or disagree with the following statements... Please be honest, there are no right or wrong answers.

\begin{tabular}{|c|c|c|c|c|}
\hline We are & & Unsure & Mildly Disagree & Strongly \\
Disagree
\end{tabular}


How much do you agree or disagree with the following statements...

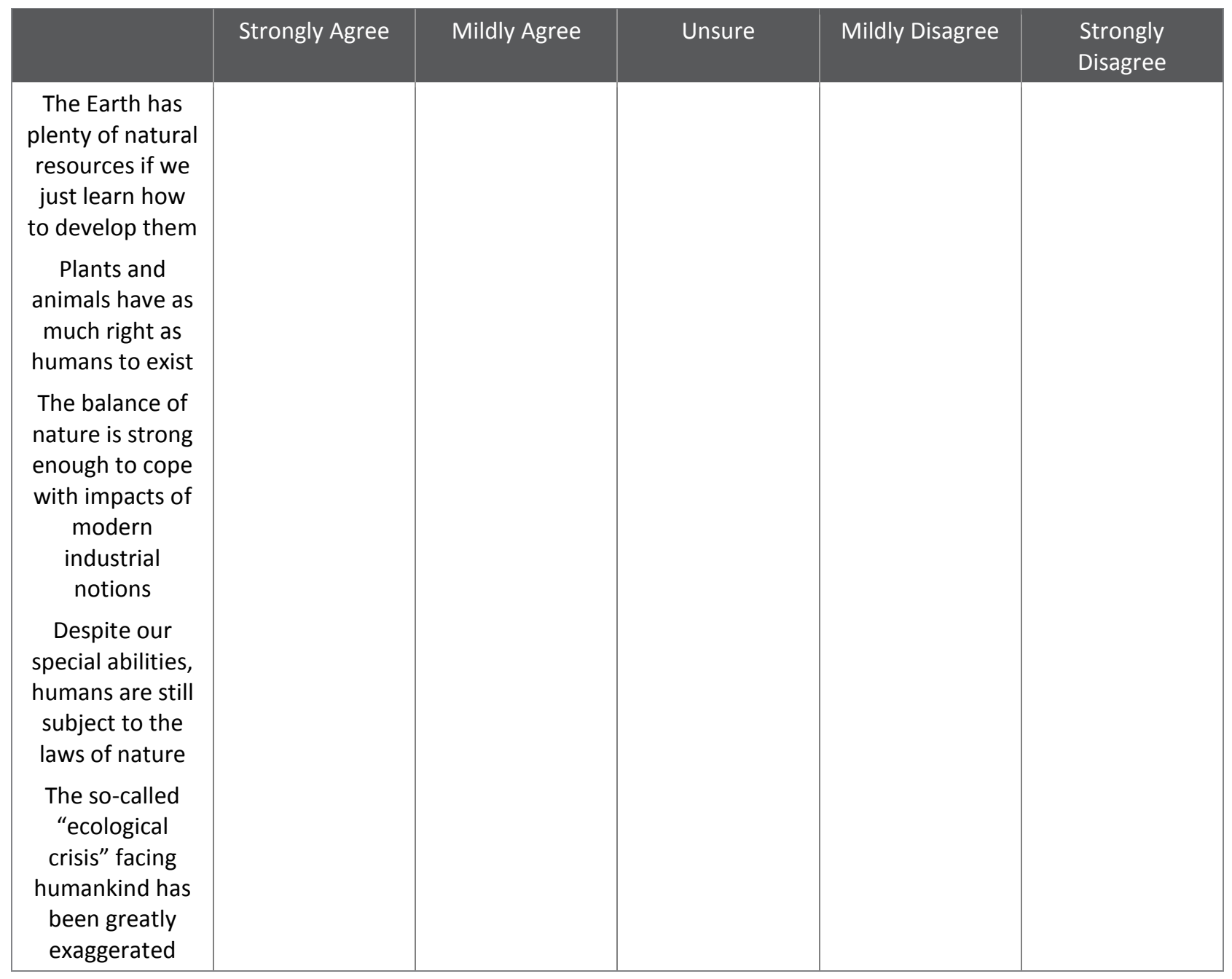


How much do you agree or disagree with the following statements...

\begin{tabular}{|c|c|c|c|c|c|}
\hline & Strongly Agree & Mildly Agree & Unsure & Mildly Disagree & $\begin{array}{l}\text { Strongly } \\
\text { Disagree }\end{array}$ \\
\hline $\begin{array}{l}\text { The Earth is like } \\
\text { a spaceship with } \\
\text { very limited } \\
\text { room and } \\
\text { resources } \\
\text { Humans were } \\
\text { meant to rule } \\
\text { over the rest of } \\
\text { nature } \\
\text { The balance of } \\
\text { nature is very } \\
\text { delicate and } \\
\text { easily upset } \\
\text { Humans will } \\
\text { eventually learn } \\
\text { enough about } \\
\text { how nature } \\
\text { works to be able } \\
\text { to control it } \\
\text { If things } \\
\text { continue on } \\
\text { their present } \\
\text { course, we will } \\
\text { soon experience } \\
\text { a major } \\
\text { ecological } \\
\text { catastrophe }\end{array}$ & & & & & \\
\hline
\end{tabular}


Energy and Transportation How often do you or someone in your household do the following:

\begin{tabular}{|c|c|c|c|c|c|}
\hline & Always & Often & Sometimes & Rarely & Never \\
\hline $\begin{array}{c}\text { Carpool or use } \\
\text { public } \\
\text { transportation } \\
\text { Walk or bike } \\
\text { short distances } \\
\text { Maintain correct } \\
\text { tire pressure for } \\
\text { the family } \\
\text { vehicle(s) (if you } \\
\text { do not have a } \\
\text { car, leave } \\
\text { blank) }\end{array}$ & & & & & \\
\hline
\end{tabular}


General Views on Energy Issues Please indicate how much you agree or disagree with the following statements:

\begin{tabular}{|c|c|c|c|c|}
\hline & Strongly Agree & Agree & Disagree & Strongly \\
Disagree
\end{tabular}


Behaviours Around the House How often do you or someone in your household do the following:

\begin{tabular}{|c|c|c|c|c|c|}
\hline & Always & Often & Sometimes & Rarely & Never \\
\hline $\begin{array}{l}\text { Turn the heat } \\
\text { down at night } \\
\text { Put on more } \\
\text { clothes, such as } \\
\text { a sweater, } \\
\text { instead of } \\
\text { raising the } \\
\text { temperature } \\
\text { In the summer, } \\
\text { use air- } \\
\text { conditioning } \\
\text { sparingly (if you } \\
\text { do not have AC, } \\
\text { leave blank) } \\
\text { Use cold-water } \\
\text { wash or rinse } \\
\text { settings to wash } \\
\text { clothing } \\
\text { Use energy } \\
\text { efficient lighting } \\
\text { (LEDs or CFLs) } \\
\text { Use a } \\
\text { clothesline or } \\
\text { drying rack to } \\
\text { dry clothing }\end{array}$ & & & & & \\
\hline
\end{tabular}


Thank you for your time so far. There are just a few more questions to help us group people's responses.

Are you OR a member of your household the owner of your house?

Yes

No

Don't know

What type of house do you live in?

Detached

Semi-detached

Row house - end unit

Row house - non-end unit

Town house - end unit

Town house - non-end unit

Apartment

Other - please specify

Don't know

How long have you or your household lived in your current house? Please answer using only one of the response options.

My date of move in was:

Number of months:

Number of years:

Don't know

In what year was your house originally built?

Before 1900

1900-1909

1910-1919

1920-1929

1930-1939

1940-1949

1950-1959

1960-1969

1970-1979

1980-1989

1990-1999

2000-2009

2010 or later

Don't know 
Excluding the basement, how many storeys is your house?

One storey

One and half storeys

Two storeys

Two and half storeys

Three storeys

Split level

Other - please specify

Don't know

Most houses in Ontario are built over basements or crawl spaces. What is your house built over?

Basement

Crawl space

Other - please specify

No foundation

Don't know

If No foundation Is Selected, Then Skip To Does your house have an attic (a spac...If Don't know Is

Selected, Then Skip To Does your house have an attic (a spac...If Other - please specify Is Selected, Then Skip To Does your house have an attic (a spac...If Other - please specify Is Not Empty, Then Skip To Does your house have an attic (a spac...If Basement Is Selected, Then Skip To During the heating season, is your ba...If Crawl space Is Selected, Then Skip To During the heating season, is your ba...

During the heating season, is your basement/crawl space usually heated?

Yes

No

Don't know

Not applicable

Does your house have an attic (a space between the roof and top floor of your house)? This space does not have to be useable.

Yes

No

Don't know

If No - skip to first garage q... Is Selected, Then Skip To Does your house have an attached gara...If Don't know - skip to first ... Is Selected, Then Skip To Does your house have an attached gara...

Is there insulation in your attic?

Yes

No

Don't know 
Does your house have an attached garage (garage connected to, and sharing some walls with the house)?

Yes

No

Don't know

If No - skip to area question Is Selected, Then Skip To What is the heated floor area of your...If Don't

know - skip to area q... Is Selected, Then Skip To What is the heated floor area of your...

How much insulation does your garage have?

Full insulation - all wall and garage doors are insulated

Full insulation - all walls but not the garage doors are insulated

Partial insulation - some walls are insulated

Don't know

During the heating season, is your garage usually heated?

Yes

No

Don't know

What is the heated floor area of your house? Please include all heated spaces (example: basement if it is heated and attached). Please exclude any unheated spaces (example: garage if it is not attached).

600 square feet $(55 \mathrm{~m} 2)$ or less

601 to 1000 square feet (56 to $95 \mathrm{~m} 2$ )

1001 to 1500 square feet (96 to $140 \mathrm{~m} 2$ )

1501 to 2000 square feet (141 to $185 \mathrm{~m} 2$ )

2001 to 2500 square feet (186 to $230 \mathrm{~m} 2$ )

2501 to 3000 square feet ( 231 to $280 \mathrm{~m} 2$ )

3001 to 3500 square feet ( 281 to $325 \mathrm{~m} 2$ )

3501 to 4000 square feet ( 326 to $371 \mathrm{~m} 2$ ) (

4001 square feet $(372 \mathrm{~m} 2)$ or more

Don't know

What is the MAIN type of heating equipment that provides most of the heat in your house?

Furnace with forced air (hot air vents)

Boiler with hot water or steam radiators or underfloor heating

Electric radiant heating (portable)

Electric baseboards

Heat pump

Other - please specify

Don't know 
What source of energy does your furnace/boiler use? Please exclude the energy used for running the fan and/or pump.

Electricity

Natural gas

Heating oil

Wood

Propane

Other - please specify

Don't know

What source of energy does your cooking stove use?

Electricity

Natural gas

Heating oil

Wood

Propane

Other- please specify

Don't know

What type of hot water heater is used in your house?

Standard hot water tank

Tankless (instant water heater)

Combination boiler (typically a wall-hung unit)

Other - please specify

Don't know

What source of energy does the hot water heater use?

Electricity

Natural gas

Solar

Other - please specify

Don't know

Do you have a heat recovery ventilator (HRV)?

Yes

No

Don't know 
Does your house have an air conditioner?

Yes

No

Don't know

If No - skip to thermostat que... Is Selected, Then Skip To Do you have a thermostat to control t...If Don't know - skip to thermo... Is Selected, Then Skip To Do you have a thermostat to control t...

Is the air conditioner...?

Central-air system

Stand alone unit(s) in a window or elsewhere

Heat pump

Other-please specify

Don't know

Do you have a thermostat to control the heating system?

Yes

No

Don't know

If No Is Selected, Then Skip To Have you done any improvements/retrof...If Don't know Is Selected, Then Skip To Have you done any improvements/retrof...

How many thermostats do you have?

One

More than one

Don't know

Is your main thermostat programmable? This is the type of thermostat that can be set to automatically change the temperature according to the time of day.

Yes

No

Don't know

Is it currently programmed?

Yes

No

Don't know

I don't have a programmable thermostat 
At what temperature is your thermostat set during the winter and summer? If you don't know, please leave the space blank.

\begin{tabular}{|c|c|c|c|}
\hline & $\begin{array}{c}\text { When you are home and } \\
\text { awake }\left({ }^{\circ} \mathrm{C}\right)\end{array}$ & $\begin{array}{c}\text { When you are home but } \\
\text { asleep }\left({ }^{\circ} \mathrm{C}\right)\end{array}$ & $\begin{array}{c}\text { When you are away from } \\
\text { home }\left({ }^{\circ} \mathrm{C}\right)\end{array}$ \\
\hline $\begin{array}{c}\text { Winter } \\
\text { Summer }\end{array}$ & & & \\
\hline
\end{tabular}

How often do you or other members of your household override your programmable thermostat?

A few times a week

About once a week

A few times a month

About once a month

Less often

Never

Don't know

I don't have a programmable thermostat

Have you done any improvements/retrofits to your house to reduce energy consumption in the last 10 years? Please check all that apply.

Improved attic insulation

- Improved wall insulation

Replaced windows and or skylights

$\square$ Replace doors

$\square$ Use caulking or weather stripping

$\square$ Use a programmable thermostat

- Purchased energy efficient appliances

$\square$ Use energy efficient lighting (CFLs or LEDs)

$\square$ Other - please specify

No

Don't know

Have you heard of the following province wide and saveONenergy conservation/efficiency initiatives?

\begin{tabular}{|c|c|c|}
\hline Smart Meters & Yes & No \\
peaksaver PLUS & $\square$ & $\square$ \\
PowerShift & $\square$ & $\square$ \\
ENERGY STAR appliances or home & $\square$ & $\square$ \\
building standards & $\square$ & $\square$ \\
Heating and Cooling Program & $\square$ & $\square$ \\
Fridge and Freezer Pickup & $\square$ & $\square$ \\
\hline
\end{tabular}


Are you

Male

Female

What is your marital status?

Single/never been married

Married/Common-law

Separated

Divorced

Widowed

What is the highest level of education completed by any member of your householdLess than high school (Grades 1-8) Some high school

High school diploma or equivalent (

Some college

College, CEGEP or other non-university certificate or diploma

Undergraduate university degree, certificate or diploma

Some university

Master's or Doctorate degree

Professional degree such as dentistry, veterinary medicine

Other - please specify

None of the above

Prefer not to answer

What is the first language that you learned to speak and still understand?

English

French

Other - please specify

In which of the following categories does your yearly total household income fall? Please include income from all sources, before taxes.

Less than $\$ 20,000 \$ 20,000$ to less than $\$ 40,000$

$\$ 40,000$ to less than $\$ 60,000$

$\$ 60,000$ to less than $\$ 80,000$

$\$ 80,000$ to less than $\$ 100,000$

$\$ 100,000$ to less than $\$ 120,000$

$\$ 120,000$ to less than $\$ 140,000$

$\$ 140,000$ to less than $\$ 160,000$

$\$ 160,000$ to less than $\$ 180,000$ (

$\$ 180,000$ to $\$ 200,000$

More than $\$ 200,000$

Prefer not to answer 
Please specify the year you were born:

Including yourself, please indicate the number of people in each of the following age groups that live in your house.

I Infants 0-12 months

口 1 to 10 years old

口 11 to 20 years old

口 21 to 30 years old

口 31 to 40 years old

口 41 to 50 years old

口 51 to 65 years old

Age 65 years or older 


\title{
Appendix 8
}

\author{
Research Ethics Board Approval
}

\section{RYERSONUNIVERSITY}

RESEARCH ETHICS BOARD

To: Runa Das

Ensciman

Re: REB 2014-127: Towards understanding the relationship between energy literacy and energy consumption

Date: August 14, 2015

Dear Runa Das,

The review of your protocol REB File REB 2014-127 is now complete. The project has been approved for a one year period. Please note that before proceeding with your project, compliance with other required University approvals/certifications, institutional requirements, or governmental authorizations may be required.

This approval may be extended after one year upon request. Please be advised that if the project is not renewed, approval will expire and no more research involving humans may take place. If this is a funded project, access to research funds may also be affected.

Please note that REB approval policies require that you adhere strictly to the protocol as last reviewed by the REB and that any modifications must be approved by the Board before they can be implemented. Adverse or unexpected events must be reported to the REB as soon as possible with an indication from the Principal Investigator as to how, in the view of the Principal Investigator, these events affect the continuation of the protocol.

Finally, if research subjects are in the care of a health facility, at a school, or other institution or community organization, it is the responsibility of the Principal Investigator to ensure that the ethical guidelines and approvals of those facilities or institutions are obtained and filed with the REB prior to the initiation of any research.

Please quote your REB file number (REB 2014-127) on future correspondence.

Congratulations and best of luck in conducting your research.

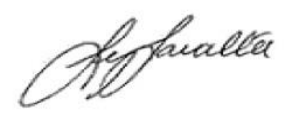

Lynn Lavallée, Ph.D.

Chair, Research Ethics Board 


\section{References}

Abrahamse, W., \& Steg, L. (2009). How do socio-demographic and psychological factors related to households' direct and indirect energy use and savings? Journal of Economic Psychology, 30, 711-720.

Abrahamse, W., \& Steg, L. (2011). Factors related to household energy use and intention to reduce it: the role of psychological and socio-demographic variables. Human Ecology Review, 18, 30-40.

Abrahamse, W., Steg, L., Vlek, C., \& Rothengatter, T. (2005). A review of intervention studies aimed at household energy conservation. Journal of Environmental Psychology, 25, 273291.

Allen, J. B., \& Ferrand J. L. (1999). Environmental locus of control, sympathy, and proenvironmental behaviour. A test of Geller's actively caring hypothesis. Environment and Behavior, 31, 338-353.

Andersson, L., Shivarajan, S., \& Blau, G. (2005). Enacting ecological sustainability in the MNC: A test of an adapted value-belief-norm framework. Journal of Business Ethics, 59, 295305.

Angus Reid Public Opinion. (2010). Energy Literacy Survey. Retrieved October 1, 2011 from http://www.centreforenergy.com/AboutEnergy/CanadianEnergy/EnergyLiteracySurvey.a sp.

Attari, S. Z., DeKay, M. L., Davidson, C. L., \& Bruine de Bruin, W. (2010). Public perceptions of energy consumption and savings. Proceedings of the National Academy of Sciences, $107,16054-16059$.

Aydinalp, M., Ugursal, V. I., \& Fung, A. S. (2003). Modelling of residential energy consumption at the national level. International Journal of Energy Research, 27, 441-453.

Ajzen, I. (1985). From intentions to actions: a theory of planned behavior. In J. Kuhl \& J. Beckmann (Eds.), Action-Control: From Cognition to Behavior (pp. 11-39). Heidelberg, Germany: Springer.

Azjen, I. (1991). The theory of planned behavior. Organizational Behavior and Human Decision Processes, 50, 179-211.

Ajzen, I. (2011). The theory of planned behavior: Reactions and reflections. Psychology and Health, 26, 1113-1127.

Azjen, I. \& Fishbein, M. (1980). Understanding attitude and predicting social behavior. Englewood Cliffs, NJ: Prentice-Hall.

Bamberg, S., \& Moser, G. (2007). Twenty years after Hines, Hungerford, and Tomera: a new meta-analysis of psycho-social determinants of pro-environmental behaviour. Journal of Environmental Psychology, 27, 14-25. 
Barrow, L. H., \& Morrisey, J. T. (1989). Energy literacy of ninth-grade students: A comparison between Maine and New Brunswick. Journal of Environmental Education, 20, 22-25.

Beck, U. (1992). Risk society: Towards a new modernity. London: Sage.

Becker, Lawrence, J., Seligman, C., Fazio, R. H., \& Darley, J. M. (1981). Relating attitudes to residential energy use. Environment and Behavior, 13, 590-609.

Biesiot, W., \& Noorman, K. J. (1999). Energy requirements of household consumption: A case study of The Netherlands. Ecological Economics, 28, 367-383.

Black, J. S., Stern, P. C., \& Elworth, J. T. (1985). Personal and contextual influences on household energy adaptations. Journal of Applied Psychology, 70, 3-21.

Bloom, B., Engelhart, M., Furst, E., Hill, W, \& Krathwohl, D. (1956). Taxonomy of educational objectives, Handbook I: Cognitive domain. New York, NY: David McKay Co.

Blum, N., Nazir, J., Breiting, S., Goh, K. C., \& Pedretti, E. (2013). Balancing the tensions and meeting the conceptual challenges of education for sustainable development and climate change. Environmental Education Research, 19, 206-217.

Borden, D., \& Francis, J. L. (1978). Who cares about ecology? Personality and sex difference in environmental concern. Journal of Personality, 46, 190-203.

Bourdieu, P. (1984). Distinction: A social critique of the judgment of taste. New York and London: Routledge.

Brounen, D., Kok, N., \& Quigley, J. M. (2013). Energy literacy, awareness, and conservation behavior of residential households. Energy Economics, 38, 42-50.

Brown, C., Gorgolewski, M., \& Goodwill, A. (2015). Using physical, behavioral, and demographic variables to explain suite-level energy use in multiresidential buildings. Building and Environment, 89, 308-317.

Buchanan, K., Russo, R., \& Anderson, B. (2014). Feeding back about eco-feedback: How do consumers use and respond to energy monitors? Energy Policy, 73, 138-146.

Burgess, J., Harrison, C., \& Filius, P. (1998). Environmental communication and the cultural politics of environmental citizenship, Environment and Planning A, 30, 1445-1460.

City of Toronto. (1998-2016). Toronto Neighbourhood Profiles. Retrieved November 18, 2010 from http://www.toronto.ca/demographics/neighbourhoods.htm.

Collins, D. (2003). Pretesting survey instruments: An overview of cognitive methods. Quality of Life Research, 12, 229-238.

Collins, S. E., \& Carey, K. B. (2007). The theory of planned behaviour as a model of heaving episodic drinking among college students. American Psychological Bulletin, 21, 498-507. 
Comeau, L., Stedman, R., Beckley, T., \& Parkins, J. (2015). Citizen perspectives on energy issues: National survey 2015: University of New Brunswick, University of Alberta, Cornell University.

Conner, M., \& Sparks, P. (2005). Theory of planned behaviour and health behaviour. In M. Connor \& P. Norman (Eds.), Predicting health behaviour ( $2^{\text {nd }}$ ed., pp. 170-222). Maidenhead: OUP.

Council of Ministers of Education Canada. (2007). Report of UNECE and UNESCO on indicators of education for sustainable development. Retrieved from http://www.cmec.ca/Publications/Lists/Publications/Attachments/105/Canada-reportantidiscrimination-2007.en.pdf

Council of Ministers of Education Canada. (2015). Toolkit of promising practices that assist in the alignment of skills and education systems with the needs of the labour market. Retrieved from http://www.cmec.ca/Publications/Lists/Publications/Attachments/349/Toolkit_jan152016_EN.pdf

Cornell Statistical Consulting Unit. (June 2012). StatNews \#83. Interpretating coefficients in regression with log-transfromed variables.

Curry, T. E., Ansolabehere, S., \& Herzog, H. (2007). A survey of public attitudes towards climate change and climate change mitigation technologies in the United States: Analyses of 2006 results. Publication No. LFEE, 1.

Curry, T. E., Reiner, D. M., de Figueiredo, M. A., \& Herzog, H. J. (2005). A survey of public attitudes towards energy \& environment in Great Britain. Cambridge, MA, Massachusetts Institute of Technology.

Czaja, R., \& Blair, J. (2005). Designing surveys: A guide to decisions and procedures. London: Pine Forge Press.

de Leeuw, A., Valois, P., Ajzen, I., \& Schmidt, P. (2015). Using the theory of planned behavior to identify key beliefs underlying pro-environmental behavior in high-school students: implications for educational interventions. Journal of Environmental Psychology, 42, 128-138.

Dennis, M. L., Soderstrom, E. J., Koncinski, W. S. Jr., \& Cavanaugh, B. (1990). Effective dissemination of energy-related information. Applying social psychology and evaluation research. American Psychologist, 45, 1109-1117.

DeVellis, R.F. (2003). Scale development: Theory and applications. London: Sage Publications.

DeWaters, J., \& Powers, S. (2013). Establishing measurement criteria for an energy literacy questionnaire. The Journal of Environmental Education, 44, 38-55. 
DeWaters, J., Qaqish, B., Graham, M., \& Powers, S. (2013). Designing an energy literacy questionnaire for middle and high school youth. The Journal of Environmental Education, 44, 56-78.

Dietz, T., Gardner, G. T., Gilligan, J., Stern, P. C., \& Vandenbergh, M. P. (2009). Household actions can provide a behavioral wedge to rapidly reduce US carbon emissions. Proceedings of the National Academy of Sciences, 106, 18452-18456.

Disinger, J. F., \& Roth, C. E. (1992). Environmental literacy. ERIC/CSMEE Digest, ED351201, $1-7$.

Doran, R., \& Larsen, S. (2016). The relative importance of social and personal norms in explaining intentions to choose eco-friendly travel options. International Journal of Tourism Research, 18, 159-166.

Douglas, M., \& Wildavsky, A. (1982). Risk and Culture: An Essay on the Selection of Technological and Environmental Dangers. Berkeley, CA: University of California Press.

Dull, A., \& Janky, B. (2011). Environmental attitudes and household electricity use among Budapest Residents. International Review of Social Research, 1, 115-131.

Dunlap, R. E. (1985). Public opinion: behind the transformation. EPA Journal, 11, 15-17.

Dunlap, R. E., Liere, K. D. Van, Mertig, A. G., \& Jones, R. E. (2000). Measuring Endorsement of the New Ecological Paradigm : A Revised NEP Scale. Journal of Social Issues, 56, 425-442.

Ebel, R.L., \& Frisbie, D.A. (1991). Essentials of educational measurement. Toronto: Pearson.

ecoENERGY Carbon Capture Storage Task Force. (2008). Canada's Fossil Energy Future. The way forward on Carbon Capture and Storage. Retrieved from: http://www.nrcan.gc.ca/publications/fossil-energy-future/1167

Eisenberg, N. \& Miller, P. (1987). The relation of empathy to prosocial and related behaviors. Psychological Bulletin, 101, 91-119.

Ellickson, R. C. (2001). The market for social norms. American Law and Economic Review, 3, $1-49$.

Emanuel, K. (2005). Increasing Destructiveness of Tropical Cyclones over the Past 30 Years. Nature, 436, 686-688.

Escudero, E.B., Reyna, N.L., \& Morales, M.R. (2000). The Level of Difficulty and Discrimination Power of the Basic Knowledge and Skills Examination (EXHCOBA). Revista Electrónica de Investigación Educativa, 2, 1-16. 
Ewing, R. \& Rong, F. (2008). The impact of urban form on US residential energy use. Housing Policy Debate, 19, 1-30,

Fan, X. (1998). Item response theory and classical test theory: An empirical comparison of their item/person statistics. Educational and Psychological Measurement, 58, 357-381.

Faruqui, A., Sergici, S., \& Sharif, A. (2010). The impact of informational feedback on energy consumption-A survey of the experimental evidence. Energy, 35, 1598-1608.

Field, A. (2009). Discovering statistics using SPSS (Third Edition). Thousand Oaks, CA: SAGE Publications Inc.

Fishbein, M., \& Ajzen, I. (1975). Belief, attitude, intention, and behavior: An introduction to theory and research. Reading, MA: Addison-Wesley.

Foulds, C., Powell, J., \& Seyfang, G. (2016). How moving home influences appliances ownership: a Passivhaus case study. Energy Efficiency, 9, 455-472.

Frederick, S., Loewenstein, G., \& O’Donoghue, T. (2002). Time discounting and time preference: A critical review. Journal of Economic Literature, 40, 351-401.

Frederiks, E. R., Stenner, K., \& Hobman, E. V. (2015a). The socio-demographic and psychological predictors of residential energy consumption: A comprehensive review. Energies, 8, 573-609.

Frederiks E. R., Stenner, K., \& Hobman, E. V. (2015b). Household energy use: Applying behavioural economics to understand consumer decision-making and behaviour. Renewable and Sustainable Energy Reviews, 41, 1385-1394.

Gadermann, A. M., Guhn, M., \& Zumbo, B. D. (2012). Estimating Ordinal Reliability for LikertType and Ordinal Item Response Data: A Conceptual, Empirical, and Practical Guide. Practical Assessment, Research \& Evaluation, 17, 1-13.

Gambro, J. S., \& Switzky, H. N. (1999). Variables associated with American high school students' knowledge of environmental issues related to energy and pollution. Journal of Environmental Education, 30, 15-22.

Gardner, G. T., \& Stern, P. C. (2008). The short list: The most effective actions U.S. households can take to curb climate change. Environment Magazine, 51, 12-24.

Gatersleben, B., Steg, L., \& Vlek, C. (2002). Measurement and Determinants of Environmentally Significant Consumer Behavior. Environment and Behavior, 34, 335-362.

Geller, E. S. (1981). Evaluating energy conservation programs: Is verbal report enough? Journal of Consumer Research, 8, 331-335.

Geller, E. S. (1995). Actively caring for the environment: An integration of behaviorism and humanism. Environment and Behavior, 27, 184-195. 
Geller, E. S., Roberts, D. S., \& Gilmore, M. R. (1996). Predicting propensity to actively care for occupational safety. Journal of Safety Research, 27, 1-8.

Giddens, A. (1990). The consequences of modernity. Cambridge: Polity Press.

Gifford, R. (2011). The dragons of inaction: Psychological barriers that limit climate change mitigation and adaptation. American Psychologist, 66, 290.

Gill, Z. M., Tierney, M. J., Pegg, I. M., \& Allan, N. (2010). Low-energy dwellings: the contribution of behaviours to actual performance. Building Research \& Information, 38, 491-508.

Gillingham, K., Newell, R. G., \& Palmer, K. (2009). Energy efficiency economics and policy. Annual Review of Resource Economics, 1, 597-619.

Godkin, G., \& Kok, G. (1996). The theory of planned behavior: a review of its applications to health-related behaviors. American Journal of Health Promotion, 11, 87-98.

Government of Canada (2016). Canada's second biennial report on climate change. Retrieved from https://www.ec.gc.ca/GES-GHG/default.asp?lang=En\&n=02D095CB-1

Gram-Hanssen, K. (2014). New needs for better understanding of household's energy consumption-behaviour, lifestyle or practices? Architectural Engineering and Design Management, 10, 91-107.

Gronow, J., \& Warde, A. (Eds.). (2001). Ordinary consumption. Berkshire: Harwood Academic Publishers.

Guagnano, G. A. (1995). Locus of control, altruism and agentic disposition. Population and Environment: A Journal of Interdisciplinary Studies, 17, 63-77.

Guagnano, G. A., Stern, P. C., \& Dietz, T. (1995). Influences on attitude-behavior relationships a natural experiment with curbside recycling. Environment and behavior, 27, 699-718.

Guerra Santin, O., Itard, L., \& Visscher, H. (2009). The effect of occupancy and building characteristics on energy use for space and water heating in Dutch residential stock. Energy and Buildings, 41, 1223-1232.

Guilford, J.P., \& Fruchter, B. (1973). Fundamental statistics in psychology and education. Toronto: McGraw-Hill.

Hackett, B., \& Lutzenhiser, L. (1991). Social Structures and Economic Conduct: Interpreting Variations in Household Energy Consumption. Sociological Forum, 6, 449-70.

Hango, D. (2013). Gender differences in science, technology, engineering, mathematics and computer science (STEM) programs at university. Insights on Canadian Society. Catalogue no. 75- 006- X. p. 1-11. 
Hargreaves, T. (2011). Practice-ing behaviour change: applying social practice theory to proenvironmental behaviour change. Journal of Consumer Culture, 11, 79-99.

Harvey, G. D. (1977). Environmental education: A delineation of substantive structure. Dissertation Abstracts International, 38, 611A-612A.

Hayes, S. C., \& Cone, J. D. (1977). Reducing residential electrical energy use: Payments, information, and feedback. Journal of Applied Behavior Analysis, 10, 425-435.

Heath, Y., \& Gifford, R. (2002). Extending the theory of planned behaviour: predicting the use of public transportation. Journal of Applied Social Psychology, 32, 2154-2189.

Heberlein, T. A. (1972). The Land Ethic Realized: Some Social Psychological Explanations for Changing Environmental Attitudes1. Journal of Social Issues, 28, 79-87.

Herring, S. C., Hoerling, M. P., Kossin, J. P., Peterson, T. C., \& Stott, P. A. (2015). Explaining extreme events of 2014 from a climate perspective. Bulletin of the American Meteorological Society, 96(12), S1-S172.

Hines, J. M., Hungerford, H. R., \& Tomera, A. N. (1987). Analysis and synthesis of research on responsible environmental behaviour: A meta-analysis. Journal of Environmental Education, 18, 1-8.

Hirsh, J. B. (2010). Personality and environmental concern. Journal of Environmental Psychology, 30, 245-248.

Hirsh, J. B., \& Dolderman, D. (2007). Personality predictors of consumerism and environmentalism: a preliminary study. Personality and Individual Differences, 43, 15831593.

Hirst, E. (1984). Household energy conservation: A review of the federal residential conservation service. Public Administration Review, 44, 421-430.

Hirst, E., \& Grady, S. (1982-1983). Evaluation of a Wisconsin utility home energy audit program. Journal of Environmental Systems, 12, 303-320.

Hobman, E. V., \& Ashworth, P. (2013). Public support for energy sources and related technologies: The impact of simple information provision. Energy Policy, 63, 862-869.

Hofman, H. (1980). Energy crisis-Schools to the rescue again. School Science and Mathematics, 80, 468-478.

Hofstee, W. K. B., Ten Berge, J. M. F., \& Hendriks, A. A. J. (1998). How to score questionnaires. Personality and Individual Differences, 25, 909.

Hollweg, K. S., Taylor, J. R., Bybee, R. W., Marcinkowski, T. J., McBeth, W. C., \& Zoido, P. (2012). Developing a framework for assessing environmental literacy. Washington, DC: North American Association for Environmental Education. Washington, DC: North 
American Association for Environmental Education. Retrieved from http://www.naaee.net/framework

Hopper, J. R., \& Neilsen, J. M. (1991). Recycling as altruistic behavior: Normative and behavioral strategies to expand participation in a community recycling program. Environment and Behavior, 23, 195-220.

Hungerford, H. R., \& Peyton, R. B. (1976). Teaching environmental education. Portland, ME: J. Weston Walch.

Hungerford, H. R., Peyton, R. B., \& Wilke, R. (1980). Goals for curriculum development in environmental education. Journal of Environmental Education, 11, 42-47.

Hutton, R. B., \& McNeill, D. L. (1981). The value of incentives in stimulating energy conservation. Journal of Consumer Research, 8, 291-298.

Inglehart, R. (1997). Modernization and Postmodernization: Cultural, Economic and Political Change in 43 Societies. Princeton University Press: Princeton, NJ.

International Energy Agency. (2016). Canada: Indicators for 2013. Retrieved from: http://www.iea.org/statistics/statisticssearch/report/?country=CANADA\&product=indicat ors\&year $=2013$

Iozzi, L., Laveault, D., \& Marcinkowski, T. (1990). Assessment of learning outcomes in environmental education. Paris, France: UNESCO.

IPCC, 2007: Climate Change 2007: The Physical Science Basis. Contribution of Working Group I to the Fourth Assessment Report of the Intergovernmental Panel on Climate Change [Solomon, S., D. Qin, M. Manning, Z. Chen, M. Marquis, K.B. Averyt, M. Tignor and H.L. Miller (eds.)]. Cambridge University Press, Cambridge, United Kingdom and New York, NY, USA, 996 pp.

Ironmonger, D. S., Aitken, C. K., \& Erbas, B. (1995). Economies of scale in energy use in adultonly households. Energy Economics, 17, 301-310.

ISO (2008). Energy performance of buildings - calculation of energy use for space heating and cooling. Retrieved April 5, 2016 from https://www.iso.org/obp/ui/\#iso:std:iso:13790:ed2:v1:en

Kallgren, C. A., Reno, R. R., \& Cialdini, R. B. (2000). A focus theory of normative conduct: when norms do and do not affect behavior. Personality and Social Psychology Bulletin, $26,1002-1012$.

Katz, E., Levin, M. L., \& Hamilton, H. (1963). Traditions of research on the diffusion of innovation. American Sociological Review, 28, 237-252. 
Katzev, R. D., \& Johnson, T. R. (1984). Comparing the Effects of Monetary Incentives and Footin-the-Door Strategies in Promoting Residential Electricity Conservation. Journal of Applied Social Psychology, 14, 12-27.

Kaza, N. (2010). Understanding the spectrum of residential energy consumption: A quantile regression approach. Energy Policy, 38, 6574-6585.

Kempton W., \& Lutzenhiser, L. (1992). Introduction. Energy and Buildings, 18, 171-76.

Kempton, W., Harris, C. K., Keith, J. G., \& Weihl, J. S. (1985). Do consumers know "what works" in energy conservation? Marriage and Family Review, 9, 115-133.

Kline, R. B. (2005). Principles and Practice of Structural Equation Modeling (2nd ed.). New York: Guilford.

Knabe, A. (2012). Applying Ajzen's theory of planned behavior to a study of online course adoption in public relations education. Retrieved from Proquest Digital Dissertations .

Kollmuss, A., \& Agyeman, J. (2002). Mind the gap: why do people act environmentally and what are the barriers to pro-environmental behavior? Environmental Education Research, 8, 239-260.

Krathwohl, D. R., Bloom, B. S., \& Masia, B. B. (1973). Taxonomy of educational objectives, the classification of educational goals. Handbook II: Affective Domain. New York, NY: David

Lei, P.-W., \& Wu, Q. (2007). CTTITEM: SAS macro and SPSS syntax. Behavior Research Methods, 39, 527-530.

Lewis, A., \& Gwendolyn, B. (1999). Reducing Household Energy Consumption: A Qualitative and Quantitative Field Study. Journal of Environmental Psychology, 19, 75-85.

Liao, H. C., \& Chang, T. F. (2002). Space-heating and water-heating energy demands of the aged in the US. Energy Economics, 24, 267-284.

Linn, R.L., \& Gronlund, R.E. (2000). Measurement and Assessment in Teaching. Princeton, NC: Merrill.

Livingstone, D. W. (1999). Exploring the icebergs of adult learning: Findings of the first Canadian survey of informal learning practices. The Canadian Journal for the Study of Adult Education, 13, 49.

Livingstone, D. W. (2006). Informal learning: conceptual distinctions and preliminary findings. The Informal Education Reader, 249, 203-227.

Livingstone, D. W. (2007). Re-exploring the icebergs of adult learning: Comparative findings of the 1998 and 2004 Canadian Surveys of Formal and Informal Learning Practices. The Canadian Journal for the Study of Adult Education, 20, 1-24. 
Lorenzo-Seva, U., \& Ferrando, P.J. (2015). POLYMAT-C: a comprehensive SPSS program for computing the polychoric correlation matrix. Behavior research methods, 47, 884-889.

Lucey, T. (2005). Assessing the reliability and validity of the Jumpstart survey of financial literacy. Journal of Family and Economic Issues, 26, 283-284.

Lutzenhiser, L. (1993). Social and Behavioral Aspects of Energy Use. Annual Review of Energy \& Environment, 18, 247-289.

Lutzenhiser, L., \& Gossard, M. H. (2000). Lifestyle, status and energy consumption. In Proceedings of ACEEE Efficiency and Sustainability Summer Study. Pacific Grove, CA: American Council for an Energy Efficient Economy.

Madden, T. J., Ellen, P. S., \& Ajzen, I. (1992). A comparison of the theory of planned behavior and the theory of reasoned action. Personality and Social Psychology Bulletin, 18, 3-9.

Magno, C. (2009). Demonstrating the difference between classical test theory and item response theory using derived test data. International Journal of Educational and Psychological Assessment, 1, 1-11.

Mahajan, V., Muller, E., \& Srivastava, R. K. (1990). Determination of adopter categories by using innovation diffusion models. Journal of Marketing Research, 27, 37-50.

Markle, G. L. (2013). Pro-Environmental Behavior: Does It Matter How It's Measured? Development and Validation of the Pro-Environmental Behavior Scale (PEBS). Human Ecology, 41, 905-914.

Maslow, A H. (1943). A theory of human motivation. Psychological Review, 50, 370-396.

Mathieson, K. (1991). Predicting user intentions: comparing the technology acceptance model with the theory of planned behavior. Information systems research, 2, 173-191.

McClelland, L., \& Cook, S. W. (1979-1980). Energy conservation effects of continuous in-home feedback in all-electric homes. Journal of Environmental Systems, 9, 169-173.

McClelland, L., \& Cook, S. W. (1980). Promoting energy conservation in master-metered apartments through group financial incentives. Journal of Applied Psychology, 10, 20-31.

McFadden D. (1999). Rationality for Economists? Journal of Risk and Uncertainty, 19, 73-105.

McKenzie-Mohr, D. (2011). Fostering sustainable behavior: An introduction to communitybased social marketing ( $3^{\text {rd }}$ ed.). Gabriola Island, BC: New Society Publishers.

McMakin, A. H., Malone, E. L., \& Lundgren, R. E. (2002). Motivating residents to conserve energy without financial incentives. Environment and Behavior, 34, 848-863.

Ministry of Environment and Climate Change. (2016). Ontario's Climate Change Action Plan. Retrieved from https://www.ontario.ca/page/climate-change-action-plan. 
Moezzi, M., \& Lutzenhiser, L. (2010). What's missing in theories of the residential energy user. In Proceedings of the ACEEE Sumer Study on Energy Efficiency in Buildings. Pacific Grove, CA: American Council for an Energy Efficient Economy.

Moller, J., \& Herb, M.W. (2013). Dimensional comparison theory. Psychological Review, $120,544-560$.

Morrison, D. E., \& Dunlap, R. E. (1986). Environmentalism and elitism: a conceptual and empirical analysis. Environmental Management, 10, 581-589.

NAEP (National Association of Educational Progress). (1978). Energy knowledge and attitudes: national assessment of energy awareness among young adults. Education Commission of the States, Denver, Colorado.

Nair, G., Gustavsson, L., \& Mahapatra, K. (2010). Factors influencing energy efficiency investments in existing Swedish residential buildings. Energy Policy, 38, 2956-2963.

National Energy Board. (2016). Canada's Energy Future 2016. Energy Supply and Demand Projections to 2040. Retrieved from https://www.neb-one.gc.ca/nrg/ntgrtd/ftr/2016/indexeng.html.

National Science Teachers Association (NSTA). (1971). NSTA position statement on school science education for the 70's. The Science Teacher, 38, 46-51.

Natural Resources Canada. (2016). Improving energy performance in Canada. Report to Parliament Under the Energy Efficiency Act 2013-2015. Retrieved from: http://publications.gc.ca/collections/collection_2016/rncan-nrcan/M141-10-2015-eng.pdf

Natural Resources Canada. (2015). Energy fact book. Retrieved from: https://www.nrcan.gc.ca/sites/www.../energy/.../EnergyFactBook2015-Eng_Web.pdf

Nazir, J., E. Pedretti, J. Wallace, D. Montemurro and H. Inwood. 2009. Climate Change and changing environmental attitudes. Journal of Social Issues, 28, 79-87.

NEETF. (2002). Americans' low “Energy IQ:" A risk to our energy future/why America needs a refresher course on energy. Washington, DC: National Environmental Education \& Training Foundation. Retrieved from http://www.neefusa.org/pdf/roper/Roper2002.pdf

North American Association of Environmental Education (NAAEE). (2004). National project for excellence in en-vironmental education-Guidelines for excellence. Retrieved from http://www.aaee.org/programs-and-initiatives/ guidelines- for- excellence.

Northrop M, Sassoon D (2008) Clean air jumpstart. Environ Finance, 10, 18-19.

Nosek, B. A., Graham, J., Lindner, N. M., Kesebir, S., Hawkins, C. B., Hahn, C., . . , Tenney, E. R. (2010). Cumulative and career-stage citation impact of social-personality psychology programs and their members. Personality and Social Psychology Bulletin, 36, 1283-1300. 
O’Neill, B. C., \& Chen, B. S. (2002). Demographic Determinants of Household Energy Use in the United States. Population and Development Review, 28, 53-88.

Office of Energy Efficiency. (1993). Survey of Household Energy Use, Natural Resources Canada, Ottawa, 2004.

Oliver, B. (2012-2013). Why Energy Literacy Must be a National Priority. 51.

O'Neill, B. C., \& Chen, B. S. (2002). Demographic Determinants of Household Energy Use in the United States. Population and Development Review, 28, 53-88.

Ontario, Working Group on Environmental Education. (2007). Shaping our schools sharing our future: environmental education in Ontario schools. Ottawa: Queen's Printer for Ontario.

Pacala, S. \& Socolow, R. (2004). Stabilization wedges: Solving the climate problem for the next 50 years with current technologies. Science, 305, 968-972.

Palmer, J. A. 1998. Environmental Education in the 21st Century. Theory, Practice, Progress and Promise. London: Routledge.

Pearson, G., \& Young, A. T. (Eds.). (2002). Technically speaking: why all Americans need to know more about technology. Washington, DC: National Academy Press.

Pitts, R. E., \& Wittenbach, J. L. (1981). Tax credits as a means of influencing consumer behavior. Journal of Consumer Research, 8, 335-338.

Pollution Probe. (2011). Primer on energy systems in Canada. Retrieved from: http://www.pollutionprobe.org/publications/primer-on-energy-systems-in-canada/

Poortinga, W., Steg, L., Vlek, C., \& Poortinga, N. (2004). Values, environmental concern, and environmental behavior - A study into household energy use. Environment and Behavior, $36,70-93$.

Poortinga, W., Steg. L., Vlek, C., Wiersma, G. (2003). Household prefrences for energy-saving measures: A conjoint analysis. Journal of Economic Psychology, 24, 49-64.

Popenoe, D. (1983). Sociology (5 ${ }^{\text {th }}$ ed.). Englewood Cliffs, NJ: Prentice- Hall.

Primack, B. A., Switzer, G. E., \& Dalton, M.A. (2007). Improving measurement normative beliefs involving smoking among adolescents. Archives of Pediatric Adolescent Medicine, 161, 434-439.

Rajecki, D. W. (1982). Attitudes: Themes and advances. Sinaur Associates, Sunderland, MA.

Reckwitz, A. (2002). Toward a theory of social practices: a development in culturalist theorizing. European Journal of Social Theory, 5, 243-263.

Ritchie, J. R. B., Mcdougall, G. H. G., \& Claxton, J. D. (1981). Complexities of Household Energy Consumption and Conservation. Journal of Consumer Research, 8, 233-242. 
Roberts, D. S., \& Geller, E. S. (1995). An "actively caring” model for occupational safety: A field test. Applied and Preventive Psychology, 4, 53-59.

Rockström, J., Steffen, W., Noone, K., Persson, A., Chapin III, F.S., Lambin,... \& Foley, J. A. (2009). A safe operating space for humanity. Nature, 461, 472-475.

Rokeach, M. (1968). Beliefs, attitudes, and values. San Francisco: Jossey-Bass.

Rogers, E. M. (1962). Diffusion of Innovations. New York: Free Press.

Rogers, E. M. (2002). Diffusion of preventive innovations. Addictive Behaviours, 27, 989-993.

Rogers, E. M. (2003). Diffusion of innovations ( $5^{\text {th }}$ ed.). New York: Free Press.

Røpke, I. (2009). Theories of practice - new inspiration for ecological economic studies on consumption. Ecological Economics, 68, 2490-2497.

Roth, C. E. (1992). Environmental literacy: Its roots, evolution, and directions in the 1990s. Columbus, OH: ERIC/SMEAC Information Reference Center.

Roth, C. E. (Ed.) (1996). Benchmarks on the way to environmental literacy K-12 (ED392635). Dartmouth, MA: Bench- marks for Environmental Literacy Project of the Massachusetts Secretaries Advisory Group of Environmental Education.

Sabri, S. (2013). Item Analysis of Student Comprehensive Test for Research in Teaching Beginner String Ensemble Using Model Based Teaching Among Music Students in Public Universities. International Journal of Education and Research, 12, 1-14.

Sanquist, T. F., Orr, H., Shui, B., \& Bittner, A. C. (2012). Lifestyle factors in U.S. residential electricity consumption. Energy Policy, 42, 354-364.

Santin, O. G., Itard, L., \& Visscher, H. (2009). The effect of occupancy and building characteristics on energy use for space and water heating in Dutch residential stock. Energy and buildings, 41, 1223-1232.

Sapci, O., \& Considine, T. (2014). The link between environmental attitudes and energy consumption behavior. Journal of Behavioral and Experimental Economics , 52, 29-34.

Schwartz, S. H. (1973). Normative explanations of helping behavior: A critique, proposal, and empirical test. Journal of Experimental Social Psychology, 9, 349-364.

Schwartz, S. H. (1977). Normative influences on altruism. Advances in experimental social psychology, 10, 221-279.

Seligman, C., Darley, J. M., \& Becker, L. J. (1978). Behavioral approaches to residential energy conservation. Energy and Buildings, 1, 325-337.

Shove, E. (2003). Comfort, cleanliness and convenience. Oxford/New York: Berg publisher. 
Shove, E., \& Walker, G. (2010). Governing transitions in the sustainability of everyday life. Research Policy, 39, 471-476.

Simmons, D. (1995). Working Paper \#2: Developing a framework for national environmental education standards. In D. Simmons (Ed.), The NAAEE standards project, papers on the development of environmental education standards (pp. 10-58). Troy, OH: NAAEE.

Simon, H. A. (1959). Theories of decision-making in economics and behavioural science. The American Economic Review, 49, 253-283.

Slavin, R. E., Wodanski, J. S., \& Blackburn, B. L. (1981). A group contingency for electricity conservation in master-metered apartments. Journal of Applied Behavior Analysis, 14, 357-363.

Sobel, M.E., 1981. Lifestyle and Social Structure. New York: Academic Press.

Solomon, J. (1992). Getting to know energy about energy -in school and society. London: The Falmer Press.

Southwell, B. G., Murphy, J. J., DeWaters, J. E., \& LeBaron, P. A. (2012). Americans' perceived and actual understanding of energy (RTI Press publication No. RR-0018-1208).

Research Triangle Park, NC: RTI Press. Retrieved from http://www.rti.org/rtipress.

Sovacool, B. (2009a). The cultural barriers to renewable energy and energy efficiency in the United States. Technology in Society, 31, 365-373.

Sovacool, B. (2009b). Rejecting renewables: the socio-technical impediments to renewable electricity in the United States. Energy Policy, 37, 4500-4513.

Sparks, P., \& Shepherd, R. (1992). Self-identity and the theory of planned behaviour: assessing the role of identification with "green consumerism". Social Psychology Quarterly, 56, $388-399$.

Stapp,W.B.,Bennett,D.,Bryan,W.Jr.,Fulton,J.,MacGregor,J.,Nowak,P.,... (1969).The concept of environmental education. In H. R. Hungerford, W. J. Bluhm, T. L. Volk, \& J. M. Ramsey (Eds.), Essential readings in environmental education (pp. 33-35). Champaign, IL: Stipes Publishing LLC.

Statistics Canada. (2013). Households and the Environment: Energy Use. Catalogue no. 11-526S

Statistics Canada. (2016). CANSIM table 153-0161.

Steemers, K., \& Yun, G. Y. (2009). Household energy consumption: a study of the role of occupants. Building Research \& Information, 37, 625-637.

Steg, L., Dreijerink, L., \& Abrahamse, W. (2005). Factors influencing the acceptability of energy policies: A test of VBN theory. Journal of Environmental Psychology, 25, 415-425. 
Stern, P. C. (2000). New environmental theories: toward a coherent theory of environmentally significant behavior. Journal of social issues, 56, 407-424.

Stern, P. C. (2014). Individual and household interactions with energy systems: Toward integrated understanding. Energy Research and Social Science, 1, 41-48.

Stern, P. C., \& Dietz, T. (1994). The value basis of environmental concern. Journal of Social Issues, 50, 65-84.

Stern, P. C., Aronson, E., Darley, J. M., Hill, D. H., Hirst, E., Kempton, W., \& Wilbanks, T. J. (1986). Evaluation Review, 10, 147-176.

Stern, P. C., Dietz, T., \& Black, J. S. (1985). Support for environmental protection: the role of moral norms. Population and Environment, 8, 204-222.

Stern, P. C., Dietz, T., Abel, T. D., Guagnano, G. A., \& Kalof, L. (1999). A value-belief-norm theory of support for social movements: The case of environmentalism. Human Ecology Review, 6, 81-97.

Summerton, J. (1992). District Heating Comes to Town: The Social Shaping of an Energy System. Linkoping, Swed.: Fac. Arts Sci., Linkoping Univ.

SCD. (2015). Acting on Climate Change: Solutions by Canadian Scholars. Retrieved from http://www.sustainablecanadadialogues.ca/en/scd

Swan, L. G., \& Ugursal, V. I. (2009). Modeling of end-use consumption in the residential sector: a review of modeling techniques. Renewable and Sustainable Energy Reviews, 13, 18191835.

Tabachnick, B. G. \& Fidell, L. S. (2013). Using multivariate statistics (6 ${ }^{\text {th }}$ ed.). Boston: Harper.

Tashchian, A., Slama, M. E., \& Tashchian, R. O. (1984). Measuring attitudes toward energy conservation: cynicism, belief in material growth, and faith in technology. Journal of Public Policy and Marketing, 3, 134-148.

Todd, P. M., Gigerenzer, G. (2003). Bounding rationality to the world. Journal of Economic Psychology, 24, 143-165.

Tokarik, M.S.\& Richman, R.C. (2016). Life cycle cost optimization of passive energy efficiency improvements in a Toronto house. Energy and Buildings, 118, 160-169.

Tonn, B., \& Berry, L. (1986). Determinants of participation in home energy audit/loan programs: Discrete choice model results. Energy, 11, 785-795.

Turcotte, A., M. C. M. \& J. W. (2012). Energy Literacy in Canada. University of Calgary SPP Research Papers, 5, 1-47. Retrieved from http://www.policyschool.ucalgary.ca/?q=content/energy-literacy-canada 
United Nations Educational, Scientific and Cultural Organization (UNESCO). (1978). The Tbilisi declaration. Intergovernmental Conference on Environmental Education: October 14-26, 1977. In H. R. Hungerford, W. J. Bluhm, T. L. Volk, \& J. M. Ramsey (Eds.), Essential readings in environmental education, (2nd ed., pp. 13-16). Champaign, IL: Stipes Publishing, LLC.

US EIA. (2016). International Energy Statistics. Retrieved from : http://www.eia.gov/cfapps/ipdbproject/iedindex3.cfm?tid=44\&pid=45\&aid=2\&cid=regio ns\&syid=2008\&eyid=2012\&unit=QBTU

US EIA. (2001). Residential Energy Consumption Survey. Tables HC4: Air-Conditioning. US Energy Inf. Adm., Washington, DC. http://www.eia.doe.gov/emeu/recs/recs2001/ detail tables.html

Valenzuela, C., Valencia, A., White, S., Jordan, J. A., Cano, S., Keating, J., ... Potter, L. B. (2014). An analysis of monthly household energy consumption among single-family residences in Texas, 2010. Energy Policy, 69, 263-272.

Van Houwelingen, J. H., \& Van Raaij, F. W. (1989). The effect of goal-setting and daily electronic feedback on in-home energy use. Journal of Consumer Research, 16, 98-105.

Van Liere, K. D., \& Dunlap, R. E. (1978). Moral norms and environmental behavior: An application of Schwartz's norm activation model to yard burning. Journal of Applied Social Psychology, 8, 174-188.

Van Raaij, W. F., \& Verhallen, T. M. M. (1983). A behavioral model of residential energy use. Journal of Economic Psychology, 3, 39-63.

VandeVisse, E., \& Stapp, W. B. (1975). Developing a K-12 environmental education program. In N. McInnis, \& D. Albrecht (Eds.), What makes education environmental? (pp. 93107). Louisville, KY: Environmental Educators, Inc., and Data Courier, Inc.

Volk, T. L., \& McBeth, W. C. (1997). Environmental literacy in the United States: What should be ... What is ... Getting from here to there. A report funded by the U.S. Environmental Protection Agency and submitted to the Environmental Education and Training Partnership, NAAEE. Washington, DC: U.S. EPA.

Vringer, K., \& Blok, K. (1995). The direct and indirect energy requirements of households in the Netherlands. Energy Policy, 23, 893-910.

Wilhite, H., Shove, E., Lutzenhiser, L., \& Kempton, W. (2000). Twenty years of energy demand management: we know more about individual behavior but how much do we really know about demand? In Proceedings of the 2000 ACEEE Summer Study on Energy Efficiency in Buildings. Washington, DC: American Council for an Energy Efficient Economy.

Wilke, R. (1995b). Environmental literacy and the college curriculum. EPA Journal, 21, 2830. 
Wilke, R. (Ed.). (1995a). Environmental education literacy/needs assessment project: Assessing environmental literacy of students and environmental education needs for teachers; Final Report for 1993-1995. (Report to NCEET/University of Michigan under U.S. EPA Grant \#NT901935-01-2). Stevens Point, WI: The University of Wisconsin-Stevens Point.

Wilson, C. \& Dowlatabadi, H. (2007). Models of decision making and residential energy use. Annual Review of Environmental Resources, 32, 169-203.

Yager, R. E. (2004). Using social issues as contexts for K-16 science education. In Asia-Pacific Forum on Science Learning and Teaching (Vol. 5, No. 1, pp. 1-2).

Zepeda, L., \& Deal, D. (2009). Organic and local food consumer behaviour: Alphabet theory. International Journal of Consumer Studies, 33, 697-705. 